\title{
0
0
0
0
0
0
0
0
0
}

Navigation Systems Research Program

\section{Computational Model of Ice Harbor Forebay, Washington}

Richard L. Stockstill, John E. Hite, Jr., and Jane M. Vaughan

August 2005
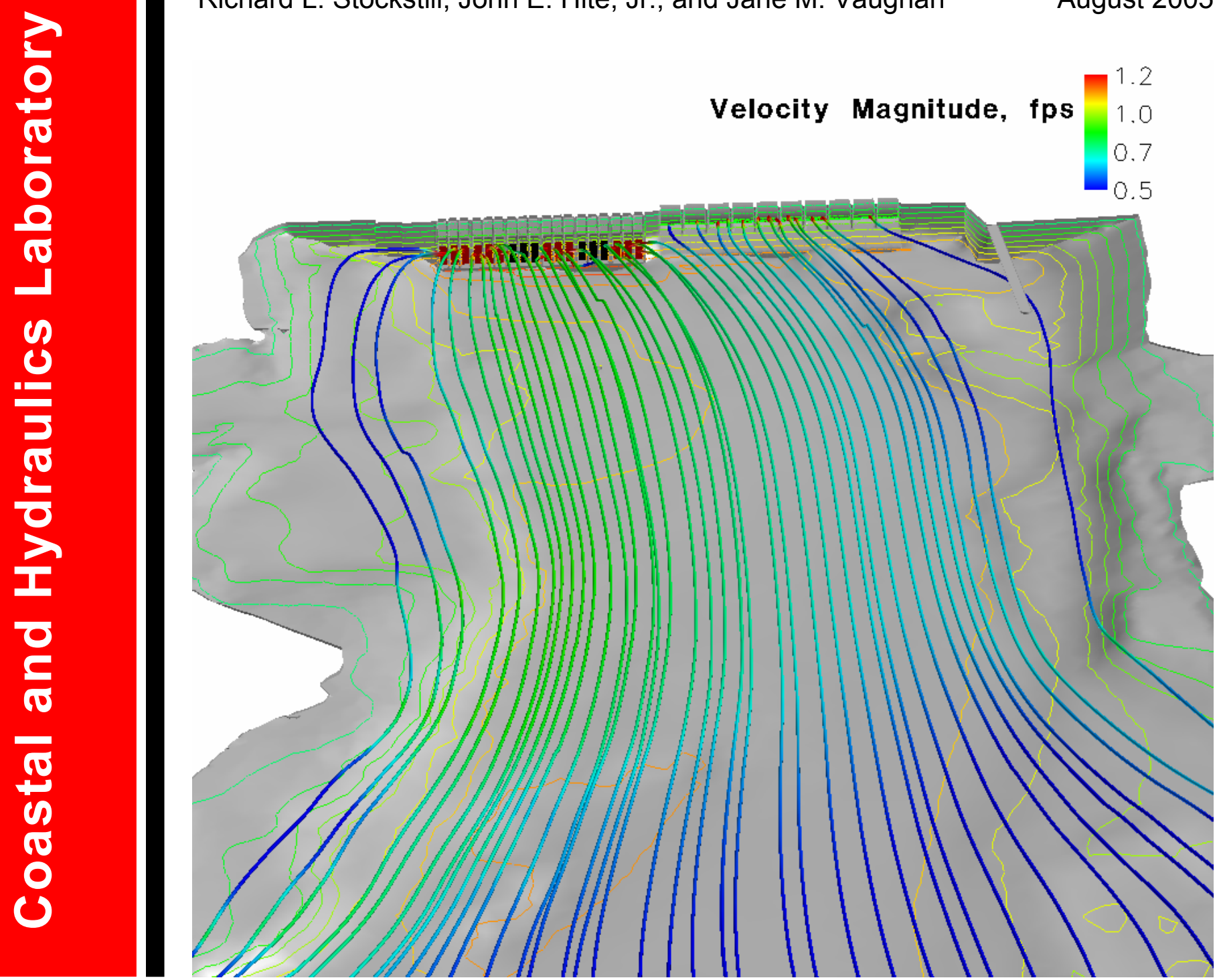


\section{Computational Model of Ice Harbor Forebay, Washington}

Richard L. Stockstill, John E. Hite, Jr., and Jane M. Vaughan

Coastal and Hydraulics Laboratory

U.S. Army Engineer Research and Development Center

3909 Halls Ferry Road

Vicksburg, MS 39180-6199

Final report

Approved for public release; distribution is unlimited 
ABSTRACT: This project serves as a demonstration of the three-dimensional (3D) numerical modeling capability of large reservoirs up to and including the complex geometries of the powerhouse, spillway, and lock guard wall structures. The 3D Navier-Stokes module of the Adaptive Hydraulic (ADH) computer code is used to compute the forebay flow at the Ice Harbor Dam. A numerical flow model of the Ice Harbor Dam forebay, which is located on the Snake River, was constructed. The model results are compared to field data and solutions obtained by an independent laboratory's in-house code.

DISCLAIMER: The contents of this report are not to be used for advertising, publication, or promotional purposes. Citation of trade names does not constitute an official endorsement or approval of the use of such commercial products. All product names and trademarks cited are the property of their respective owners. The findings of this report are not to be construed as an official Department of the Army position unless so designated by other authorized documents. 


\section{Contents}

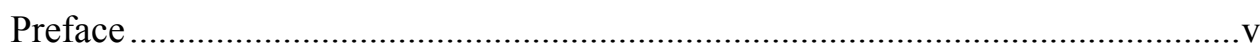

Conversion Factors, Non-SI to SI Units of Measurement................................... vi

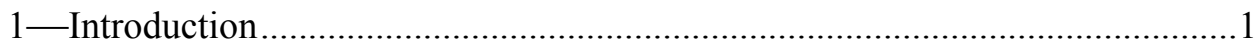

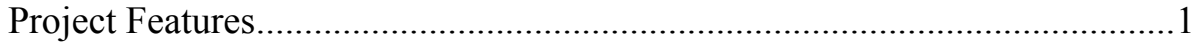

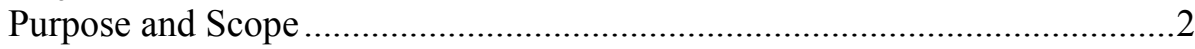

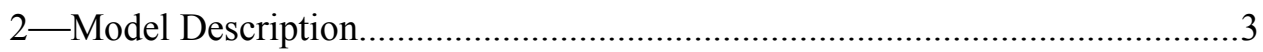

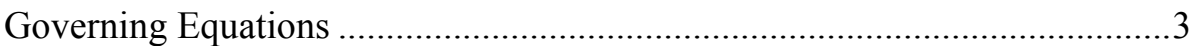

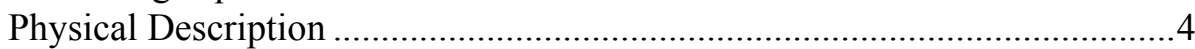

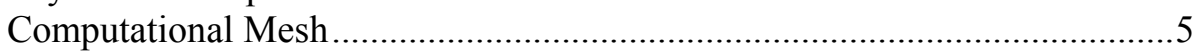

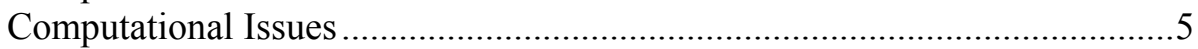

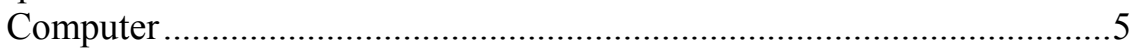

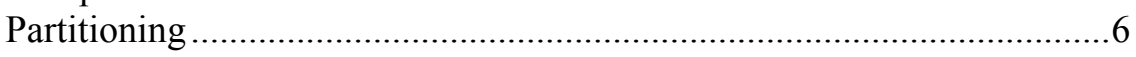

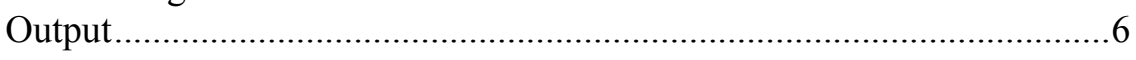

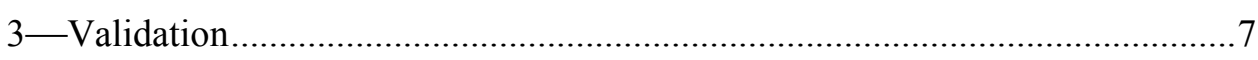

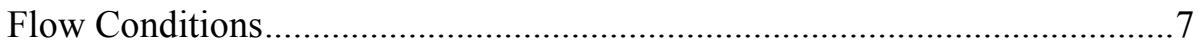

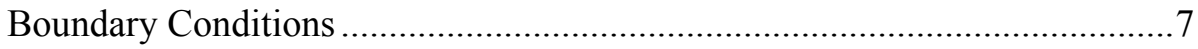

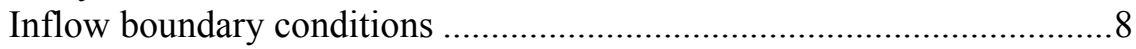

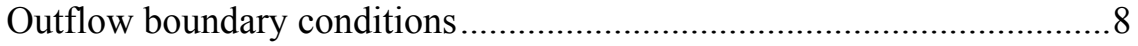

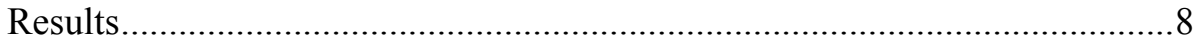

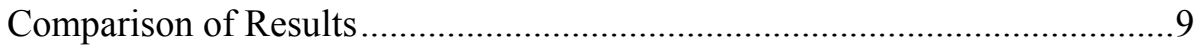

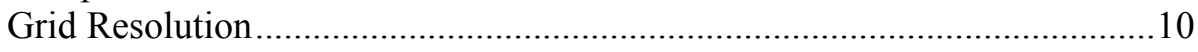

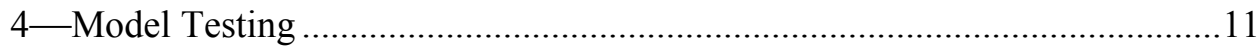

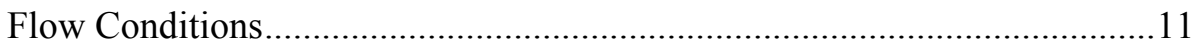

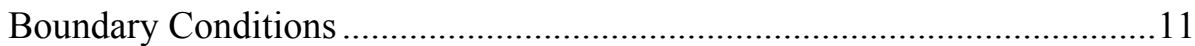

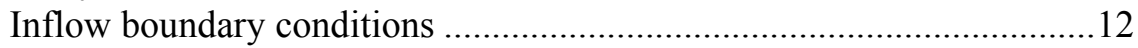

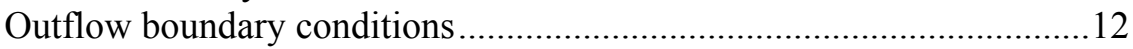

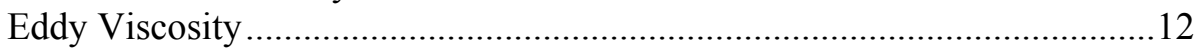

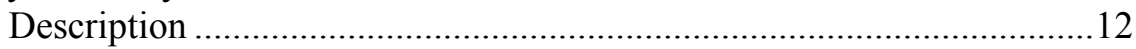

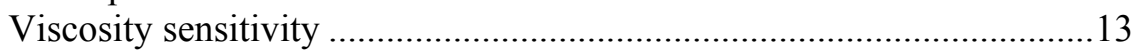

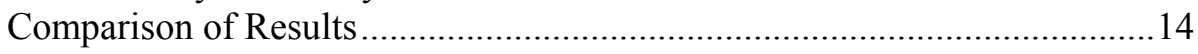

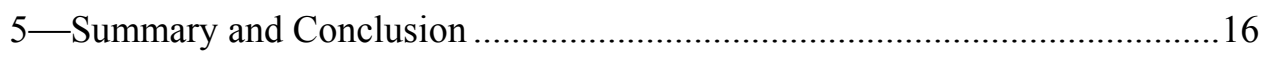

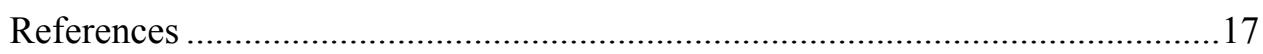


Figures 1-74

SF 298 


\section{Preface}

The model investigation reported herein was authorized and funded as a demonstration project for the Navigation Systems Research Program. Additional funding for model validation was provided by the U.S. Army Engineer Walla Walla District as a part of the Lower Monumental Dam forebay computational fluid dynamics (CFD) study (in progress).

This study was conducted at the Coastal and Hydraulics Laboratory (CHL), U.S. Army Engineer Research and Development Center (ERDC), during the period November 2003 to March 2005 by Drs. Richard L. Stockstill, John E. Hite, Jr., R. Charlie Berger, Mr. Alex R. Carrillo, and Ms. Jane M. Vaughan. Dr. Larry Weber, Director IIHR-Hydroscience and Engineering, University of Iowa, and Dr. Songheng Li, Assistant Research Engineer, IIHR-Hydroscience and Engineering, University of Iowa, served as independent technical reviewers. Dr. Sandra K. Knight was the Technical Director for navigation and Mr. James E. Clausner was the manager of the Navigation Systems Research Program.

The work was performed under the general supervision of Mr. Thomas W. Richardson, Director, CHL; Dr. William D. Martin, Deputy Director, CHL; Dr. Rose M. Kress, Chief of the Navigation Division, CHL; Mr. Bruce A. Ebersole, Chief of the Flood and Storm Protection Division, CHL; Mr. Donald C. Wilson, Chief of the Navigation Branch, CHL; and Dr. Robert T. McAdory, Chief of the Estuarine Engineering Branch, CHL. Drs. Stockstill and Hite and Ms. Vaughan wrote this report.

At the time of publication of this report Dr. James R. Houston was Director of ERDC, and COL James R. Rowan, EN, was Commander and Executive Director. 


\section{Conversion Factors, Non-SI to SI Units of Measurement}

Non-SI units of measurement used in this report can be converted to SI units as follows:

\begin{tabular}{|l|l|l||}
\hline \hline Multiply & By & To Obtain \\
\hline \hline feet & 0.3048 & meters \\
\hline miles (U.S. statute) & 1.609344 & kilometers \\
\hline square feet & 0.09290304 & square meters \\
\hline cubic feet & 0.028316847 & cubic meters \\
\hline
\end{tabular}




\section{Introduction}

This investigation serves as a demonstration of the three-dimensional (3D) numerical modeling capability of large reservoirs up to and including the complex geometries of the powerhouse, spillway, and lock guard wall structures. The 3D Navier-Stokes module of the ADaptive Hydraulic (ADH) computer code (Stockstill and Berger 2001, Berger and Stockstill 1999) is used to compute the forebay flow. ADH is a suite of finite element models of which the NavierStokes module solves the Reynolds-Averaged Navier-Stokes equations using the method of finite elements. The solution provides the three components of velocity and the pressure at each node in the computational mesh. Secondary variables such as velocity gradients can also be computed for each node.

Ice Harbor Dam forebay (Washington) was selected as the project on which the modeling capabilities were to be demonstrated because velocity data throughout the forebay were available for model validation. The Ice Harbor Dam is located on the Snake River about 9.7 miles upstream of its confluence with the Columbia River as shown on the vicinity map on Figure 1. Flow conditions at the project while spilling are shown in Figures 2 and 3.

\section{Project Features}

The Ice Harbor project was authorized by Section 2 of the River and Harbor Act of 1945 and was approved March 2, 1945. The lake behind Ice Harbor Dam has been designated Lake Sacajawea. Ice Harbor Lock and Dam-Lake Sacajawea is Unit 1 of 4 included in the Lower Snake River Project, Washington, and Idaho. The dam is $2,822 \mathrm{ft}^{1}$ long, with an effective height of $100 \mathrm{ft}$. It is of the concrete gravity type, with an earthfill embankment section at the north abutment. The dam has a ten-bay spillway that is $590 \mathrm{ft}$ long, and ten 50 - $\mathrm{ft}$ tainter gates. At el $440,{ }^{2}$ Lake Sacajawea extends northeast 32 miles upstream to Lower Monumental Dam. The Ice Harbor powerhouse contained three 90,000-kW units initially. It now has three additional $111,000-\mathrm{kW}$ units and is capable of generating $603,000 \mathrm{~kW}$ of power. The lock has clear chamber dimensions of $86 \mathrm{ft}$ by $675 \mathrm{ft}$, and a 103-ft lift. The structure has two fish ladders for passing migratory fish. Construction of the Ice Harbor Project began in December 1955, and the

\footnotetext{
${ }^{1}$ A table of factors for converting non-SI units of measurement to SI units is presented on page vi.

${ }^{2}$ All elevations (el) cited herein are in feet referenced to the National Geodetic Vertical Datum (NGVD).
} 
project began operation in December 1961. Powerhouse units 4 though 6 were installed, with all units producing power by January 1976.

\section{Purpose and Scope}

The purpose of this study was to evaluate ADH's ability to simulate forebay flow. A numerical flow model of the forebay approaching the Ice Harbor Dam was constructed and two project flow conditions were simulated. In particular, velocity comparisons were made with field data supplied by the U.S. Army Engineer District, Walla Walla, office. The study also tested the model's sensitivity to selection of eddy viscosity and grid resolution. Secondary flow variables of acceleration and velocity gradients were then compared with those computed by another flow solver.

This report is a summary of the Ice Harbor Dam forebay computational flow model and serves as a demonstration of the capability to simulate the flow approaching, engaging, and passing the project. 


\section{Model Description}

The computational model consists of the governing equations, the discretization scheme used to numerically solve the equations, the computational mesh on which the domain is discretized, and the boundary and initial conditions needed to close the system of equations.

\section{Governing Equations}

The Reynolds-Averaged Navier-Stokes (RANS) equations are employed to model the flow field approaching, interacting, and passing hydraulic structures. The RANS equations are three-dimensional (3D) with four degrees of freedom: the pressure and the three components of fluid velocity. The RANS equations make no assumptions as to pressure distributions and, because many hydraulic flow models assume the flow is hydrostatic, RANS models are referred to as nonhydrostatic models.

A finite element discretization is employed to solve the RANS equations. The particular code is the Navier-Stokes module of the ADaptive Hydraulics (ADH) flow model developed in the Coastal and Hydraulics Laboratory (CHL) of the U.S. Army Engineer Research and Development Center (ERDC). Tetrahedral shaped elements are used in the finite element formulation. This unstructured approach is quite flexible in representing the flow field's geometry.

If the instantaneous velocity is split into a mean, $V$, and a fluctuating component, $u$, the incompressible Navier-Stokes equations can be time averaged to produce the RANS equations. The RANS equations are written in terms of the mean velocity, $V(x, t)$, and pressure, $p(x, t)$, so as to reduce the modeling of turbulence to a set of equations that incorporate terms to model the effects of turbulence on the mean flow. The mean and fluctuating velocity and pressure are then substituted into the mass and momentum equations, and after time averaging over intervals that are long compared with the periods of fluctuations, one obtains the RANS equations:

$$
\nabla \cdot V=0
$$

and 


$$
\rho\left(\frac{\partial V}{\partial t}+V \cdot \nabla V\right)-\nabla \cdot \sigma+\nabla \cdot(\rho u u)=0
$$

where

$$
\begin{aligned}
x & =\text { spatial coordinate } \\
t & =\text { time } \\
\rho & =\text { fluid density } \\
\sigma & =-p I+\tau \\
\tau & =2 \mu D \\
D & =\frac{1}{2}\left(\nabla u+\nabla u^{T}\right) \\
I & =\text { identity matrix } \\
\mu & =\text { fluid viscosity }
\end{aligned}
$$

In a RANS approach, the term $\nabla \cdot(\rho u u)$ is used to represent the effect of turbulence on the mean flow. Following the suggestion of Boussinesq, an eddy viscosity is added to the molecular viscosity in the momentum equations to account for the effects of turbulence. An algebraic eddy viscosity model (also known as a zero equation model) was used for the $\mathrm{ADH}$ demonstration application to the Ice Harbor Dam forebay. ADH also has a $k-\varepsilon$ turbulence closure model, but this more sophisticated model was not used for this demonstration. The $k-\varepsilon$ model, in particular, calculates the turbulent kinetic energy, $k$, and its dissipation rate, $\varepsilon$, throughout the domain. These two variables are used to define an eddy viscosity, $\mu_{t}$. The Reynolds stress, $\tau_{i j}$, can be expressed using the kinematic form of the eddy viscosity.

\section{Physical Description}

Before the equations of motion can be applied, the domain must be discretized. This process includes the construction of a $3 \mathrm{D}$ computer-aided drafting (CAD) representation of the flow boundaries including the geometric features of the hydraulic structure and the bathymetry of the approaching river. The 3D surface model of the hydraulic structure and the forebay bathymetry CAD model was constructed using AutoCAD ${ }^{1}$ (http://usa.autodesk.com/). The coordinates were in a state plane coordinate system where the $x$-direction is easterly and the $y$-direction is northern. The entire model was translated 2,410,000 ft toward the west (i.e. $\Delta x=-2,410,000 \mathrm{ft}$ ) and 330,000 ft toward the south (i.e. $\Delta y=-330,000$ $\mathrm{ft})$. This provides more significant digits and can produce more accurate solutions. The CAD model was then used as input for the grid generator. The 3D volume mesh is of the unstructured type using tetrahedral elements. Figures 4-10 are pictures of particular portions of the Ice Harbor CAD model. Approximately one mile of the Snake River upstream of the dam was reproduced. The river is a little

\footnotetext{
${ }^{1}$ Statement of product names does not infer product endorsement.
} 
over 2,000 ft wide, immediately upstream of the lock guard wall. The model reproduced the 10 spillway bays, complete with piers and tainter gates in the appropriately raised position, and the 6 powerhouse units each having three intakes to a particular turbine. The trash racks were not included in the model, but the features such as the slots and other important offsets were. The navigation lock's floating guard wall protrudes into the flow field and was included in the model.

The spillway portion of the model included the face and crest, up to the point where the flow exited under the opened tainter gates. The piers, walls, and soffits of the powerhouse intakes were included. Forty-two feet of the conduit, from the powerhouse face to the end of the soffit's curved surface, was reproduced.

\section{Computational Mesh}

A computational mesh consisting of 609,721 tetrahedral elements and 153,602 nodes was constructed to fill the volume created by the CAD model. The commercial mesh generator used for the Ice Harbor project was ANSYS ICEM CFD (http://www-berkeley.ansys.com/). Element sizes varied; side lengths ranged from nearly $30 \mathrm{ft}$ near the center of the river about 2,500 ft upstream of the dam to a few inches at the intake to the powerhouse and under the tainter gates on the spillway. The surface meshes shown in Figures 11-15 partially illustrate the resolution of the computational mesh. The surface mesh is composed of the individual faces of the tetrahedral elements that form the boundary. Boundary conditions of these faces and their nodes are needed to determine a particular solution to the governing partial differential (RANS) equations. Natural boundary conditions involving fluxes are assigned to the surface faces and Dirichlet boundary conditions are assigned to the surface nodes. The surface mesh and portions of the volume mesh in regions near the dam are shown in Figures 16 and 17.

\section{Computational Issues}

The ADH model solves the time-dependent RANS equations. Steady state solutions are obtained by starting from some assumed initial conditions (usually a quiescent pool) and time stepping until the solution reaches steady state (if a steady-state solution exists). Often, flow fields exhibit shedding eddies and such, and there is no steady-state solution. That was not the case with the Ice Harbor model. The Ice Harbor model was initiated with a quiescent pool, and given the flux boundary conditions, the model was run for a simulated time totaling 8 hours. At this point, the differences in velocities and pressures, between consecutive solutions, were small enough that the model was considered converged to steady state.

\section{Computer}

The computer runs for this project were primarily carried out using an SGI Origin 3000 (O3K) Complex housed at the U.S. Army Engineer Research and 
Development Center, Major Shared Resource Center, Vicksburg site. The O3K Complex is a shared-memory multiprocessor system. The ADH model is more universal in that it uses distributed memory and does not require a sharedmemory system, but the $\mathrm{O} 3 \mathrm{~K}$ was readily available and so it was used for this project. The O3K Complex consists of $512400-\mathrm{MHz}$ and 1,024 700-MHz processors and a computational capacity of 1,833 GFLOPS. Other specifications for this computer can be found at http:/www.wes.hpc.mil/index.htm.

\section{Partitioning}

Large models often use high-performance computers for flow solution, and this generally involves parallelization of the problem. The method of dividing the original grid among many processors is not straightforward, but clever division can reduce both computation time and communication time between the processors. The basic idea is to divide the problem in a manner that balances the loads applied to each processor. This way, all processors complete a particular task at about the same time, which avoids processors sitting idle waiting for other processors to complete their assigned tasks. ParMETIS ( $h t t p: / / w w w . u s e r s . c s . u m n$. edu/ karypis/metis/parmetis/index.html) is used by ADH to partition the mesh in an efficient manner. This partitioning is dynamic in that it adjusts as needed during a simulation run. Computer runs on the Ice Harbor forebay model generally employed between 64 and 96 processors, depending on the current load on the $\mathrm{O} 3 \mathrm{~K}$.

\section{Output}

From a practical sense, the primary variables of pressure (scalar) and velocity (vector) were written as model output for post-processing. Other computed quantities such as the error indicator used for the adaption trigger (scalar) and the velocity gradients in the strain-rate tensor, important information for the Numerical Fish Surrogate (NFS), were also written to files. The adaption error indicators are useful only for the setup of mesh adaption and the strain tensor components were stored for future integration with the NFS. Sometimes, it is informative to

plot Froude or Reynolds numbers, and these values can be computed during postprocessing procedure. Solution figures for this report were generated using FieldView (http://www.ilight.com/) and Tecplot (http://www.tecplot.com). 


\section{Validation}

\section{Flow Conditions}

As a demonstration of the model's capability, one particular flow condition was simulated. The particular flow condition chosen to simulate is one that has been successfully modeled by the IIHR-Hydroscience and Engineering (IIHR). This flow condition was simulated so that results with the IIHR model results could be used to evaluate the ADH simulations as to their reasonableness. The pool elevation, tainter gate openings, and powerhouse loadings drive the discharges listed in Table 1.

\begin{tabular}{|c|c|c|c|}
\hline \multicolumn{4}{|c|}{$\begin{array}{l}\text { Table } 1 \\
\text { Flow Conditions Simulated for Validation with Field Data } \\
\text { Total River Discharge } 105,500 \text { cfs, Pool el } 439.5 \\
\end{array}$} \\
\hline $\begin{array}{l}\text { Powerhouse Unit (Left to Right } \\
\text { Looking D/S) }\end{array}$ & $\begin{array}{l}\text { Discharge, } \\
\text { cfs }\end{array}$ & $\begin{array}{l}\text { Spillway Bay (Left to Right } \\
\text { Looking D/S) }\end{array}$ & $\begin{array}{l}\text { Discharge, } \\
\text { cfs }\end{array}$ \\
\hline 1 & 14,900 & 1 & 1,700 \\
\hline 2 & 15,400 & 2 & 3,500 \\
\hline 3 & 0 & 3 & 3,500 \\
\hline 4 & \begin{tabular}{|l|}
16,500 \\
\end{tabular} & 4 & 5,200 \\
\hline 5 & 0 & 5 & 5,200 \\
\hline \multirow[t]{5}{*}{6} & 18,700 & 6 & 5,200 \\
\hline & & 7 & 5,200 \\
\hline & & 8 & 4,000 \\
\hline & & 9 & 3,900 \\
\hline & & 10 & 2,600 \\
\hline
\end{tabular}

\section{Boundary Conditions}

The boundary conditions employed to model this particular flow condition consist of setting flow rates at each of the powerhouse intakes, each spillway gate, at the river cross section making up the upstream limit of the model, at the water surface, and at all solid boundaries comprising the computational domain. Each spillway bay also has a geometric configuration associated with the opening of the bay's tainter gate. Boundary conditions at the solid boundaries prohibit the flux of mass and momentum through the boundary. This no-flux boundary 
condition is applied to the solid boundaries and a drag coefficient is assigned to the faces of each element forming the solid boundaries. The water surface is modeled as a rigid lid, whereby it is fixed in space. This requires that the pressure at the water surface be calculated. Modeling the water surface as a rigid lid is reasonable for large, deep bodies of water where the Froude number is small, such as the case of the flow approaching Ice Harbor Dam. A stress free condition is applied for the tangential component of shear at the water surface.

The rigid lid assumption seems reasonable for the problem at hand. Here, the water surface is flat in part, because the outflow boundaries are all submerged. If the simulation were to include an outflow at or near the water surface or, if for any other reason, the water surface is expected to be contorted, then the Free Surface routines in ADH could be employed. ADH uses Space-Time finite elements, so the moving mesh routines used to model free-surface problems are similar to an Arbitrary Lagrangian-Eulerian (ALE) scheme where the computational mesh moves such that free surface nodes maintain a specified pressure (typically zero). The mesh is adjusted each time step in response to the surface displacement. This inhibits element shearing.

\section{Inflow boundary conditions}

Flux boundaries are prescribed as shown in Table 1. The inflow boundary is the sum of the discharges through the powerhouse and the spillway. In the absence of specific data otherwise, a uniform velocity was assumed across the inflow boundary as the total discharge divided by the inflow cross-sectional area. This uniform distribution was used, although if a particular distribution is known to exist, this inflow boundary condition could be setup as well.

\section{Outflow boundary conditions}

Outflow discharges from the hydraulic features listed in Table 1 were specified as natural boundary conditions to each element face making up each outflow boundary. The average velocity at each feature was applied to each outflow face.

Specifying both inflow and outflow mass fluxes in a fixed domain (rigid lid), can result in over specification of boundary conditions because of roundoff errors). To avoid over specification of flux boundary conditions, the inflow boundary condition was changed, soon after model startup, from a specified flow rate to a simple flux boundary.

\section{Results}

General results of the flow simulation are given in a set of figures of velocity contours and vectors at horizontal planes sliced through the flow field at various elevations. The velocity contours for each figure (Figures 18-37) range from a minimum value of $0.0 \mathrm{fps}$ to a maximum value of $2.0 \mathrm{fps}$. The values of the contour lines represent the numbers provided on the contour scale. Lower velocity magnitudes are present in the forebay, especially near the shallow shores. The 
velocity approaches 30 to $40 \mathrm{fps}$ as the flow exits under the spillway tainter gates. However, for visualization purposes, the range of 0.0 to $2.0 \mathrm{fps}$ seems reasonable. Figure 38 illustrates the flow conditions along a vertical plane placed normal (perpendicular) to the axis of the dam at the center intake of powerhouse unit 6 . Figure 39 shows the velocity distribution on a vertical plane sliced normal to the axis of the dam through the center of spillway bay 6 .

Although uniform velocities were set as inflow boundary conditions, the resulting velocities just downstream of the inflow boundary were changed dramatically. The velocity in the shallows was rapidly reduced from those imposed on at the inflow boundary. The radius of influence is quite small compared to the length of river reproduced. Modeling of other projects in the future are planned that will try introducing an artificial "box" upstream of the actual topography. The bed elevations from the flat bottom of the inflow box will be gradually transitioned to those of the actual project bathymetry. This is the approach used in most large physical models and should prove useful in a computational model as well. Then a uniform velocity of total discharge divided by the cross sectional shape of the inflow "box" will be more appropriate and will not require any field data by which the inflow boundary conditions are to adjusted.

Figures 40 and 41 show streamlines of flow approaching the structure. The powerhouse units whose outflow is black are those units not operating (see Table 1).

\section{Comparison of Results}

A comparison of the CFD results was made with prototype data at selected locations in the forebay. The electronic files of the prototype data at depths of approximately 10,20, 40,60 and $80 \mathrm{ft}$ below the water surface were obtained in the form of spreadsheets from the Walla Walla District. The water-surface elevation was el 439.5 during collection of this data. The discharge through the spillway was $40,000 \mathrm{cfs}$ and the discharge through the powerhouse was $65,500 \mathrm{cfs}$.

The comparison of the CFD data and the prototype data are provided in Figures 42-46. The red vectors are the prototype data and the black vectors are the CFD results. Magnifying the screen image makes the comparison easier to view. Figure 47 presents a typical plot of the prototype data without the CFD results. In general, the comparisons are favorable and show the CFD model does a good job of computing the velocity vectors. The CFD results are more uniform than the field data. The prototype measurements are essentially an instantaneous velocity and are not time-averaged over the turbulence time scales as those of the CFD values. The direction and magnitude of the prototype data such as that shown in Figure 47 appear more random and some vectors are definitely indicating the wrong flow direction. This is due to bad samples or noise in the data. The adjacent vectors that have noticeably different directions and magnitudes demonstrate the unsteady nature of the flow and the data collection process. The CFD results, in general, under predict the velocity magnitude. However, the comparison shows that the CFD solution is acceptable for making engineering decisions. 


\section{Grid Resolution}

A test to determine the effects of grid refinement was conducted. As previously mentioned, the original mesh (hereto referred to as the unrefined grid) was composed of 153,602 nodes. The adaption capabilities of the ADH model were set such that each tetrahedron in the volume was refined one level. This increase in resolution produced a mesh containing 548,464 nodes. Figures $48-50$ show a comparison of the CFD results with and without additional grid adaption for depths of 10, 40, and $80 \mathrm{ft}$. The additional grid adaption is noted as the refined CFD results. Figures 51 and 52 show comparisons of velocity magnitude at powerhouse unit 6 and spillway bay 5, respectively. There is little difference in the velocity magnitudes, though a slight difference is evident near the structure. Comparison of solutions computed on the original mesh with those computed on the refined mesh demonstrates that the original mesh resolution $(153,602$ nodes and 609,721 tetrahedra) is acceptable for computing this type of flow field. 


\section{$4 \quad$ Model Testing}

\section{Flow Conditions}

The IIHR-Hydroscience and Engineering has been successfully modeling the flow in forebays of projects on the Lower Snake River (i.e., Blank and Weber 2000). The IIHR model, U2RANS (Unsteady and Unstructured ReynoldsAveraged Navier-Stokes solver), has been validated with field data and results from U2RANS have been compared with results from other commercial CFD codes such as STAR-CD. The ADH model was further tested in this particular study of modeling the flows in Ice Harbor forebay using a flow condition chosen to simulate one that has been successfully modeled by the IIHR. This flow condition was run so that results with the IIHR model could be compared to the ADH simulations. The pool elevation, tainter gate openings, and powerhouse loadings drive the discharges listed in Table 2. In the IIHR study for the Walla Walla District, this flow condition was referred to as the Base Condition 1.

\begin{tabular}{|c|c|c|c|}
\hline \multicolumn{4}{|c|}{$\begin{array}{l}\text { Table } 2 \\
\text { Flow Conditions for Base Condition 1, Total River Discharge } \\
74,700 \text { cfs, Pool el } 439.5\end{array}$} \\
\hline $\begin{array}{l}\text { Powerhouse Unit (Left to Right } \\
\text { Looking D/S) }\end{array}$ & $\begin{array}{l}\text { Discharge, } \\
\text { cfs }\end{array}$ & $\begin{array}{l}\text { Spillway Bay (Left to Right } \\
\text { Looking D/S) }\end{array}$ & $\begin{array}{l}\text { Discharge, } \\
\text { cfs } \\
\end{array}$ \\
\hline 1 & 10,000 & 1 & 4,300 \\
\hline 2 & 0 & 2 & 5,150 \\
\hline 3 & 10,000 & 3 & 4,300 \\
\hline 4 & 0 & 4 & 4,300 \\
\hline 5 & 0 & 5 & 4,300 \\
\hline 6 & 10,000 & 6 & 4,300 \\
\hline & & 7 & 4,300 \\
\hline & & 8 & 4,300 \\
\hline & & 9 & 5,150 \\
\hline & & 10 & 4,300 \\
\hline
\end{tabular}

\section{Boundary Conditions}

The boundary conditions employed to model this particular flow condition were set similarly to the validation conditions described previously and consisted 
of setting flow rates at each of the powerhouse intakes, each spillway gate, at the river cross section making up the upstream limit of the model, at the water surface, and at all solid boundaries comprising the computational domain. Each spillway bay also has a geometric configuration associated with the opening of the bay's tainter gate. Boundary conditions at the solid boundaries prohibit the flux of mass and momentum through the boundary. This no-flux boundary condition is applied to the solid boundaries and a drag coefficient is assigned to the face of each element forming the solid boundaries. The water surface is modeled as a rigid lid, which is reasonable for large, deep bodies of water where the Froude number is small, such as the case of the flow approaching Ice Harbor Dam. A stress free condition is applied for the tangential component of shear at the water surface.

\section{Inflow boundary conditions}

Flux boundaries are prescribed as shown in Table 2. The inflow boundary is the sum of the discharges through the powerhouse and the spillway. Velocity distribution at the inflow boundary was not uniform, but rather specified in a distribution similar to that used by IIHR in the U2RANS model. This distribution was based on field data provided by the Walla Walla District.

\section{Outflow boundary conditions}

Outflow discharges from the hydraulic features listed in Table 2 were specified as natural boundary conditions to each element face making up each outflow boundary. The average velocity at each feature was applied to each outflow face.

\section{Eddy Viscosity}

\section{Description}

As was mentioned in the Governing Equations section of this report, the RANS equations are closed using the Boussinesq method of adding an eddy viscosity to the molecular eddy viscosity in the momentum equations. This additional term, often referred to as the Reynolds stress, is a means of accounting for the effects of turbulence. Here, the Reynolds stress is

$$
\tau_{i j}=\rho v_{i j} \frac{\partial u_{i}}{\partial x_{j}}
$$

Here, $\tau_{i j}$ is stress acting in the direction $x_{i}$ on a face perpendicular to $x_{j}$. The kinematic eddy viscosity, $v_{i j}$, can be written in tensor form for a Cartesian coordinate system as 


$$
\left|\begin{array}{lll}
v_{x x} & v_{x y} & v_{x z} \\
v_{y x} & v_{y y} & v_{y z} \\
v_{z x} & v_{z y} & v_{z z}
\end{array}\right|
$$

The tensor is symmetric so that

$$
\begin{aligned}
& v_{x y}=v_{y x} \\
& v_{x z}=v_{z x} \\
& v_{y z}=v_{z y} .
\end{aligned}
$$

These turbulent viscosities can be grouped in terms of horizontal and vertical momentum diffusion due to turbulence. The terms $v_{x x}, v_{x y}$, and $v_{y y}$ can be considered the horizontal eddy viscosity terms and the terms $v_{x z}, v_{y z}$, and $v_{z z}$ represent the vertical eddy viscosity. The Ice Harbor 3D model was tested as to its sensitivity to the choice of horizontal and vertical viscosity values.

\section{Viscosity sensitivity}

The magnitudes of eddy viscosity were varied in a systematic process to determine the model's sensitivity to selection of both horizontal and vertical eddy viscosity. This is particularly important in this study where the length scales in the horizontal and vertical are so different. Although the vertical scale (flow depth) is large for typical river models (Ice Harbor forebay is as much as $140 \mathrm{ft}$ deep), the horizontal length is much larger. The diffusion of momentum due to turbulence becomes important as the flow approaches the dam, especially the accelerating flow into the intakes of the powerhouse.

\begin{tabular}{|c|c|c|}
\hline \multicolumn{3}{|c|}{$\begin{array}{l}\text { Table } 3 \\
\text { Eddy Viscosity Values Tested, Total River Discharge } 74,700 \text { cfs, } \\
\text { Pool el } 439.5\end{array}$} \\
\hline Case Number & Horizontal Eddy Viscosity, $\mathrm{ft}^{2} / \mathrm{sec}$ & Vertical Eddy Viscosity, $\mathrm{ft}^{2} / \mathrm{sec}$ \\
\hline 1 & 5.0 & \begin{tabular}{|l|} 
\\
\end{tabular} \\
\hline 2 & 5.0 & 0.5 \\
\hline 3 & 5.0 & \begin{tabular}{|l|l|} 
\\
\end{tabular} \\
\hline 4 & 0.5 & 0.25 \\
\hline
\end{tabular}

Flow solutions were obtained using four combinations of values for the horizontal and vertical eddy viscosities. The selection of viscosities tested is provided in Table 3. 
Figures 53-55 show velocity magnitude contours on horizontal planes at 10-, 40-, and 80-ft depths. Figures 56 and 57 show contours of velocity magnitude on vertical planes passing through powerhouse unit 6 and spillway bay 5 , respectively. Figures 58 and 59 show the magnitude of acceleration at powerhouse unit 6 and spillway bay 5, and Figures 60 and 61 show hydraulic strain rate comparisons at the same locations.

Model results with Case 1 conditions, horizontal and vertical eddy viscosity values set equal to the vertical values of $5.0 \mathrm{ft}^{2} / \mathrm{sec}$, are seen on the contour plots as being somewhat "stiff" in that there is inadequate diffusion of the vertical momentum due to turbulence.

The next run, Case 2, was conducted using a horizontal value of $5.0 \mathrm{ft}^{2} / \mathrm{sec}$, but with the vertical eddy viscosity reduced an order of magnitude to $0.5 \mathrm{ft}^{2} / \mathrm{sec}$. These simulation results, shown in the contour plots, increased the vertical variation in velocity as can be seen by comparing the velocity magnitudes with those for the larger vertical viscosity.

The Case 3 conditions again used a horizontal viscosity of $5.0 \mathrm{ft}^{2} / \mathrm{sec}$, but reduced the vertical viscosity in half to a value of $0.25 \mathrm{ft}^{2} / \mathrm{sec}$. This reduction in vertical viscosity had no noticeable effect on the resulting solution. Comparison of the different cases shown in Figures 56 and 57 show that the vertical variations of velocity magnitudes are essentially the same as a result of using vertical viscosity of $0.5 \mathrm{ft}^{2} / \mathrm{sec}$ and $0.25 \mathrm{ft}^{2} / \mathrm{sec}$.

The sensitivity of the computed solution to variations in the horizontal viscosity was also tested. The horizontal viscosity value for the Case 4 conditions was reduced an order of magnitude to $0.5 \mathrm{ft}^{2} / \mathrm{sec}$ and the vertical viscosity was set to $0.25 \mathrm{ft}^{2} / \mathrm{sec}$. Figures $53-55$ show that this reduction of horizontal viscosity did not significantly influence the velocity distribution throughout the flow domain. The horizontal eddy viscosity of $5.0 \mathrm{ft}^{2} / \mathrm{sec}$ produced the appropriate diffusion of the horizontal momentum due to turbulence.

\section{Comparison of Results}

The horizontal eddy viscosity value of $5.0 \mathrm{ft}^{2} / \mathrm{sec}$ and a vertical eddy viscosity value of $0.25 \mathrm{ft}^{2} / \mathrm{sec}$ are reasonable choices for modeling forebay flows at projects such as the Ice Harbor Dam. The flow domain was not identical for the ADH and U2RANS models. The difference is especially pronounced at the right bank line (looking downstream). The ADH mesh closely models the actual water line. This is apparent when the right descending bank line shown in the prototype photograph on Figure 3 is compared with the CAD model shown in Figure 4. Also, details around the structure were different in the two models. The U2RANS reproduced the upper end of the lock structure in more detail than the ADH model. Also, the U2RANS model had fine resolution near the structure's surface. This will be evident later in the comparison of the models' velocity gradients.

Secondary flow variables were also computed. Derived variables, such as acceleration and strain rate, are used by other researchers in modeling migratory fish behavior. So, these flow variables can be important if the computed flow 
field is used to forecast fish passage. The flow acceleration is a vector quantity that at steady state can be expressed as:

$$
V \cdot \nabla V
$$

The hydraulic strain rate is here defined as a scalar magnitude of the strainrate tensor

$$
\frac{\partial u_{i}}{\partial x_{j}}
$$

or in a Cartesian coordinate system as

$$
\left|\begin{array}{lll}
\frac{\partial u}{\partial x} & \frac{\partial u}{\partial y} & \frac{\partial u}{\partial z} \\
\frac{\partial v}{\partial x} & \frac{\partial v}{\partial y} & \frac{\partial v}{\partial z} \\
\frac{\partial w}{\partial x} & \frac{\partial w}{\partial y} & \frac{\partial w}{\partial z}
\end{array}\right|
$$

The comparison of ADH and U2RANS results are shown in Figures 62-74. Figures 62-67 are contours of velocity magnitudes at 10-, 40-, and 80-ft depths. Figures 68 and 69 are velocity magnitude contours on vertical slices (plane normal to dam axis) at powerhouse unit 6 and spillway bay 5 , respectively. Figures 70-72 show strain rate contours at 10-, 40-, and 80-ft depth. Figures 73 and 74 show strain rate contours at powerhouse unit 6 and spillway bay 5 . The most noticeable differences between the results are seen in the section views normal to the spillway and powerhouse although these differences in magnitudes are small. The solutions are similar and the use of either to make engineering decisions would result in the same conclusions. 


\section{Summary and Conclusion}

Two test cases were made a part of this ADH model validation study. The first case was the validation of the ADH model by comparison to observed field data at the Ice Harbor Dam forebay. This tested the model's ability to simulate forebay conditions given project operations. Comparison of the model and field data showed the numerical model was capable of reproducing field conditions. This first test also served to evaluate mesh resolution issues.

The second test was directed at answering the question of how well the unstructured $\mathrm{ADH}$ solutions matched the solutions previously computed using the IIHR-Hydroscience and Engineering's U2RANS model. The particular issue to be addressed was in regards to the computation of velocity gradients as well as the primary flow variables of velocity and pressure. Extensive testing to $\mathrm{ADH}$ results' sensitivity to choice of eddy viscosity was also included in this part of the study. The solutions from each model were very similar.

This study has demonstrated the capability of modeling the approach flow to dams. The Navier-Stokes module of the ERDC's ADH model is a viable means of simulating the flow approaching and interacting with hydraulic structures. 


\section{References}

Berger, R. C., and Stockstill, R. L. (1999). "A finite element system for flows." Proceedings of the 1999 Water Resources Engineering Conference. American Society of Civil Engineers.

Blank, J. C., and Weber, L. J. (2000). "Numerical simulations of the fish passage facilities at Lower Granite Dam," IIHR Technical Report No. 412, Iowa Institute of Hydraulic Research, University of Iowa, Iowa City.

Stockstill, R. L., and Berger, R. C. (2001). "Simulating flow in hydraulic structures using ADH." Proceedings of the World Water and Environmental Resources Congress. Environmental and Water Resources Institute, American Society of Civil Engineers. 


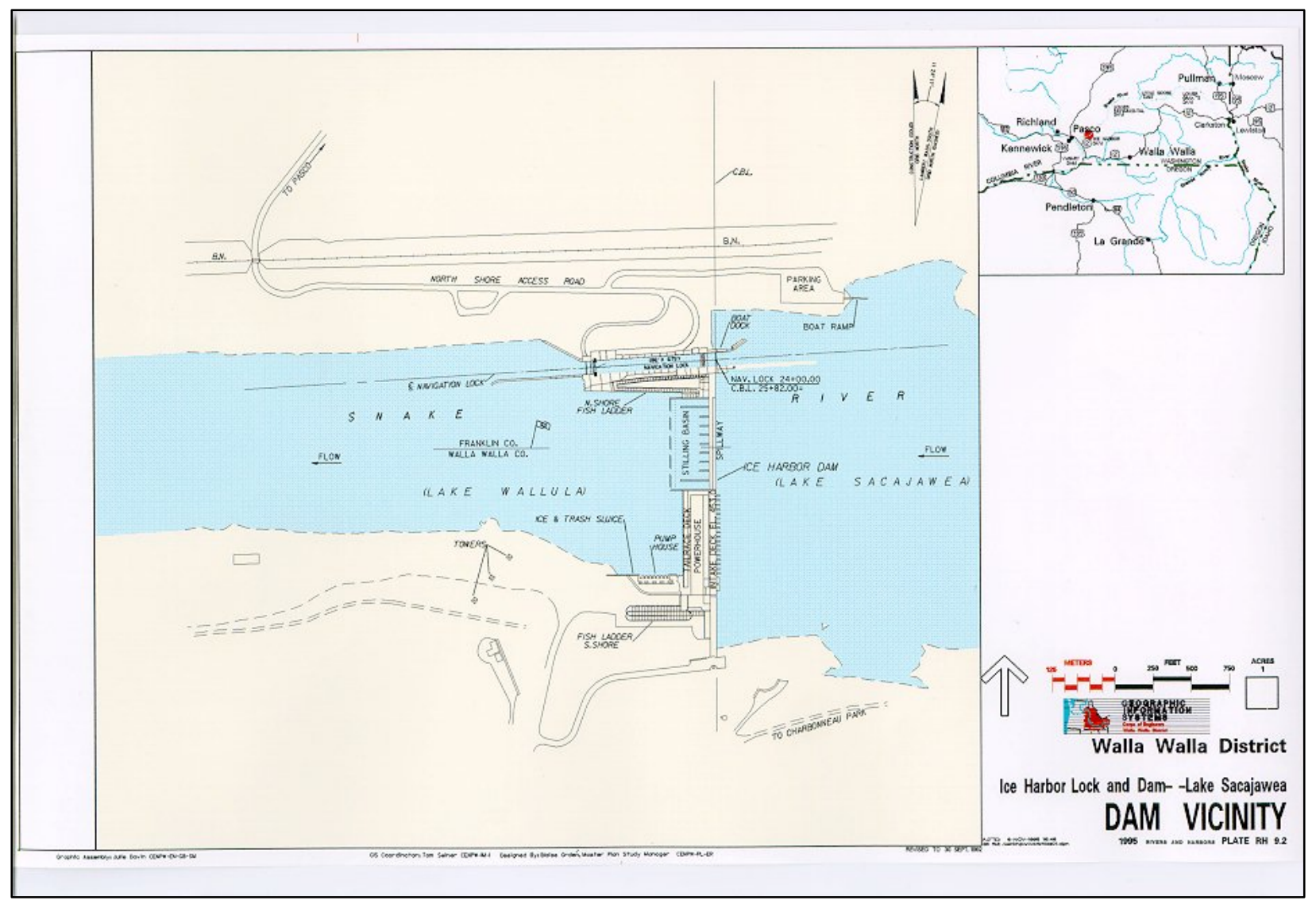

Figure 1. Vicinity map of Ice Harbor Dam

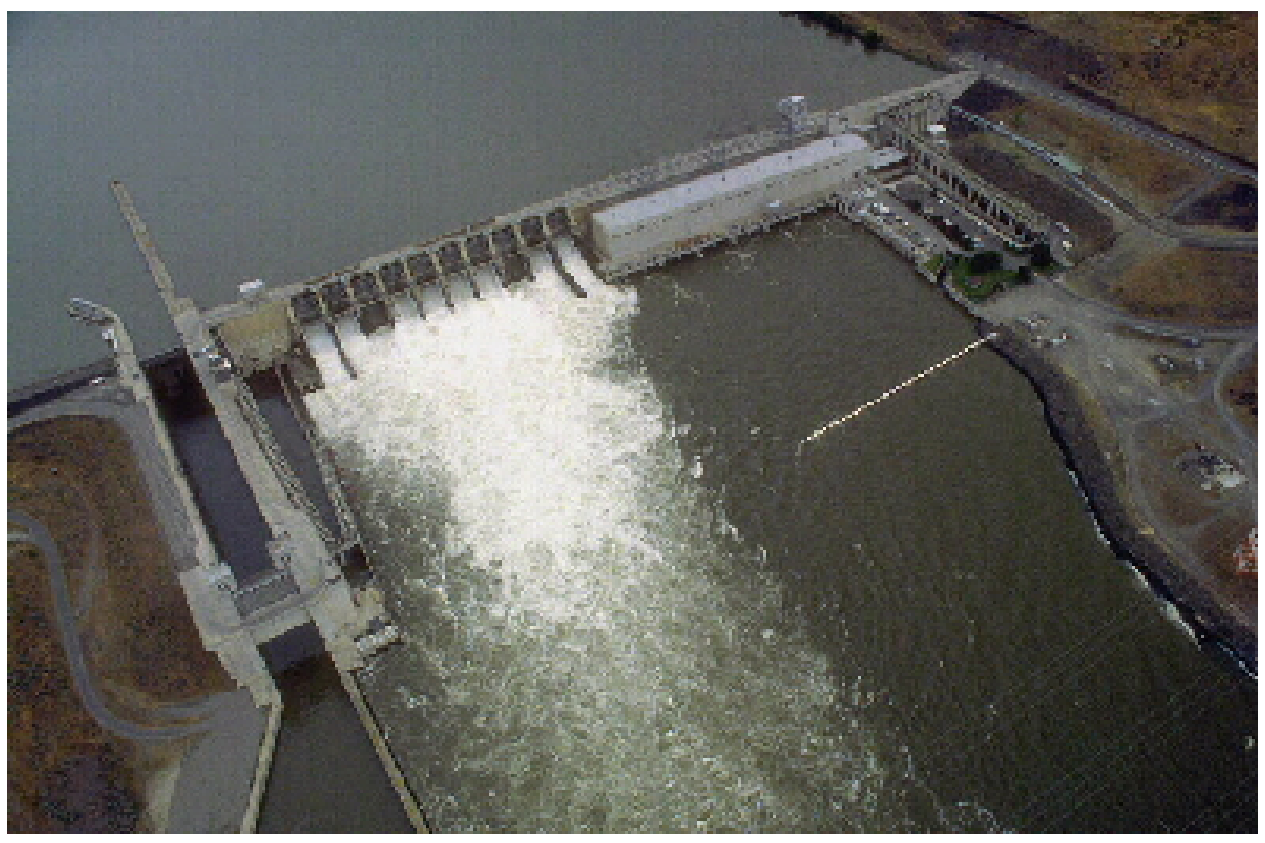

Figure 2. Ice Harbor Lock and Dam (forebay at top of photo) 


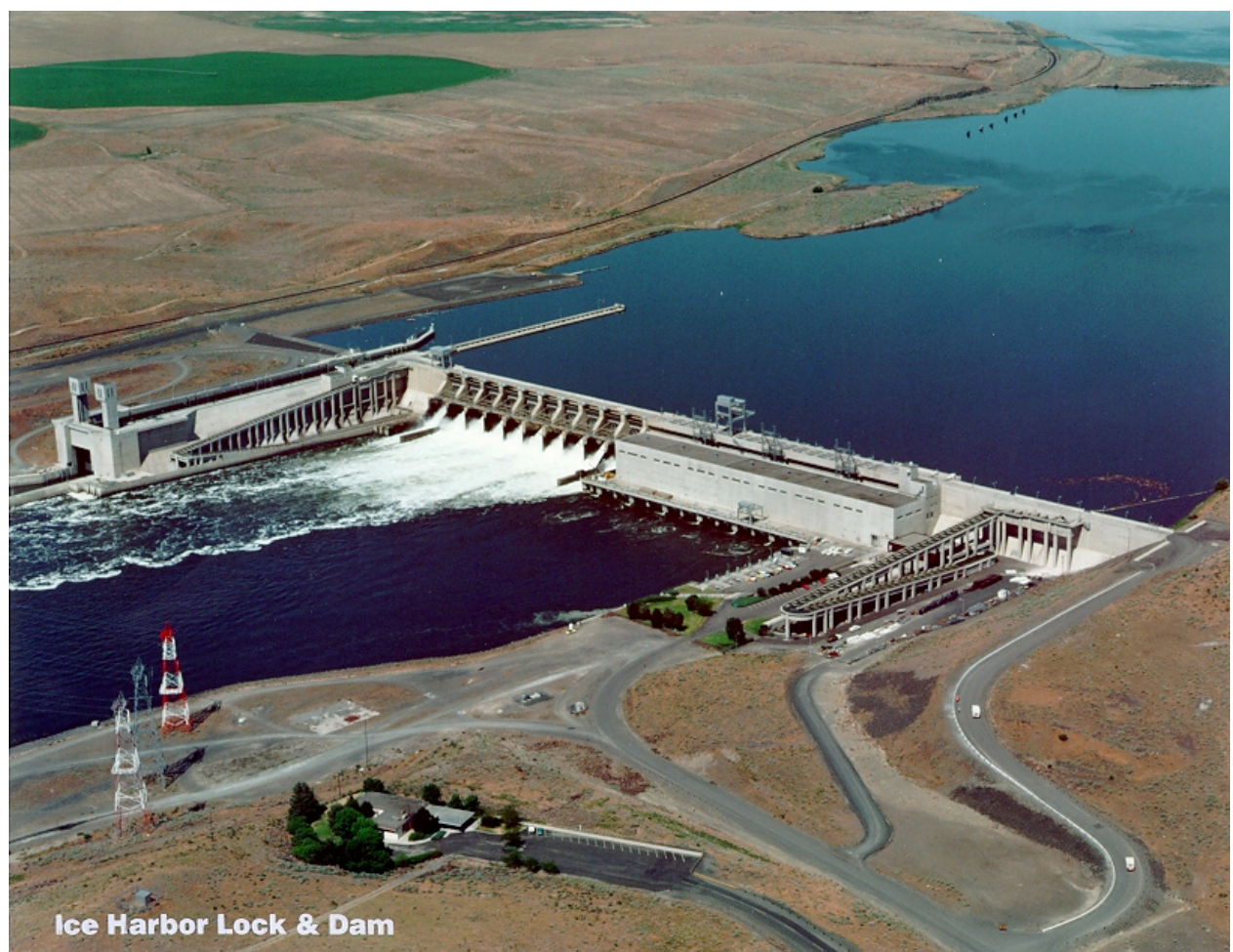

Figure 3. Ice Harbor Lock and Dam (powerhouse, spillway, and navigation lock)

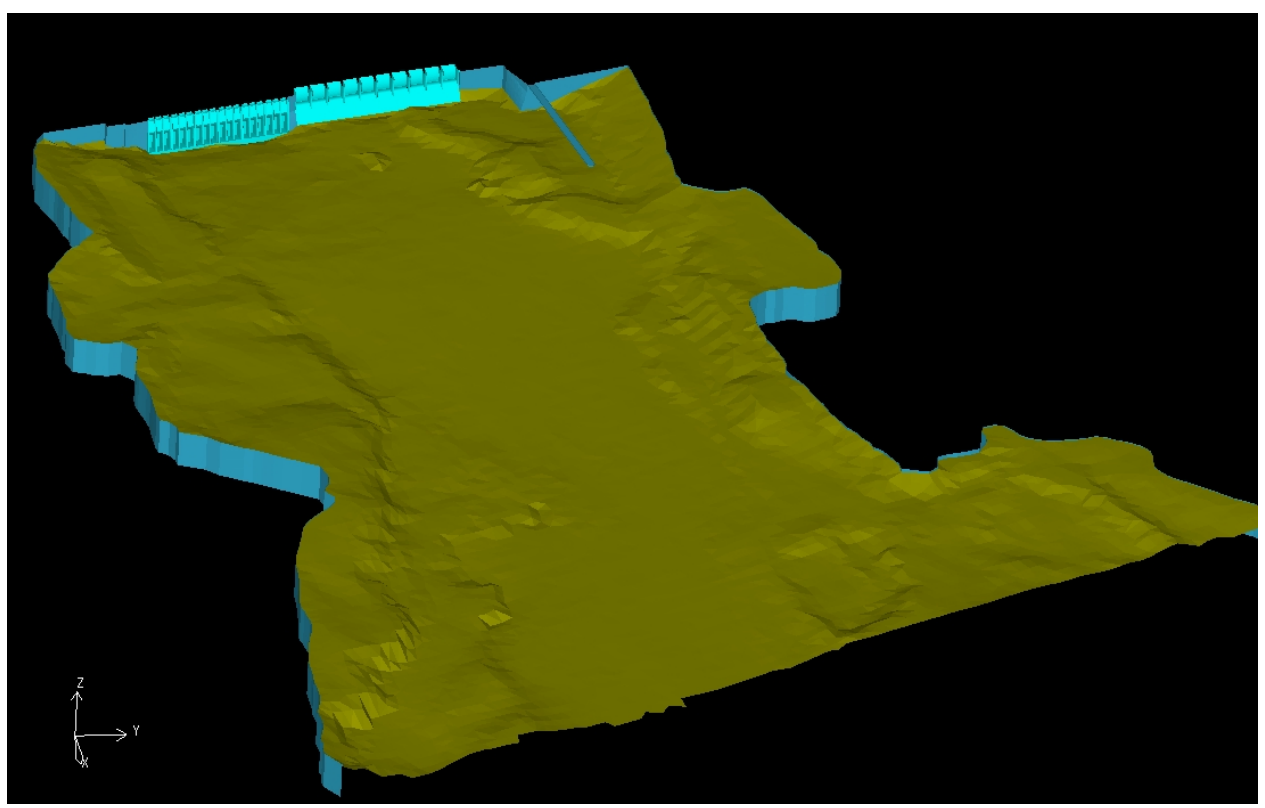

Figure 4. Overall view of CAD model of Ice Harbor forebay (water surface removed) 


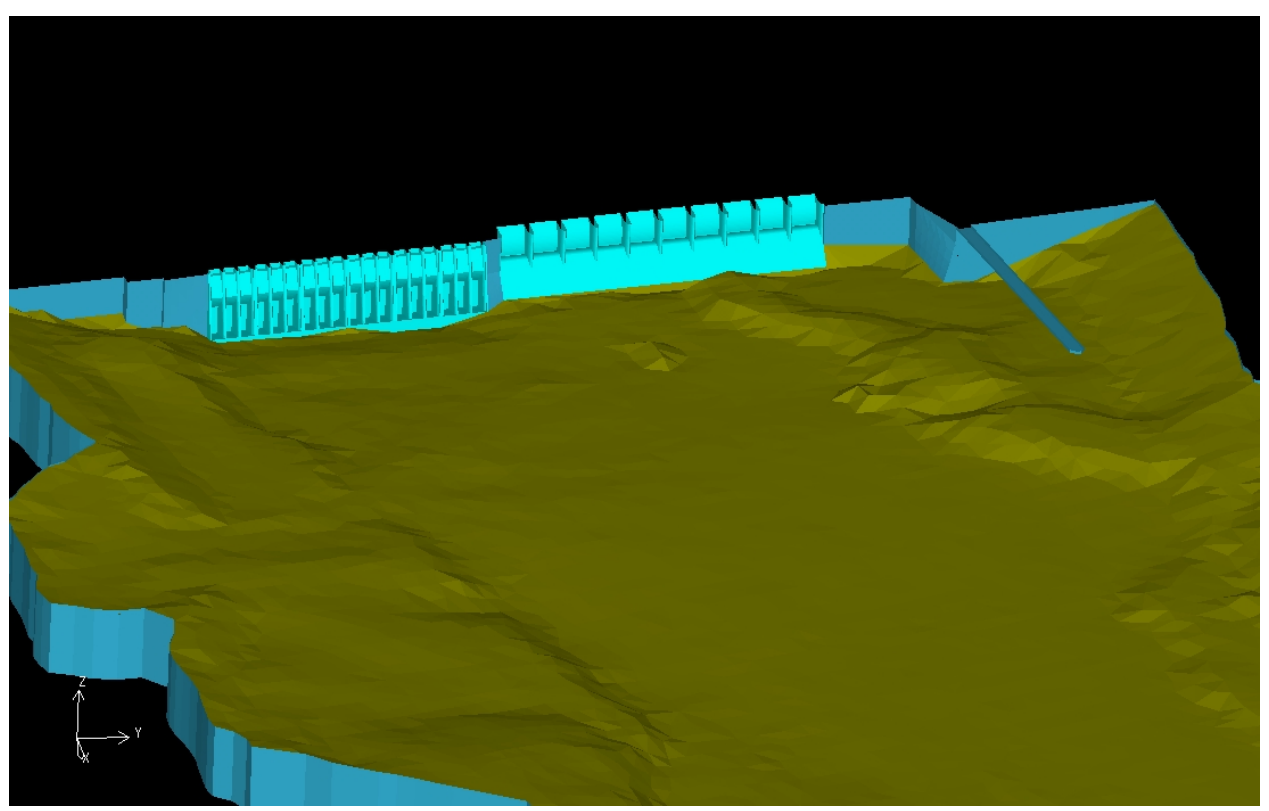

Figure 5. CAD model of Ice Harbor forebay

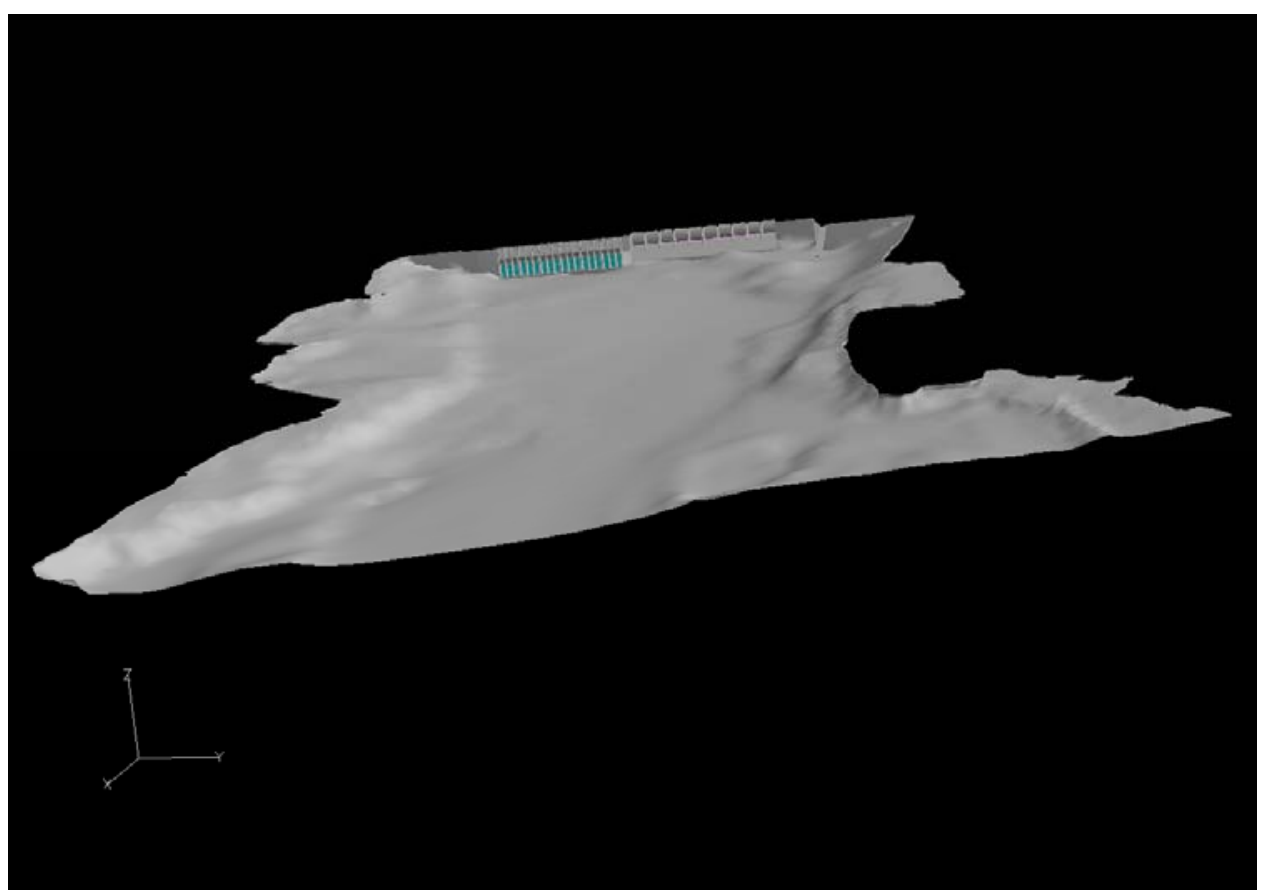

Figure 6. Bathymetric features of Ice Harbor forebay 


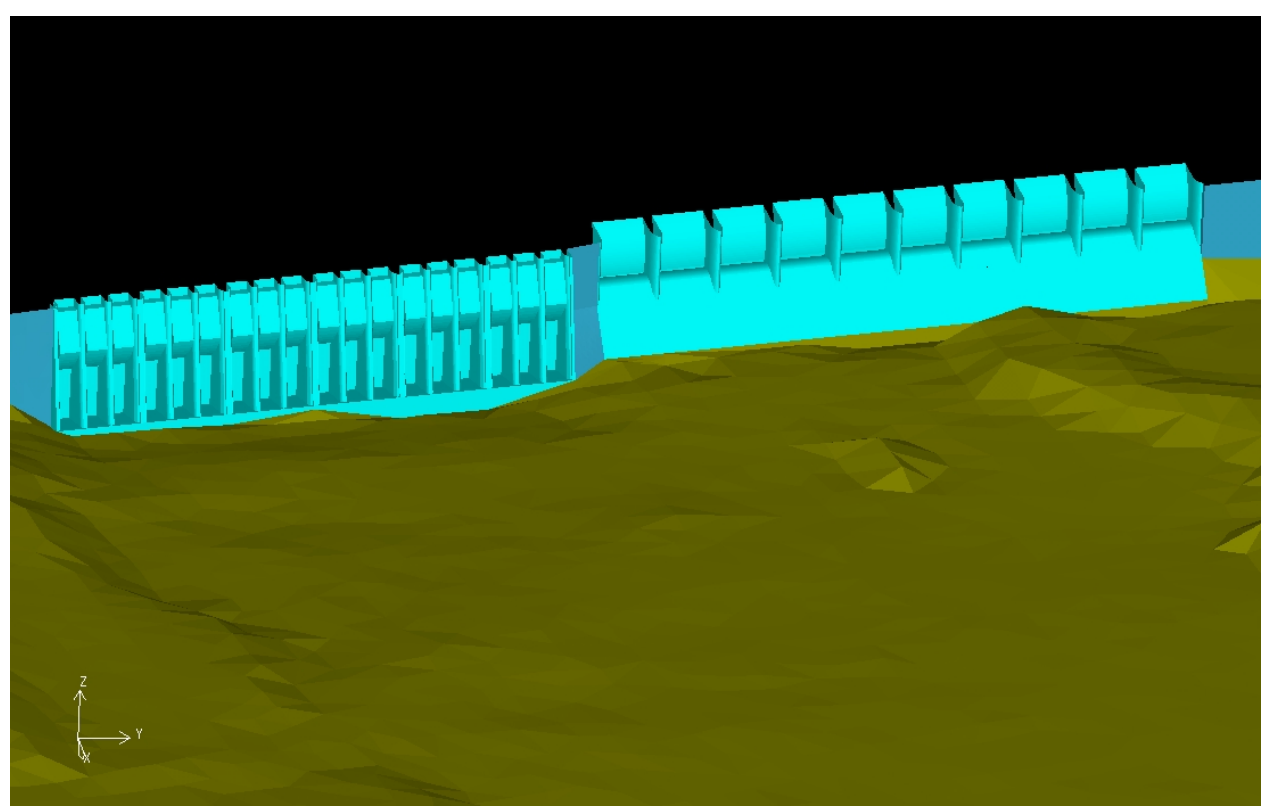

Figure 7. CAD model of powerhouse and adjacent spillway

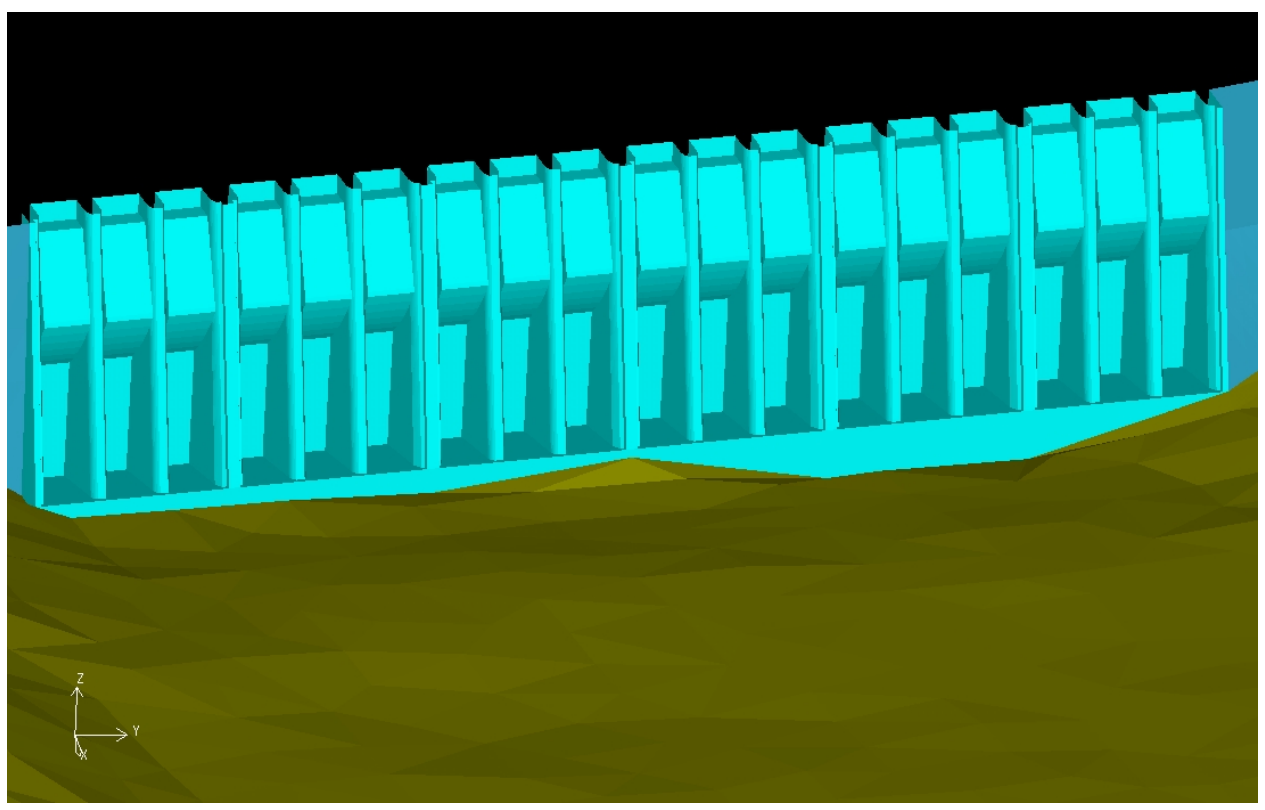

Figure 8. Detail view of CAD model of powerhouse 


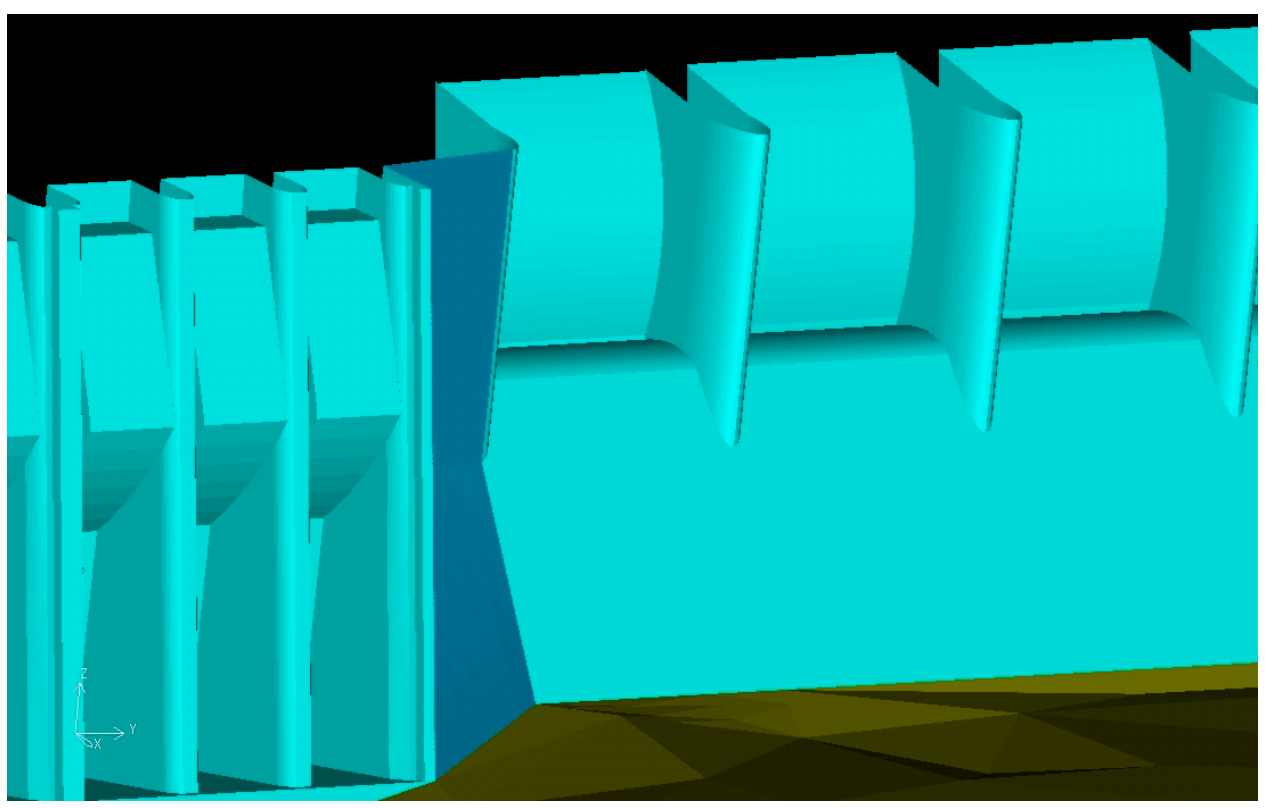

Figure 9. Details of powerhouse and adjacent spillway

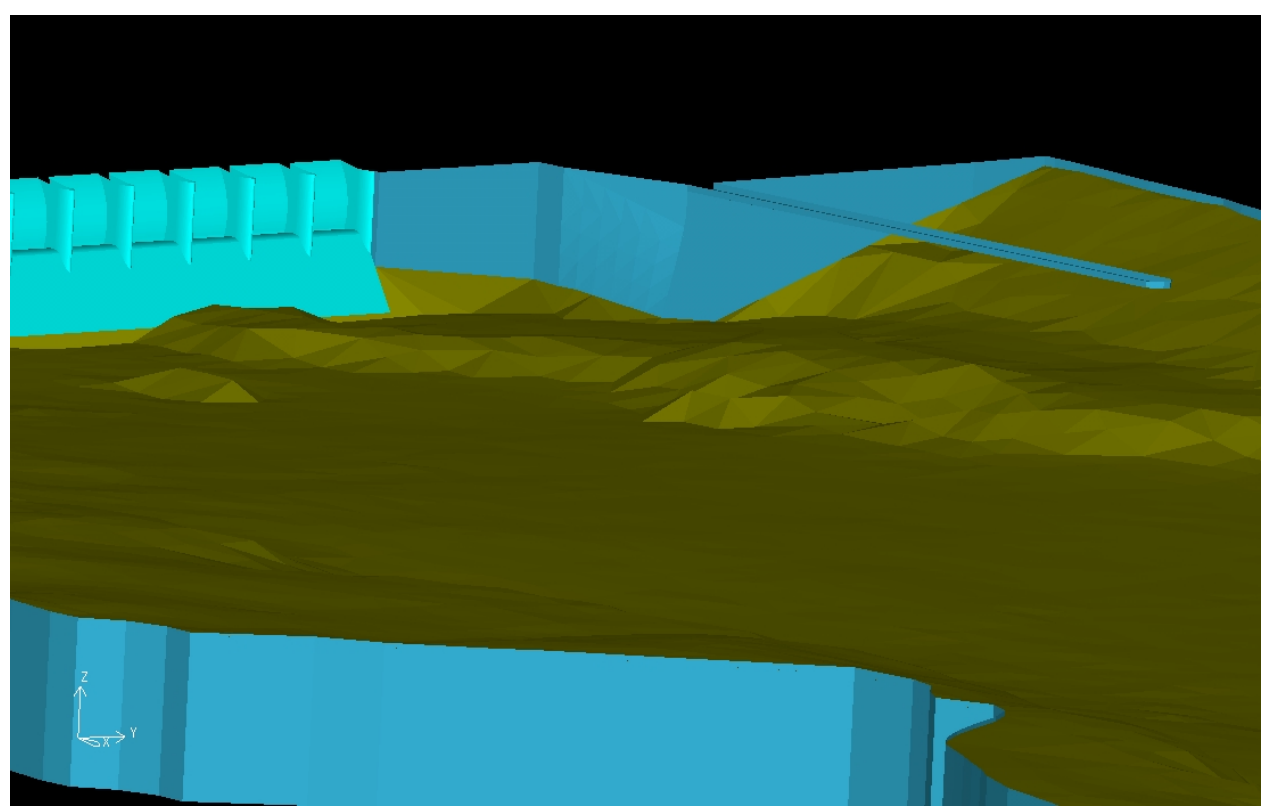

Figure 10. CAD model of right end of spillway and lock floating guard wall 


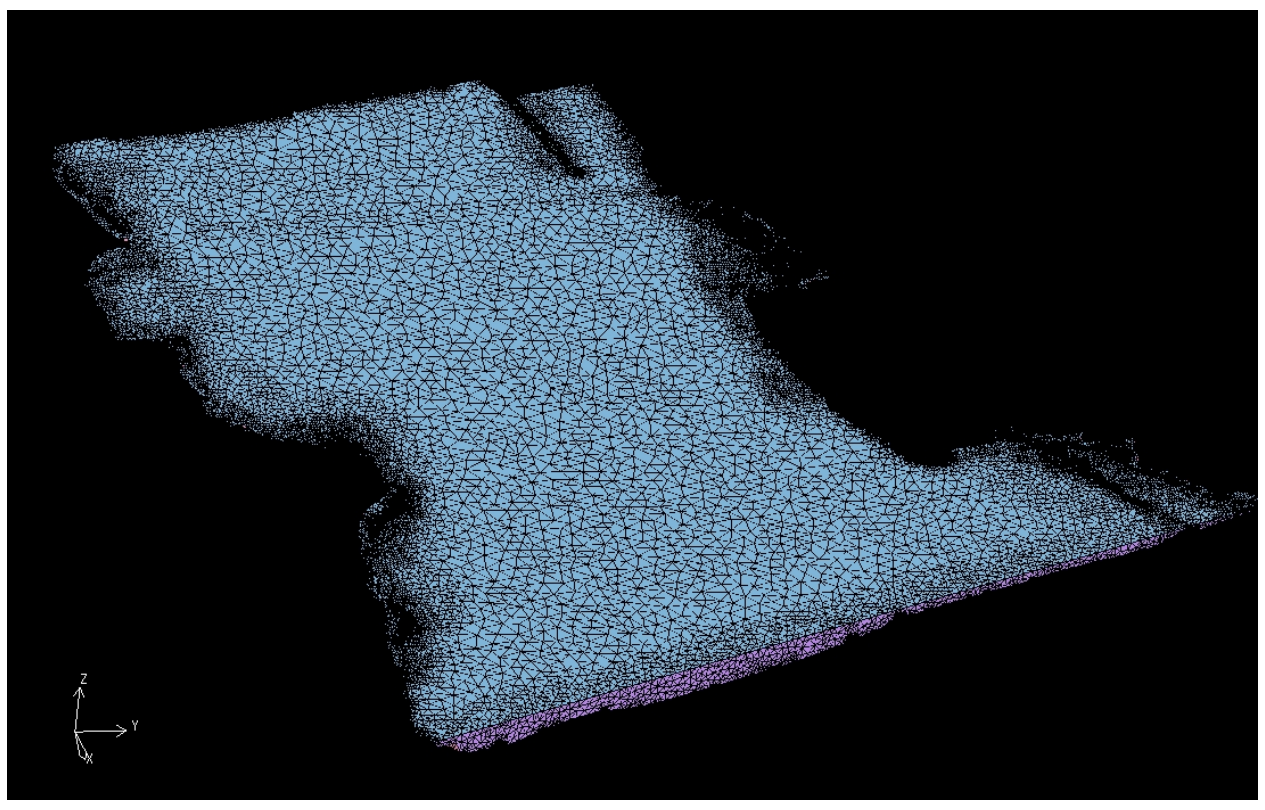

Figure 11. Overall view of surface mesh of water surface

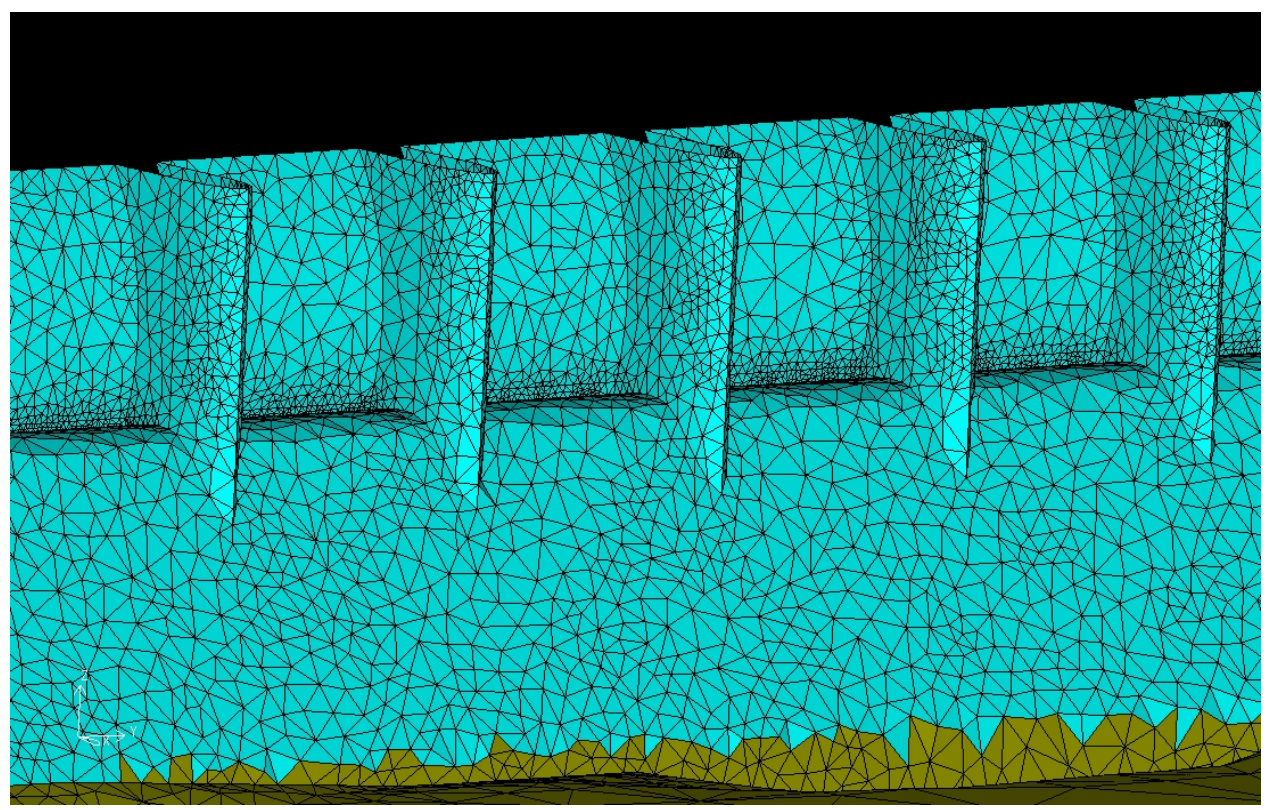

Figure 12. Surface mesh of typical spillway bay with tainter gates and piers 


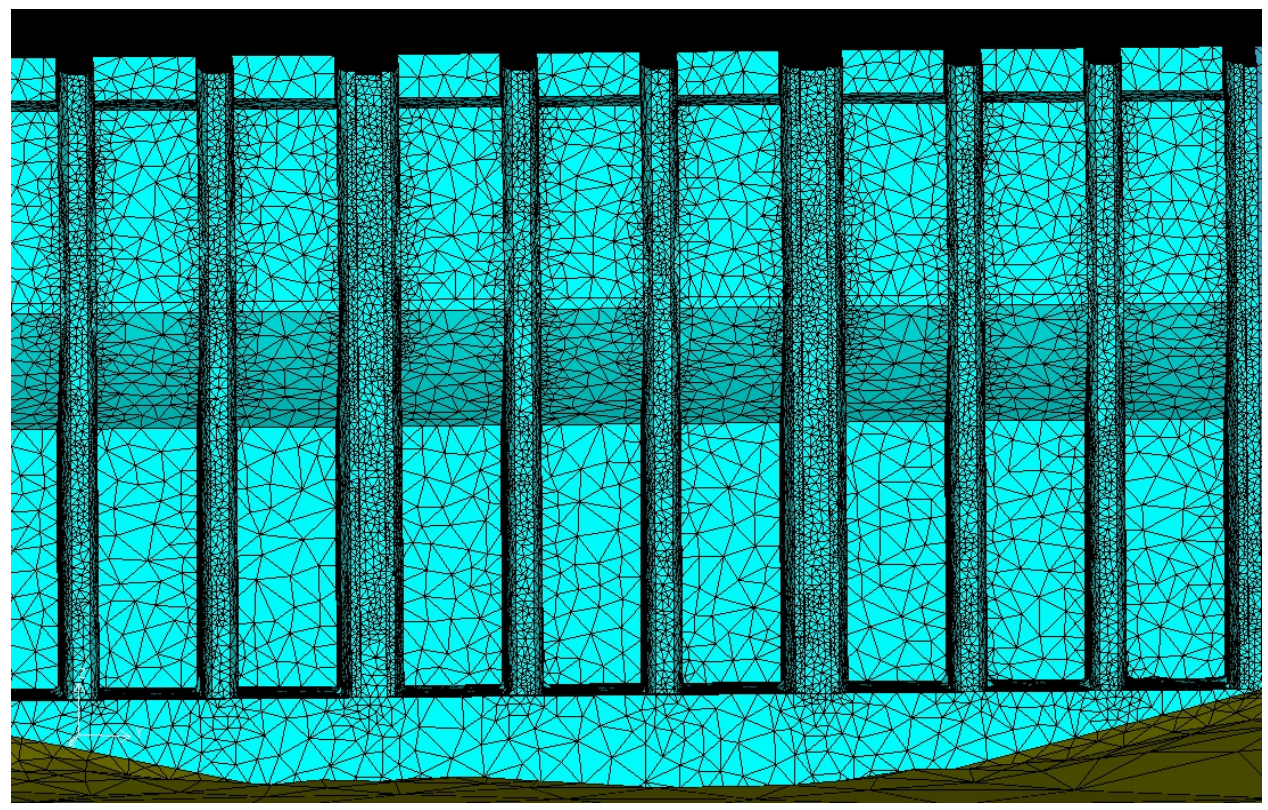

Figure 13. Detail view of surface mesh of powerhouse units

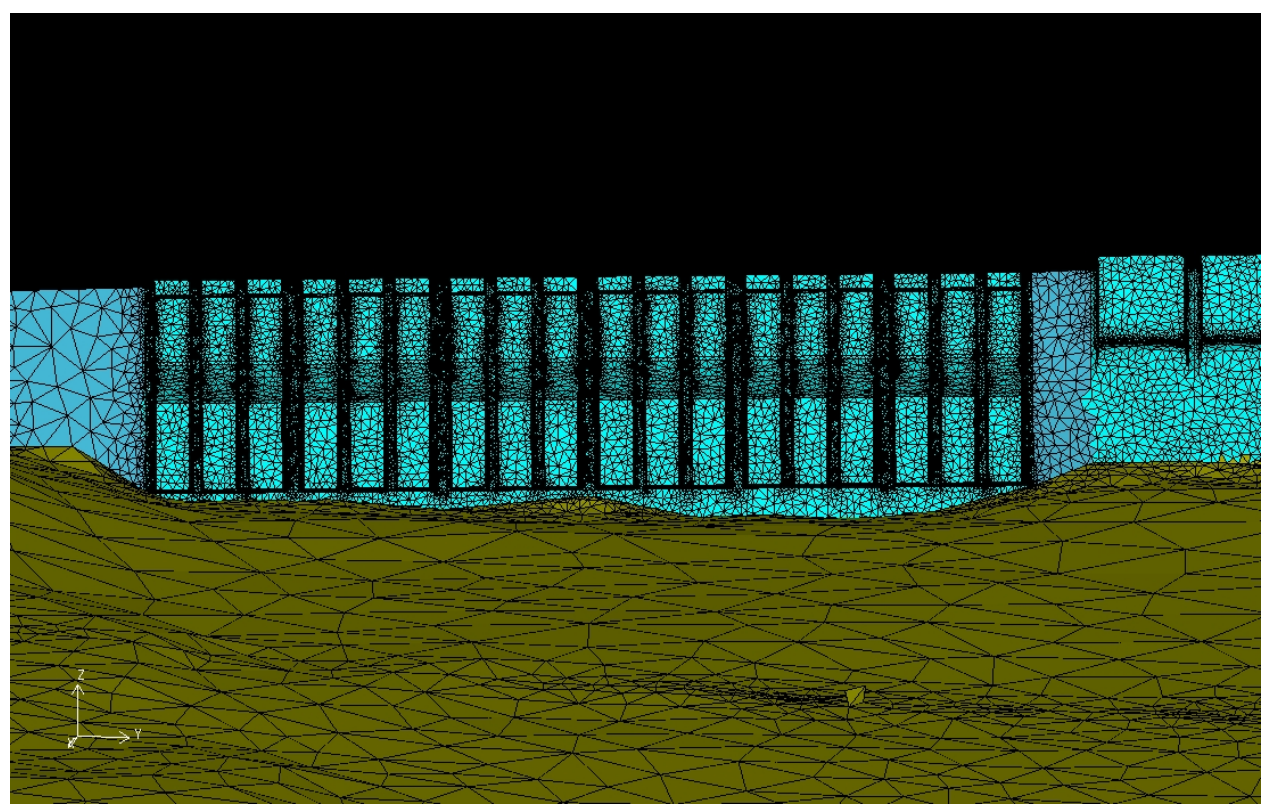

Figure 14. Surface mesh of powerhouse and adjacent bathymetry 


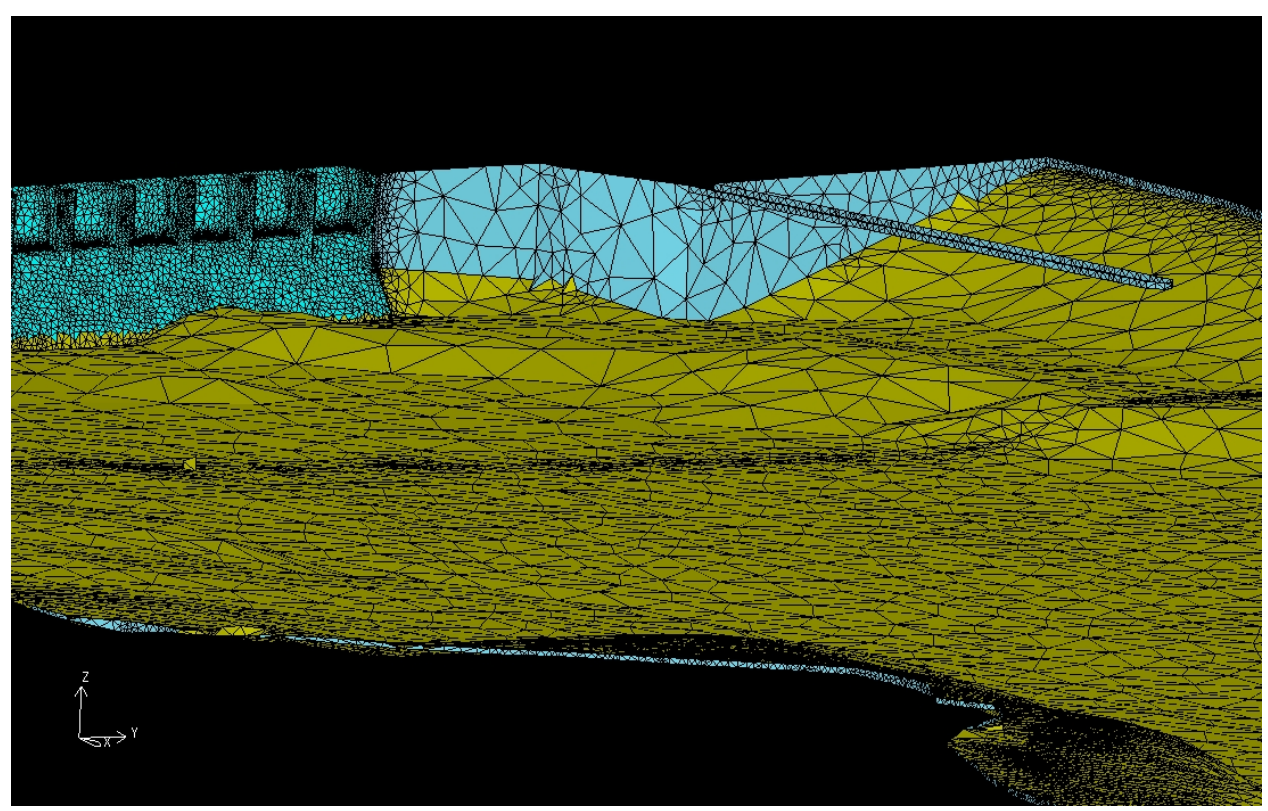

Figure 15. Surface mesh of spillway near navigation lock and floating guard wall

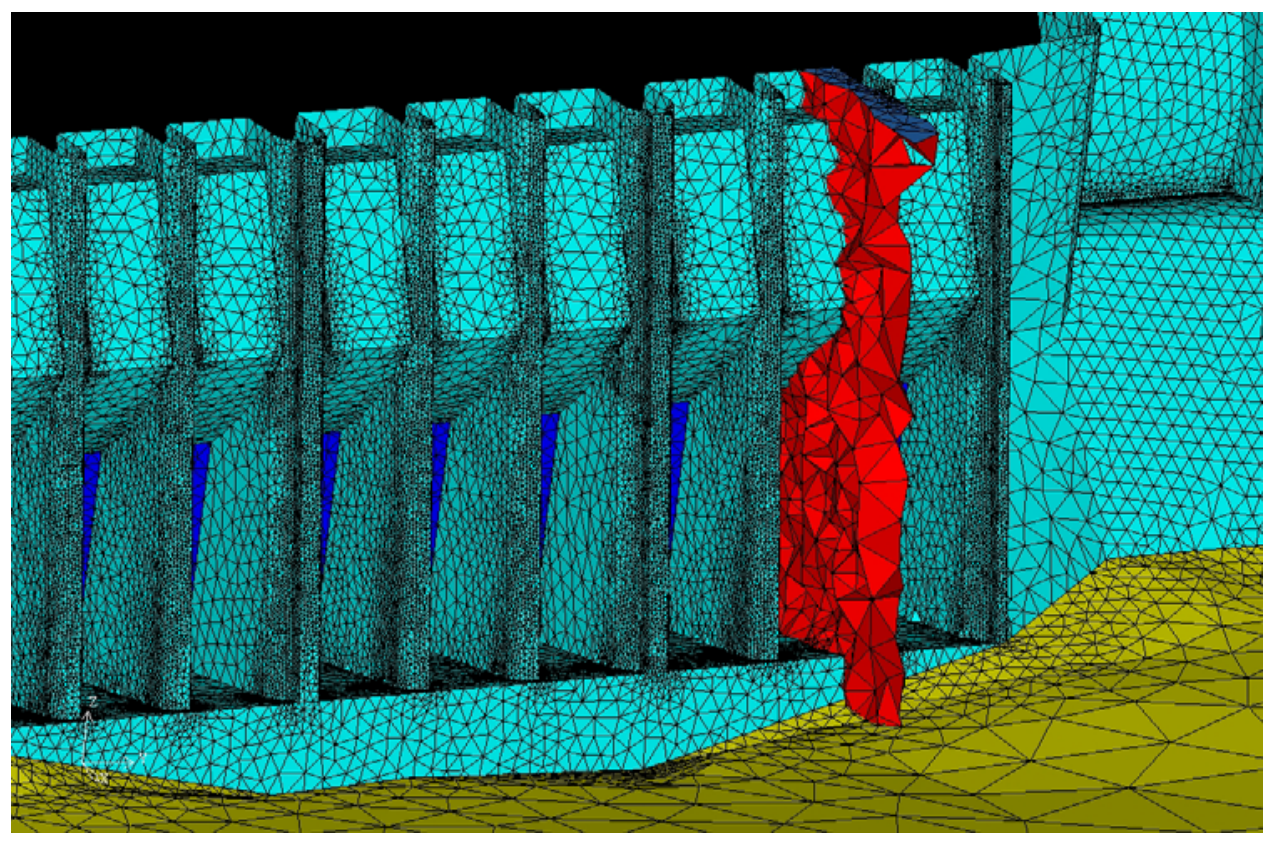

Figure 16. Surface mesh (triangles) and portion of volume mesh (tetrahedra) within powerhouse unit 6 intake 


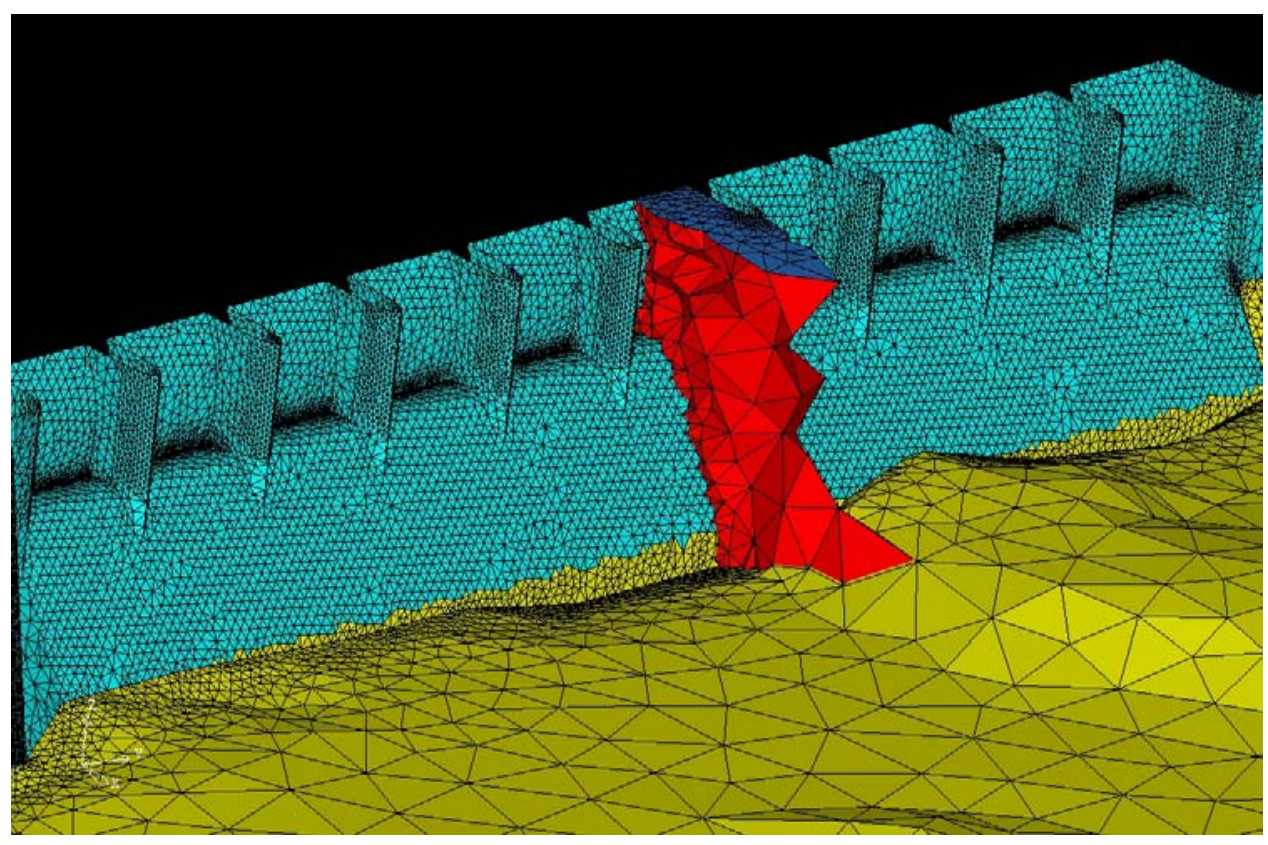

Figure 17. Surface mesh (triangles) and portion of volume mesh (tetrahedra) at spillway bay 5

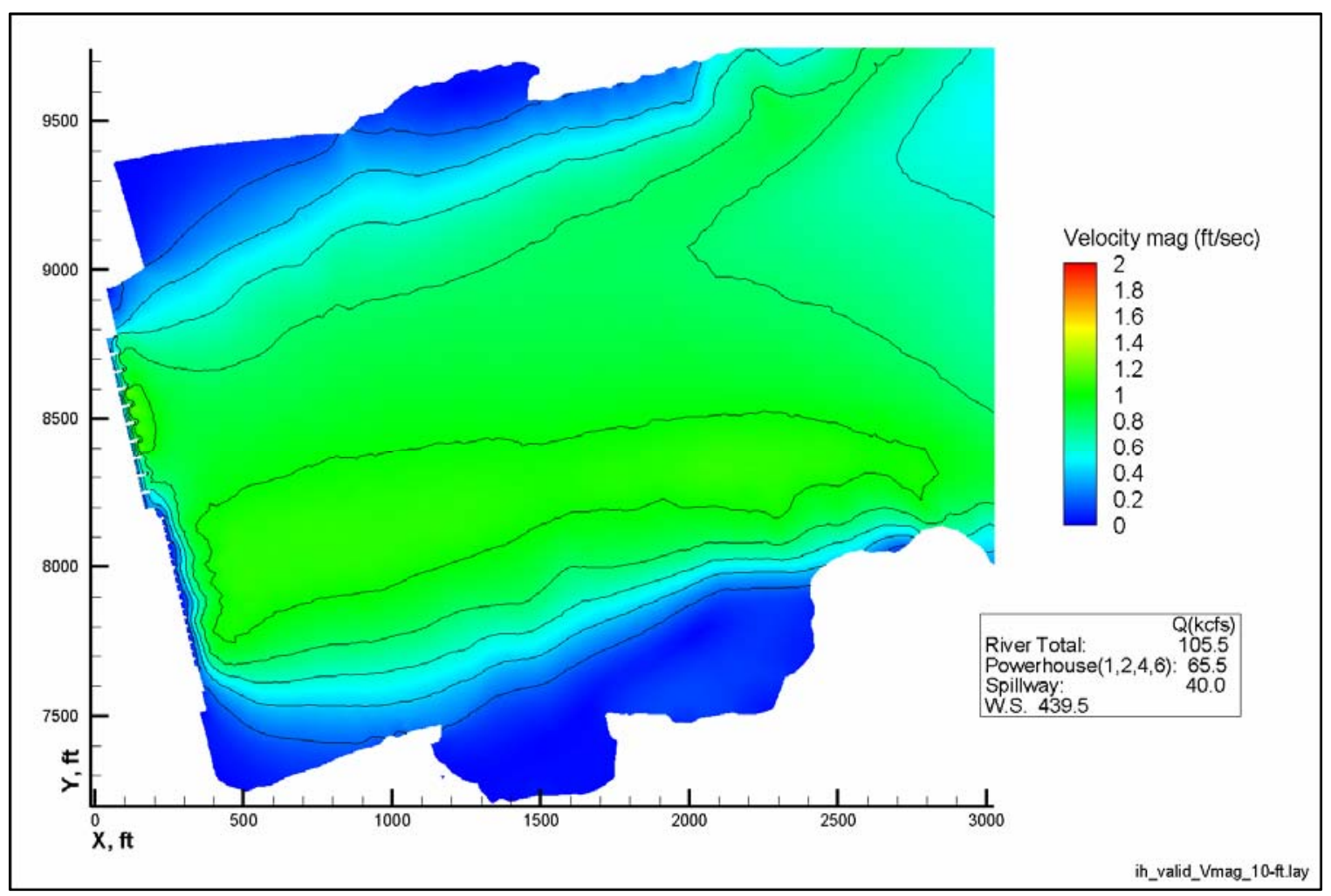

Figure 18. Velocity magnitude contours at $10-\mathrm{ft}$ depth 


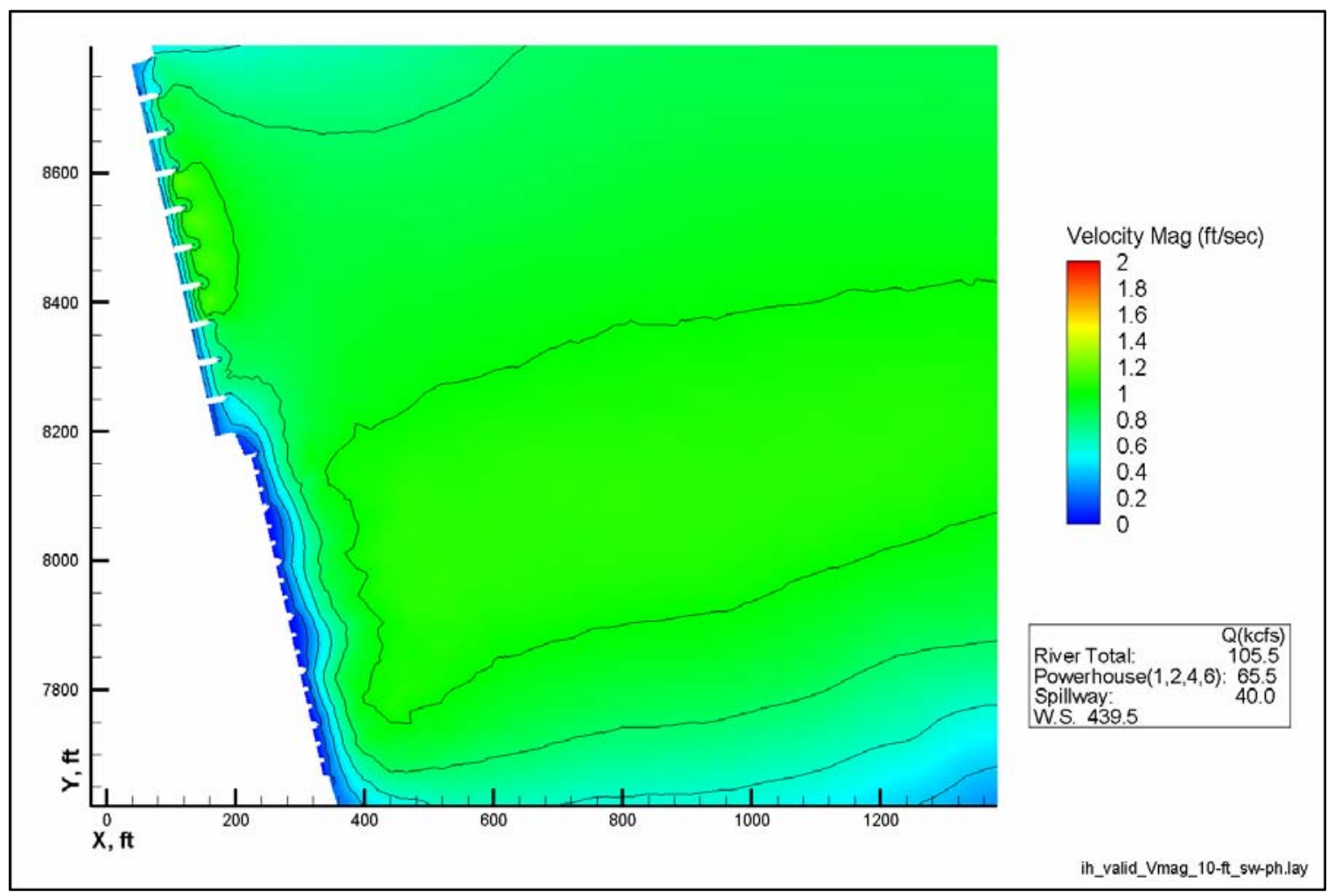

Figure 19. Velocity magnitude contours near the dam at $10-\mathrm{ft}$ depth

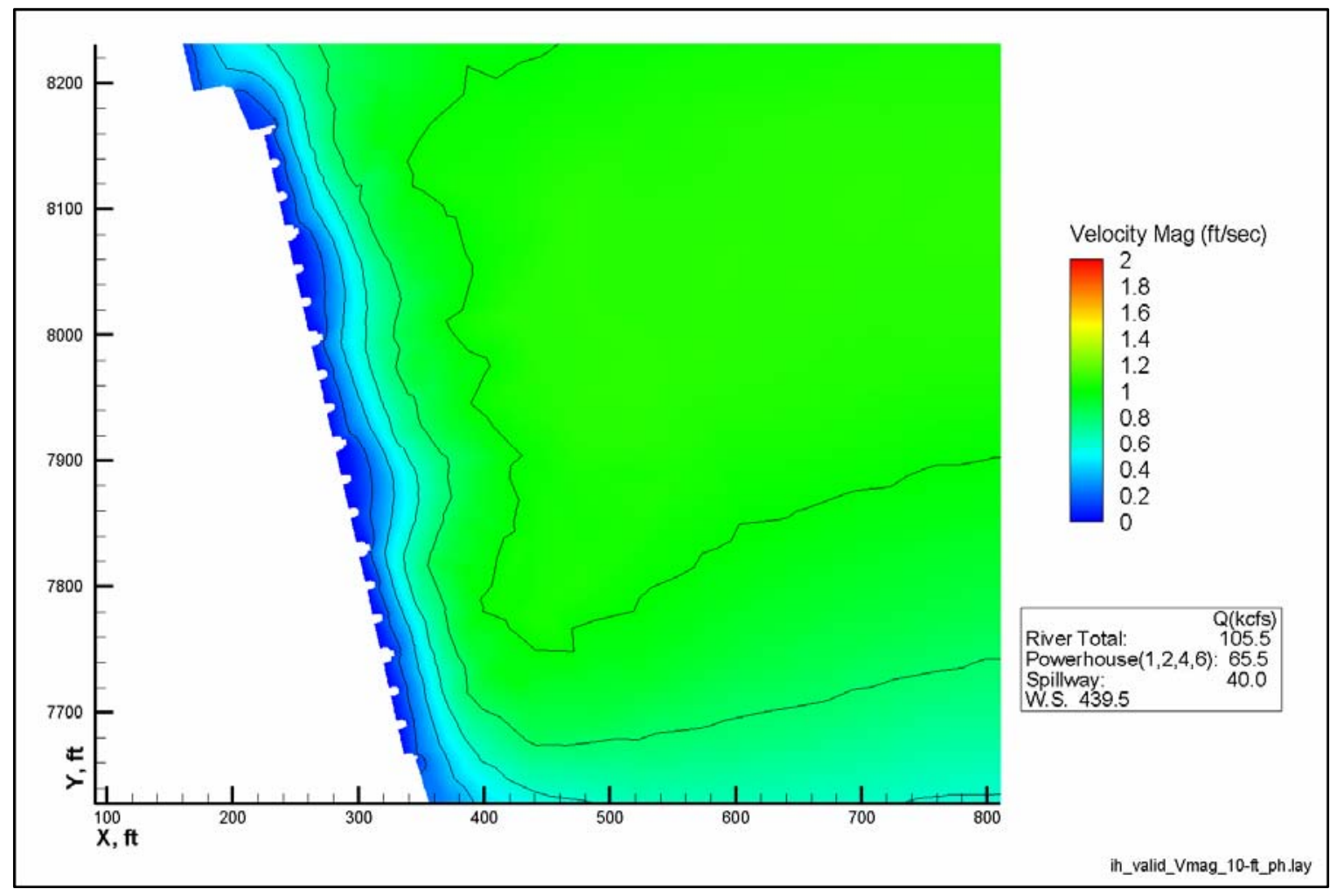

Figure 20. Velocity magnitude contours approaching the powerhouse at $10-\mathrm{ft}$ depth 


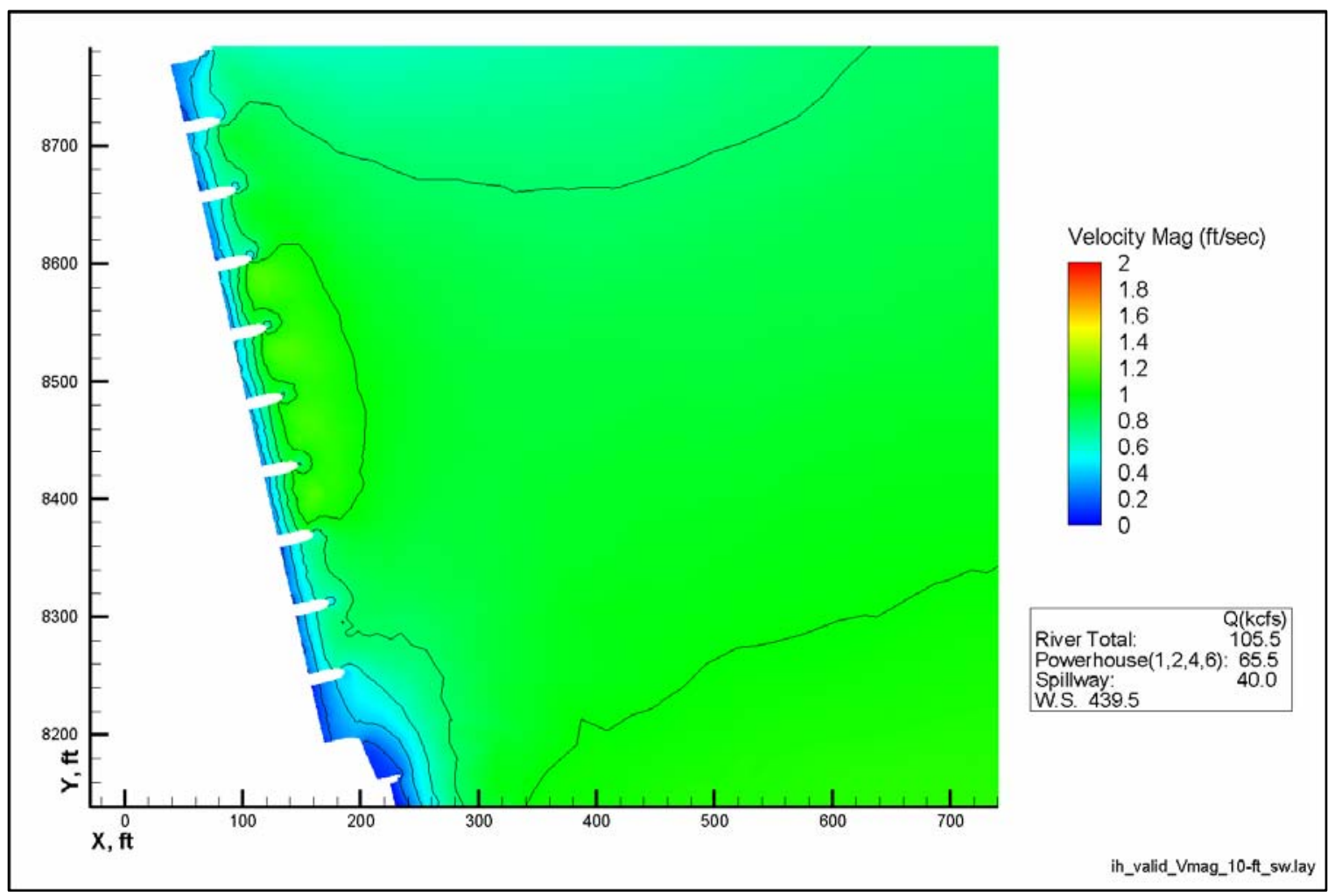

Figure 21. Velocity magnitude contours approaching the spillway at $10-\mathrm{ft}$ depth

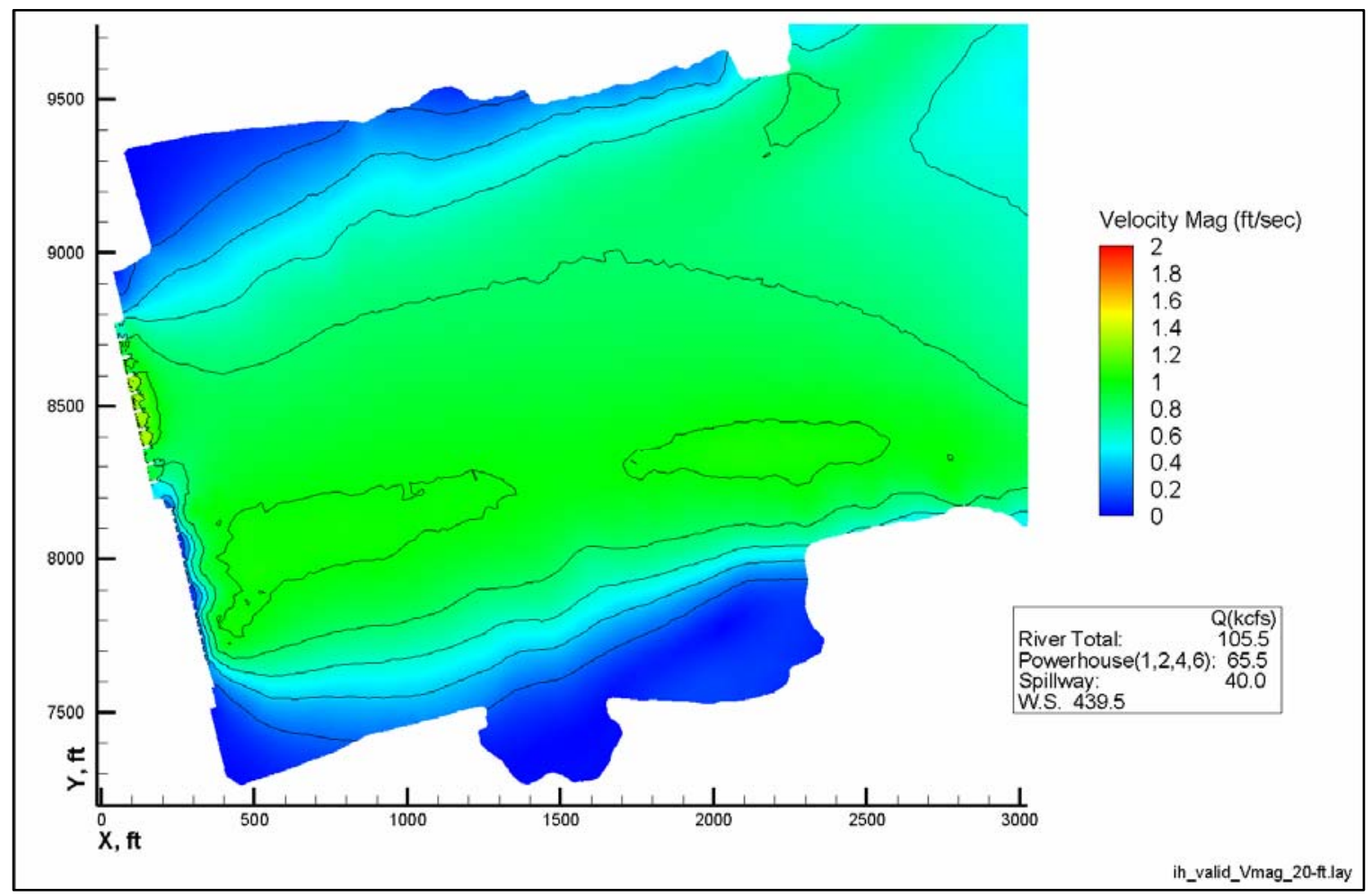

Figure 22. Velocity magnitude contours at $20-\mathrm{ft}$ depth 


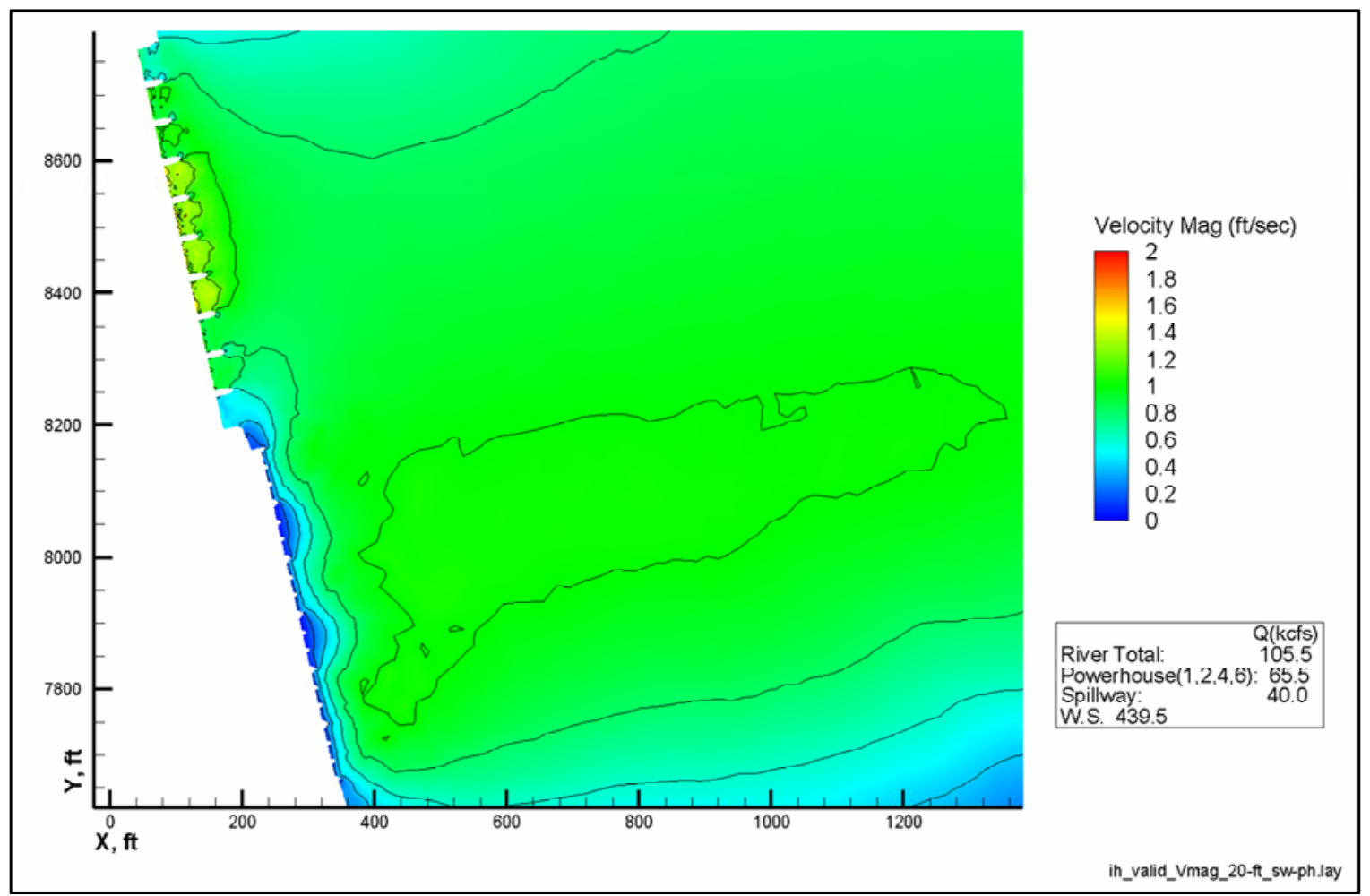

Figure 23. Velocity magnitude contours near the dam at 20-ft depth

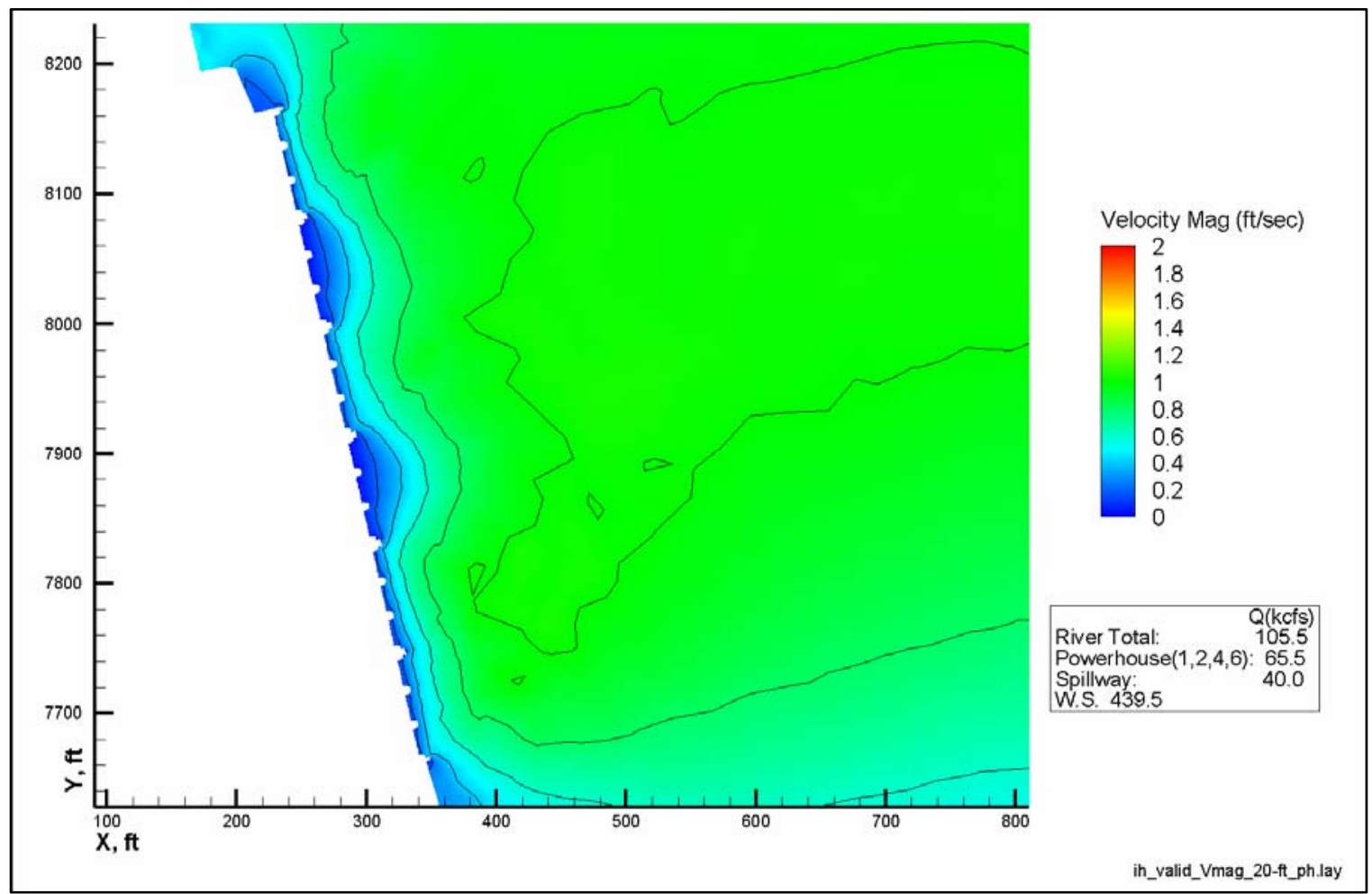

Figure 24. Velocity magnitude contours approaching the powerhouse at 20-ft depth 


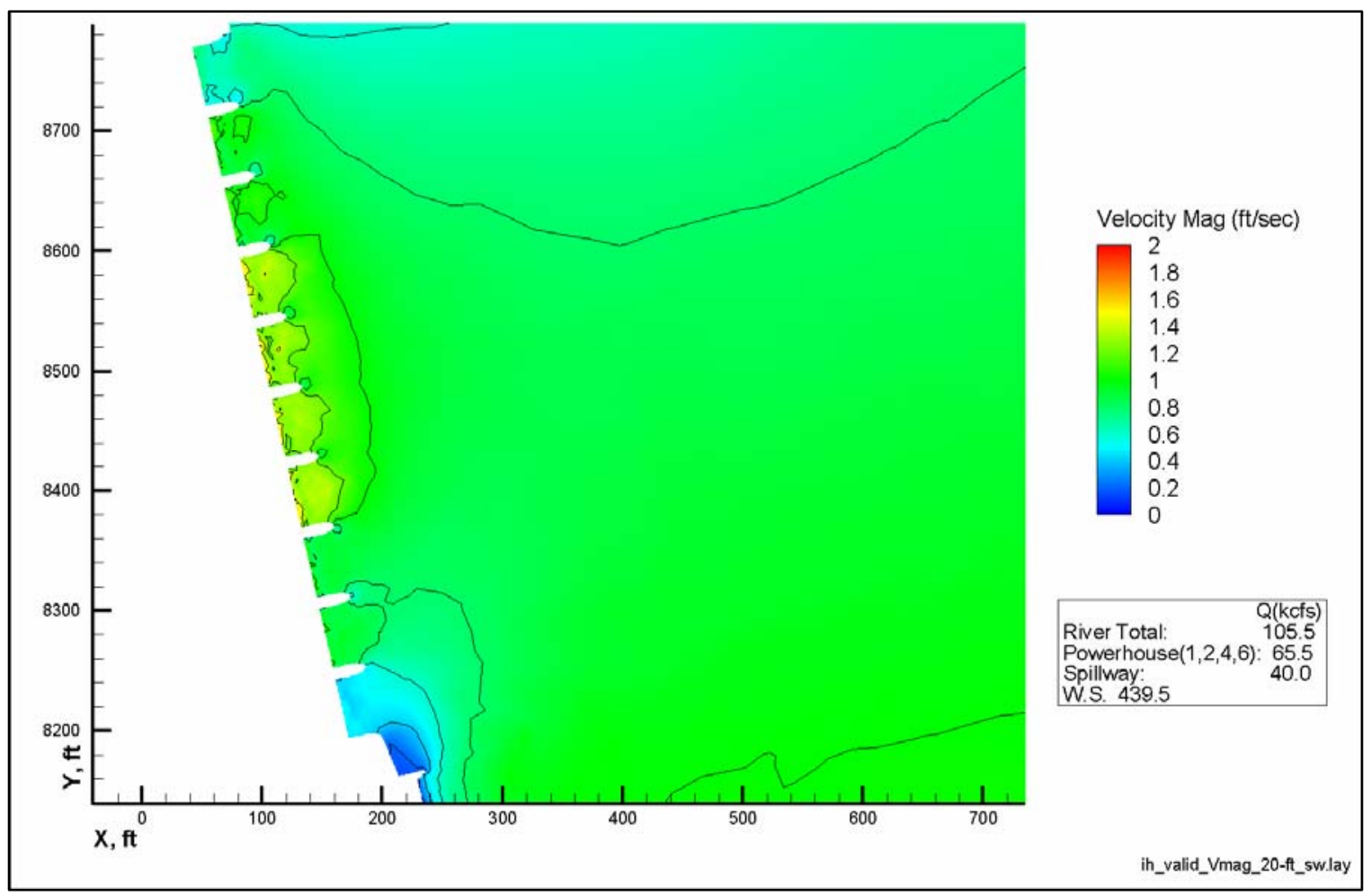

Figure 25. Velocity magnitude contours approaching the spillway at 20-ft depth

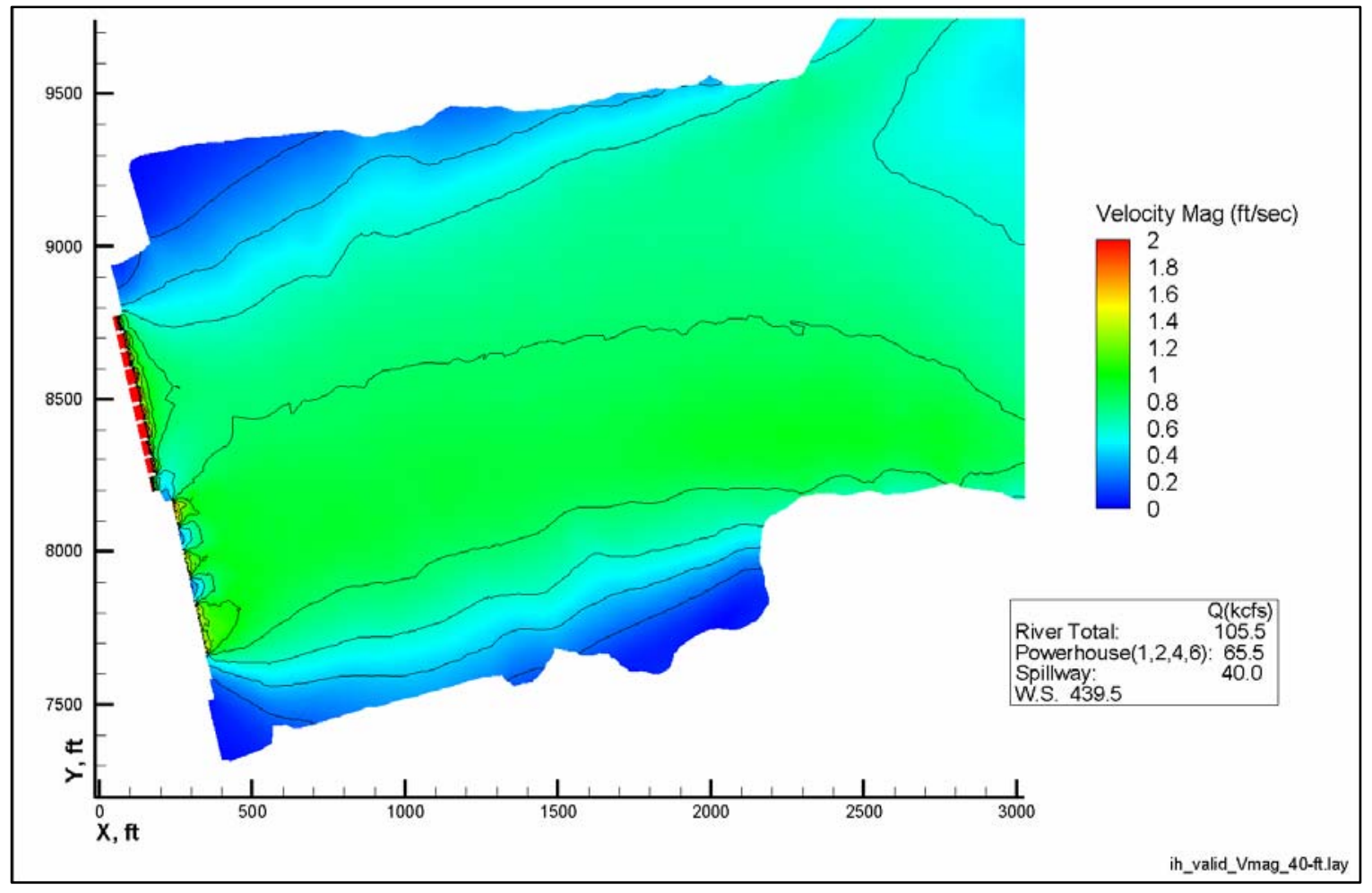

Figure 26 . Velocity magnitude contours at $40-\mathrm{ft}$ depth 


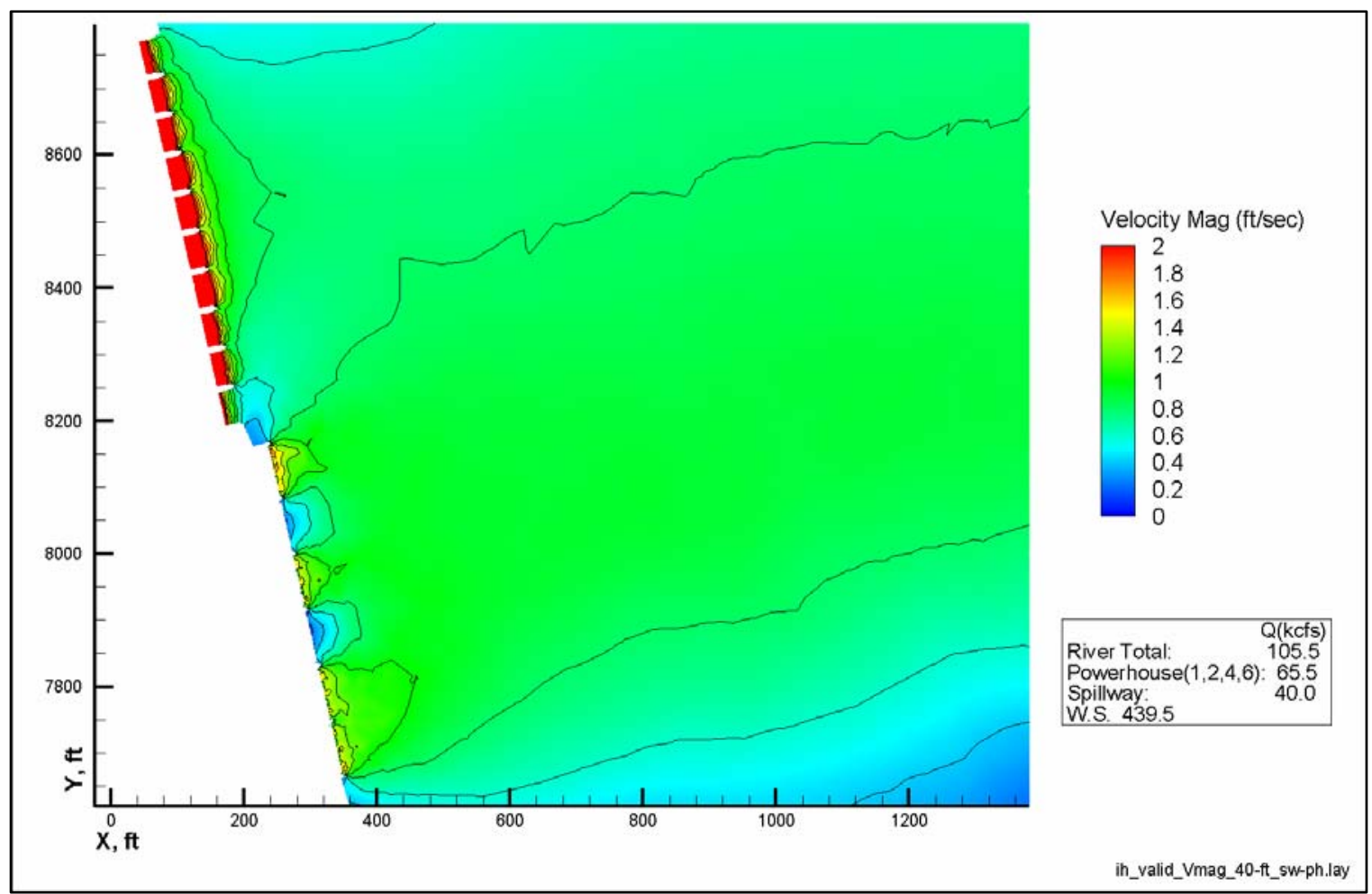

Figure 27 . Velocity magnitude contours near the dam at $40-\mathrm{ft}$ depth

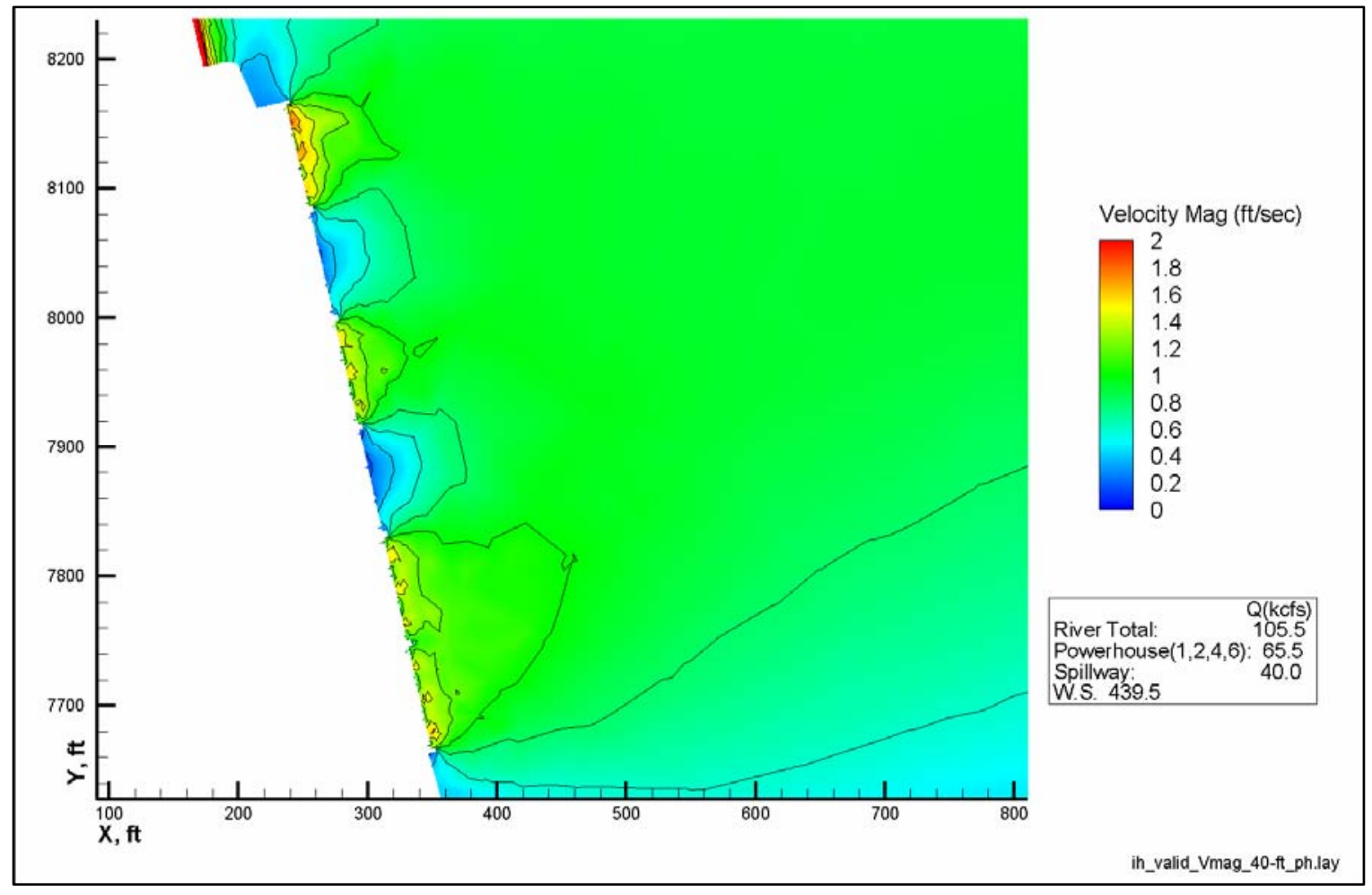

Figure 28. Velocity magnitude contours approaching the powerhouse at $40-\mathrm{ft}$ depth 


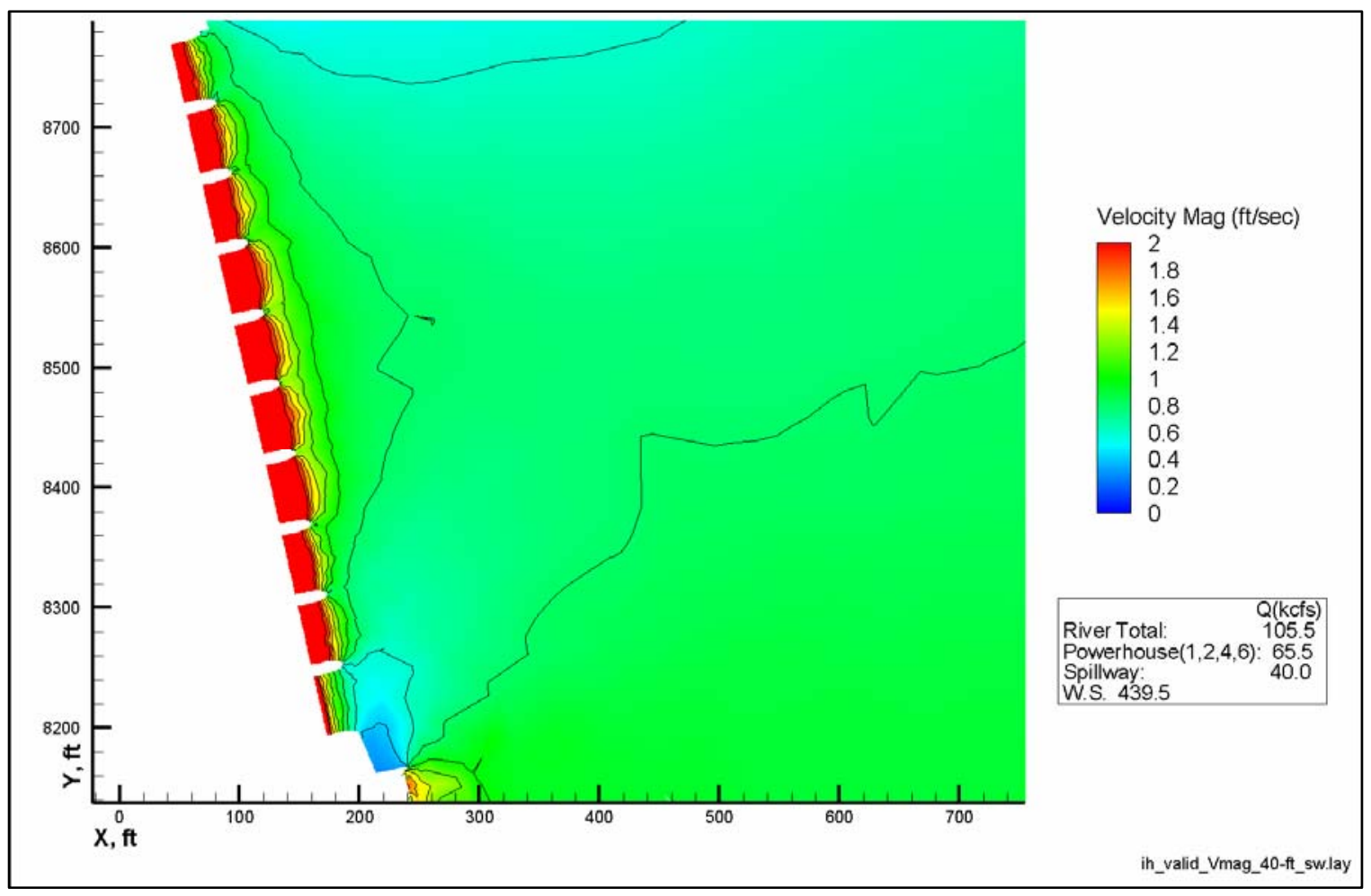

Figure 29. Velocity magnitude contours approaching the spillway at 40-ft depth

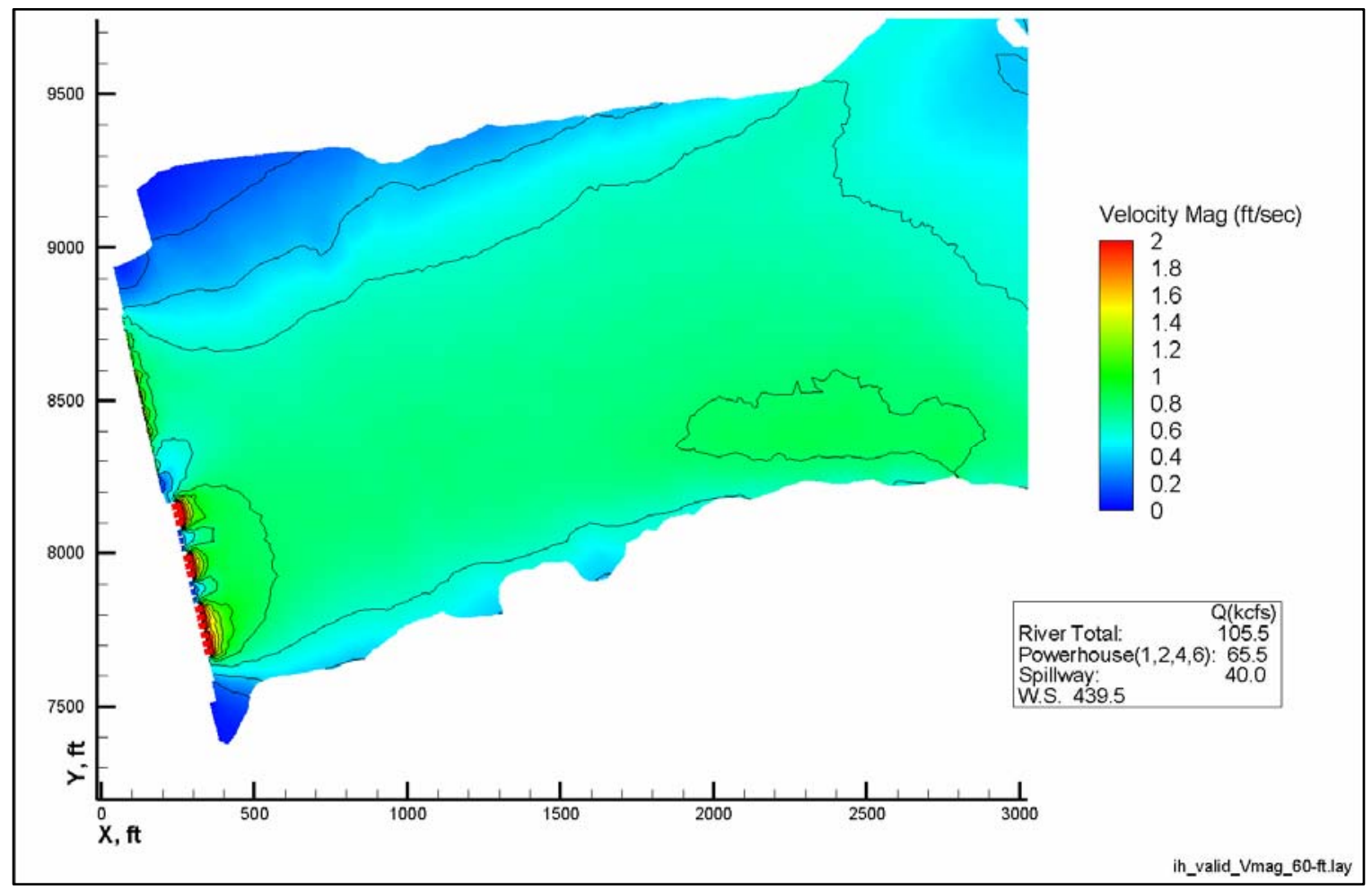

Figure 30 . Velocity magnitude contours at $60-\mathrm{ft}$ depth 


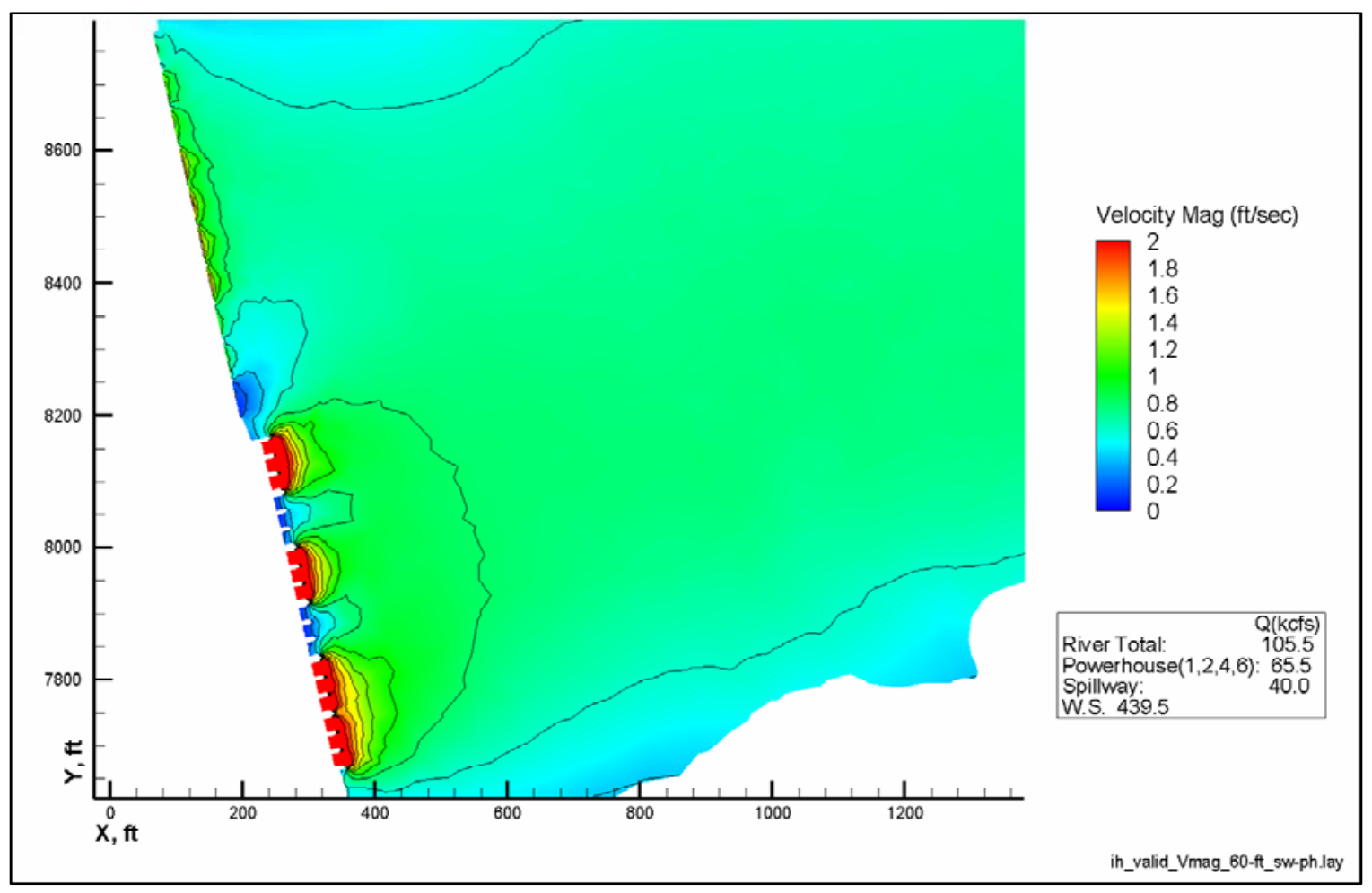

Figure 31 . Velocity magnitude contours near the dam at $60-\mathrm{ft}$ depth

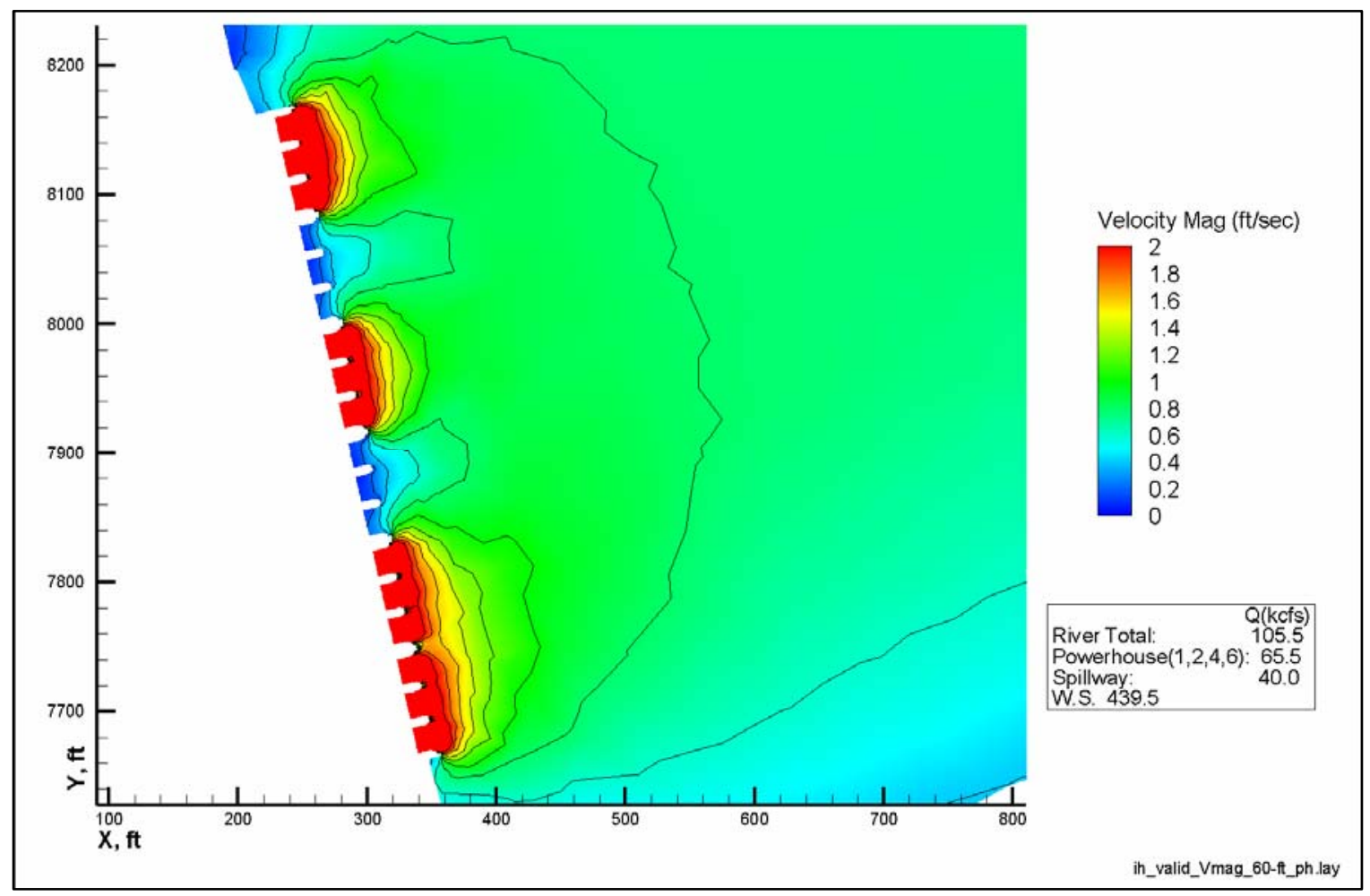

Figure 32. Velocity magnitude contours approaching the powerhouse at $60-\mathrm{ft}$ depth 


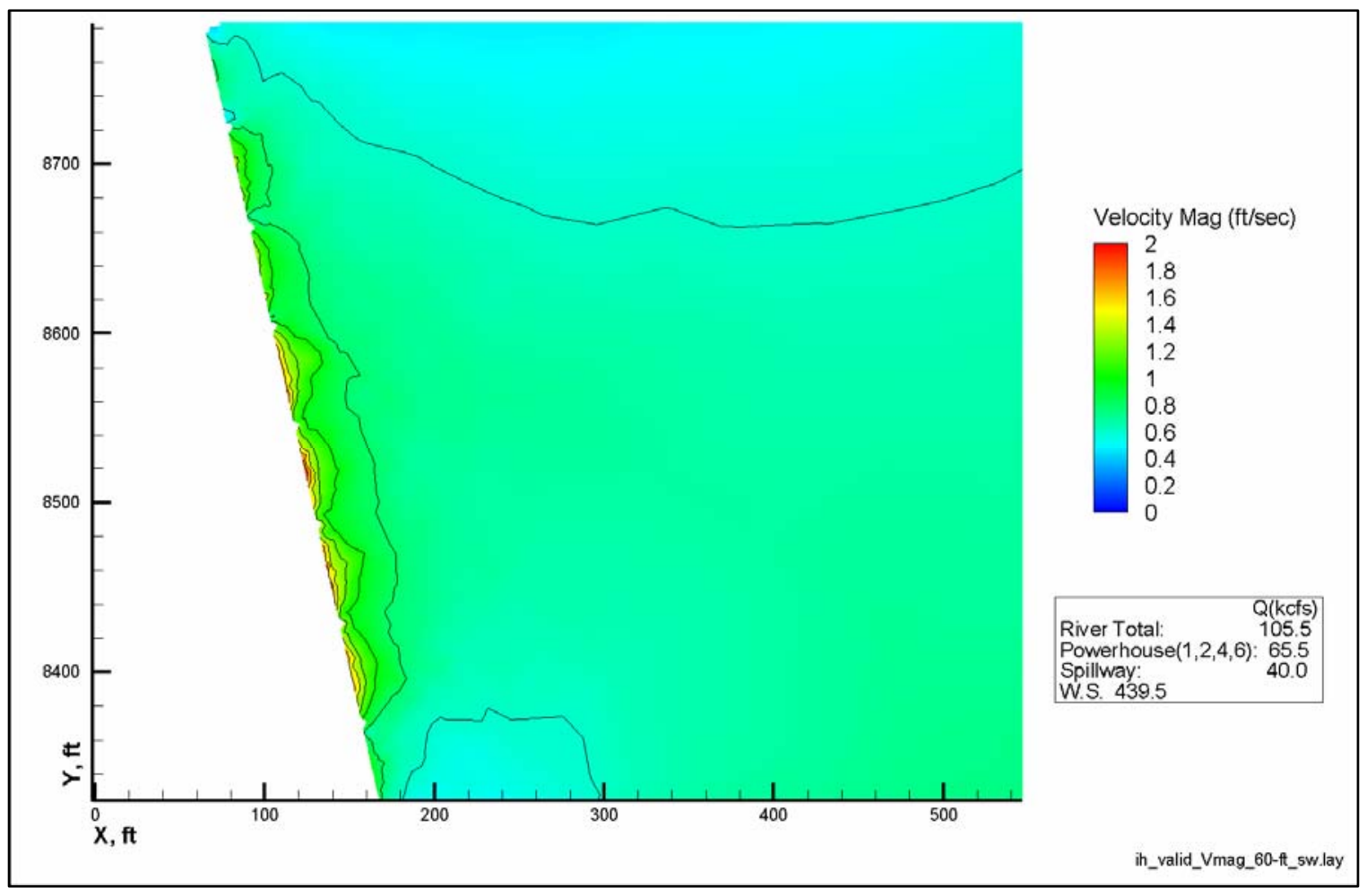

Figure 33. Velocity magnitude contours approaching the spillway at $60-\mathrm{ft}$ depth

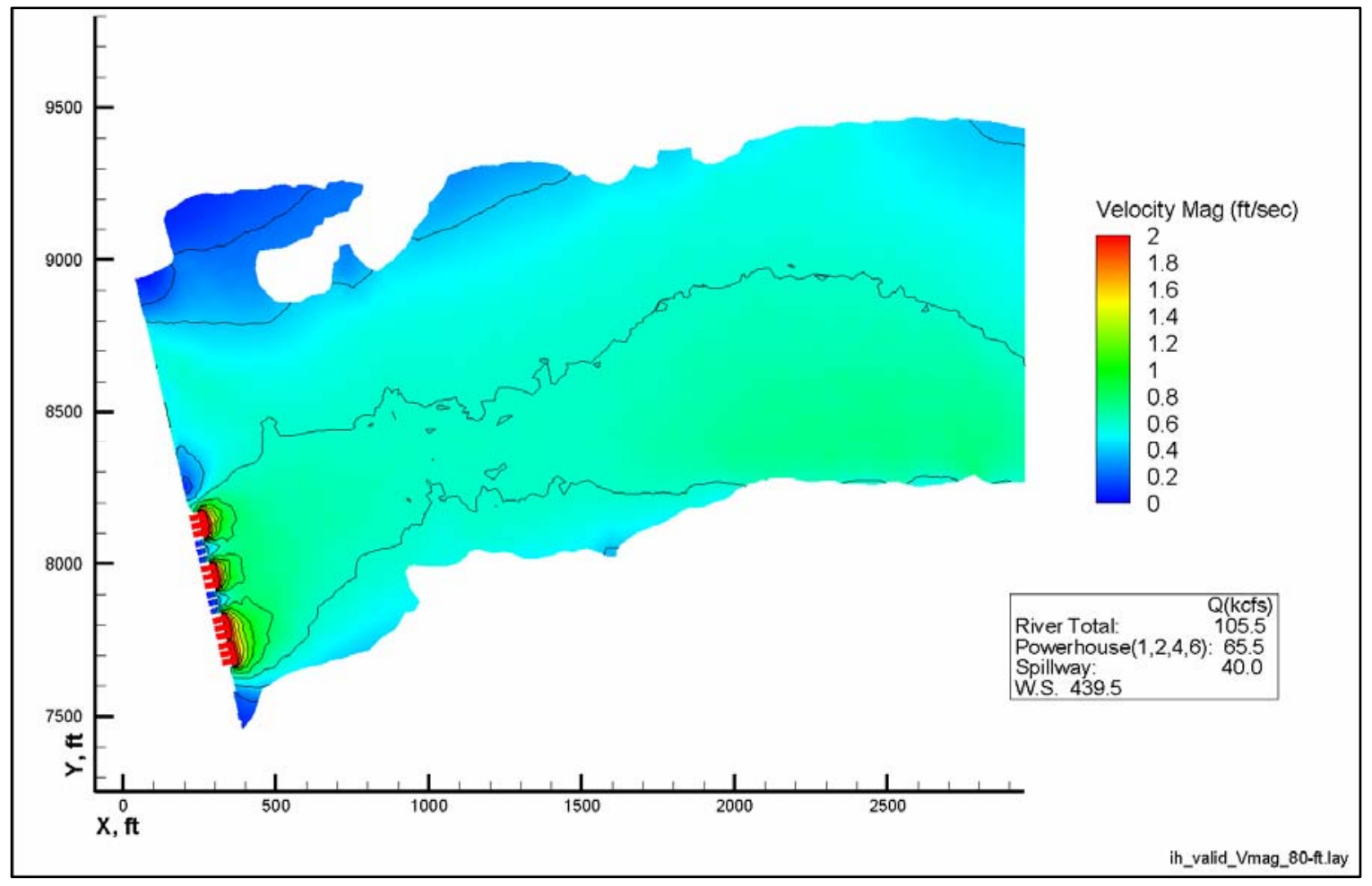

Figure 34. Velocity magnitude contours at $80-\mathrm{ft}$ depth 


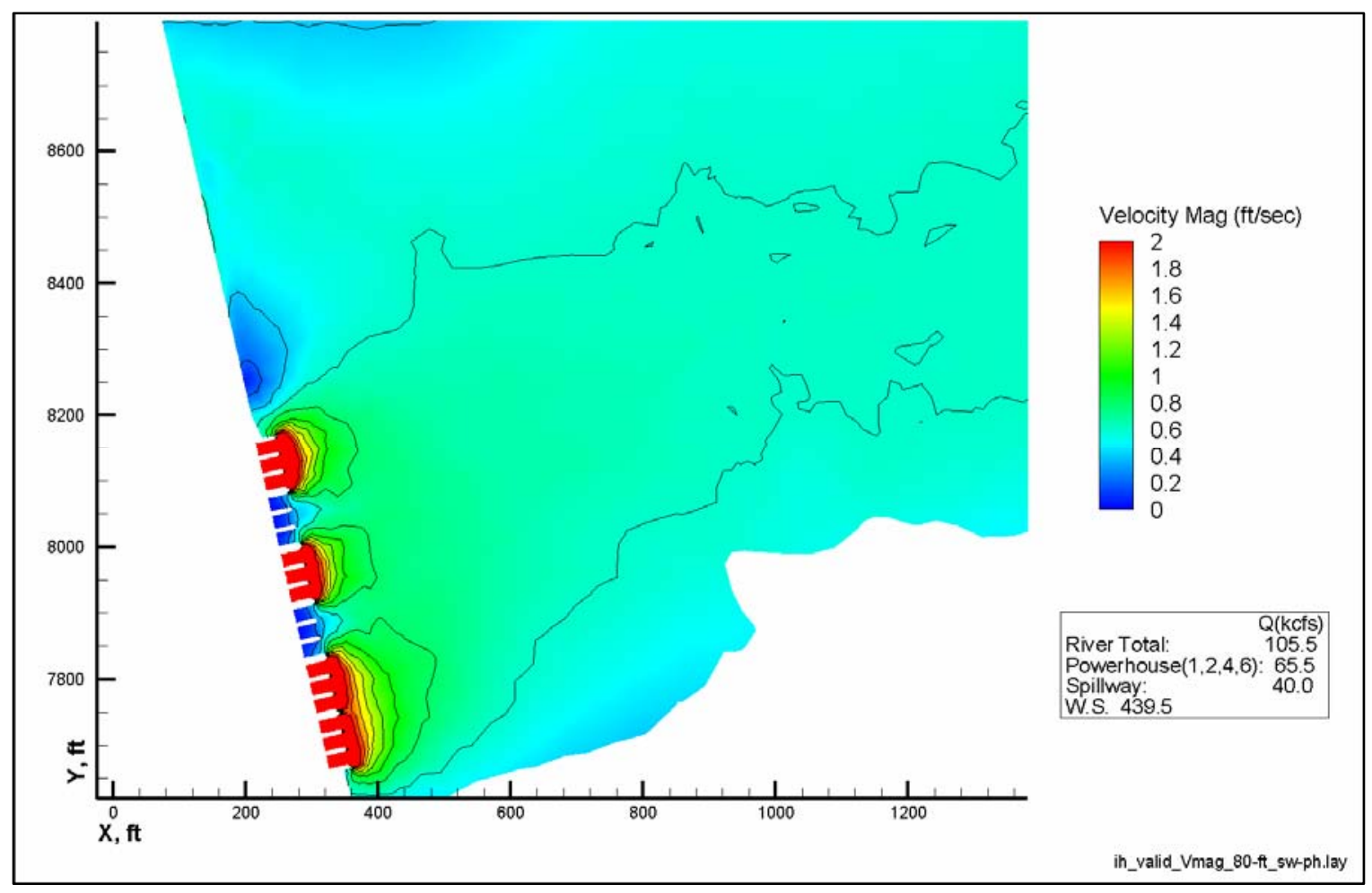

Figure 35 . Velocity magnitude contours near the dam at $80-\mathrm{ft}$ depth

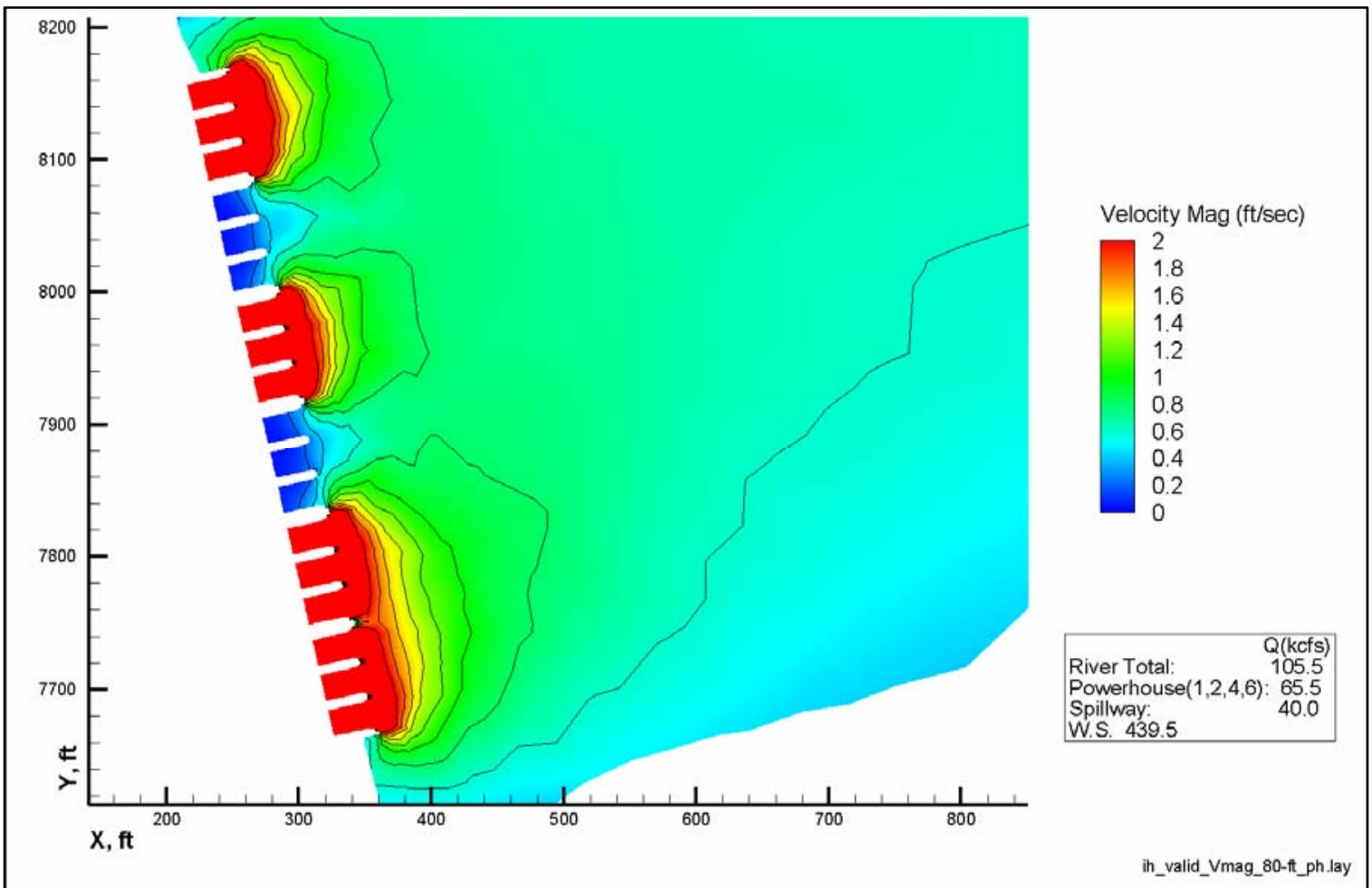

Figure 36. Velocity magnitude contours approaching the powerhouse at $80-\mathrm{ft}$ depth 


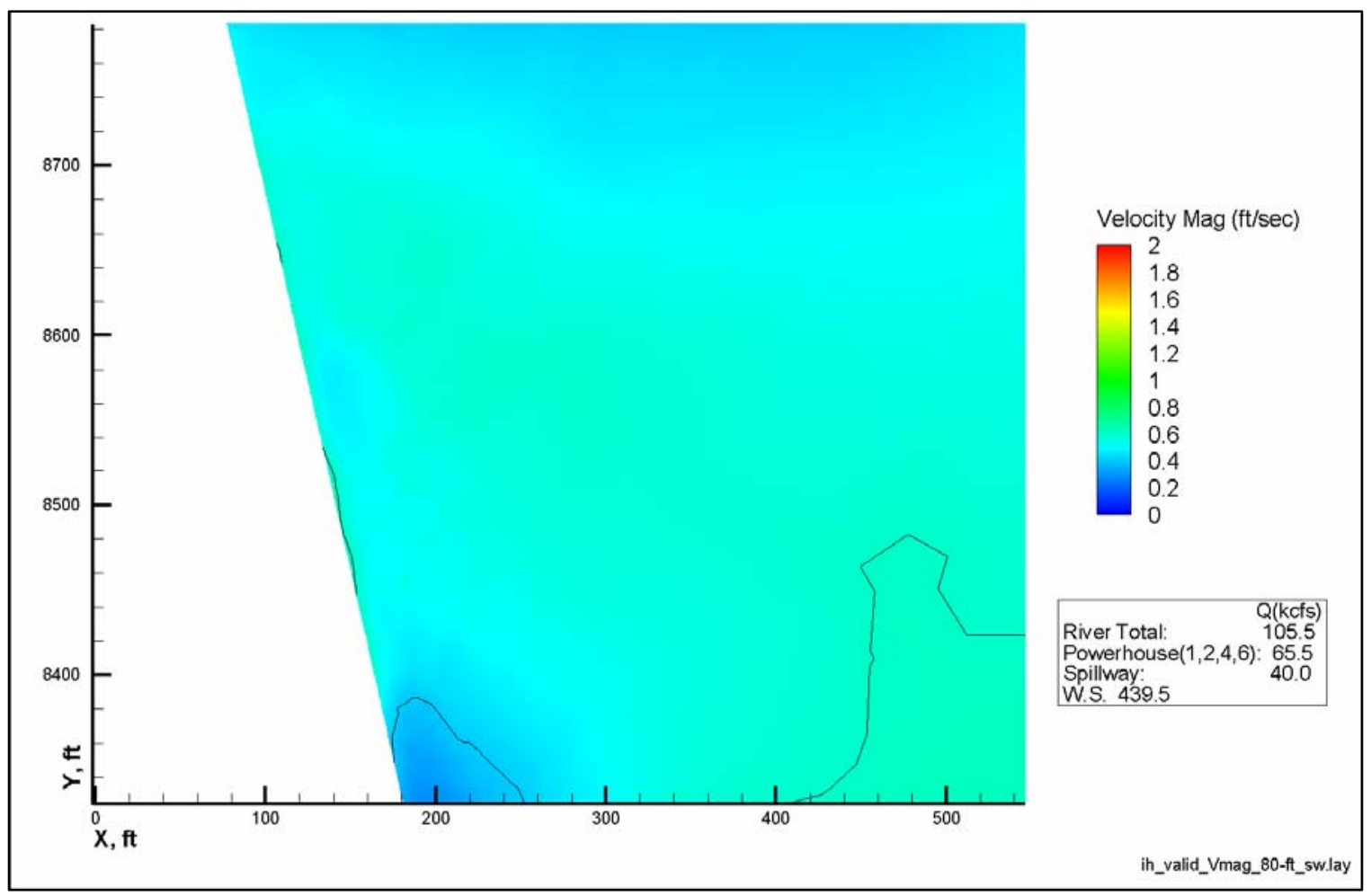

Figure 37 . Velocity magnitude contours approaching the spillway at $80-\mathrm{ft}$ depth

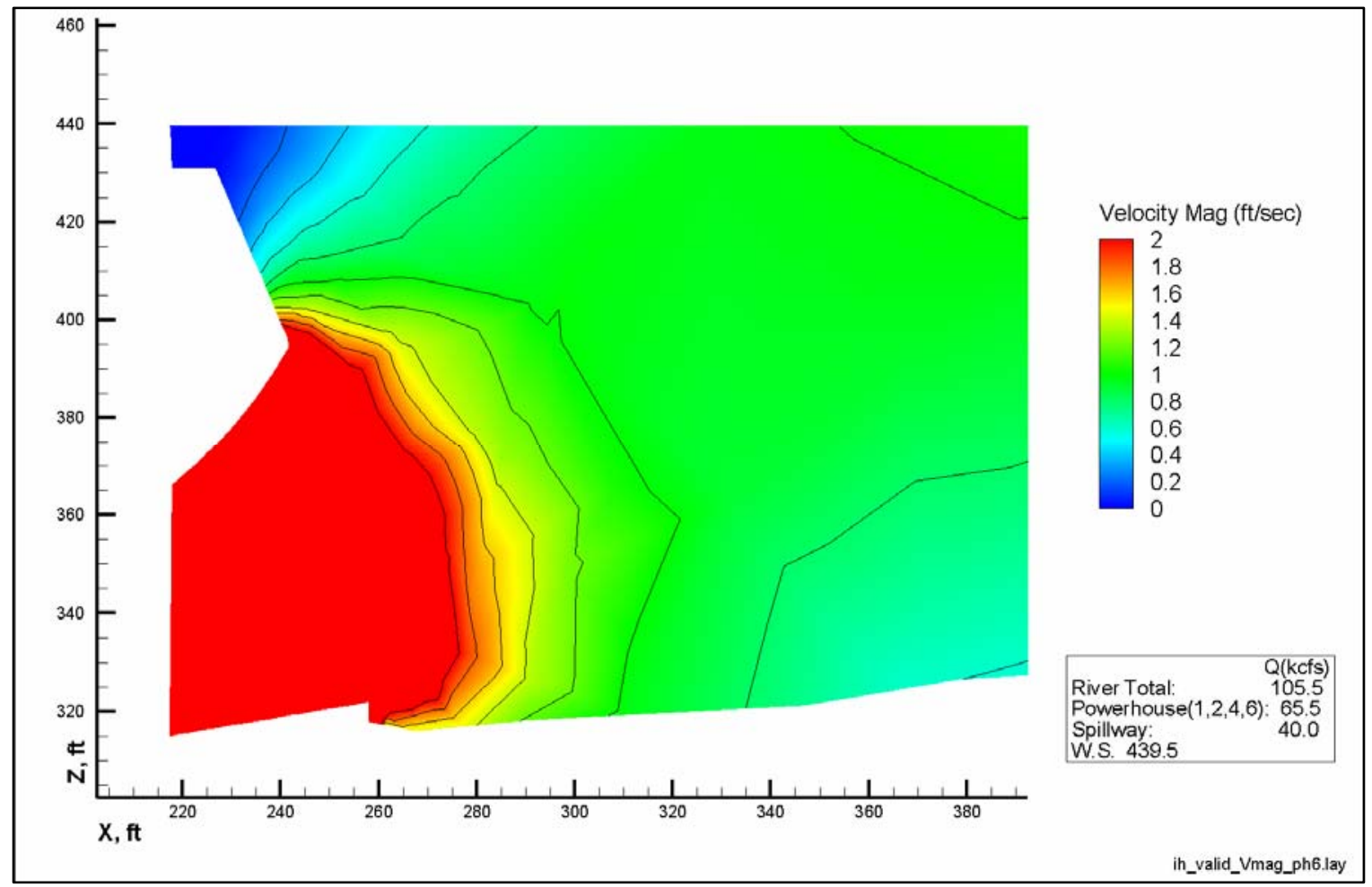

Figure 38. Velocity magnitude contours (on a vertical plane normal to dam axis) of flow entering center intake of powerhouse unit 6 


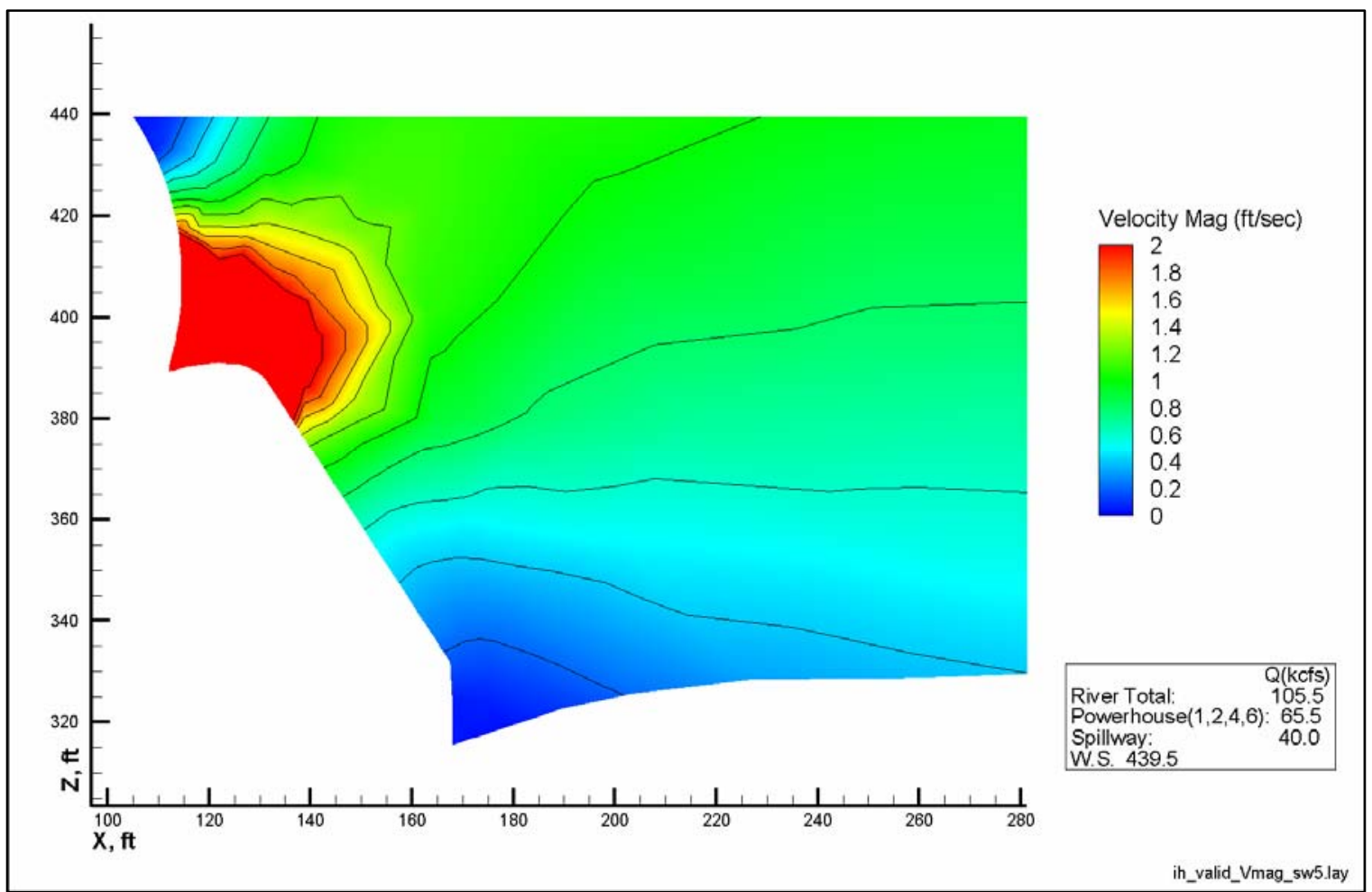

Figure 39. Velocity magnitude contours (on a vertical plane normal to dam axis) of flow through the center of spillway bay 5

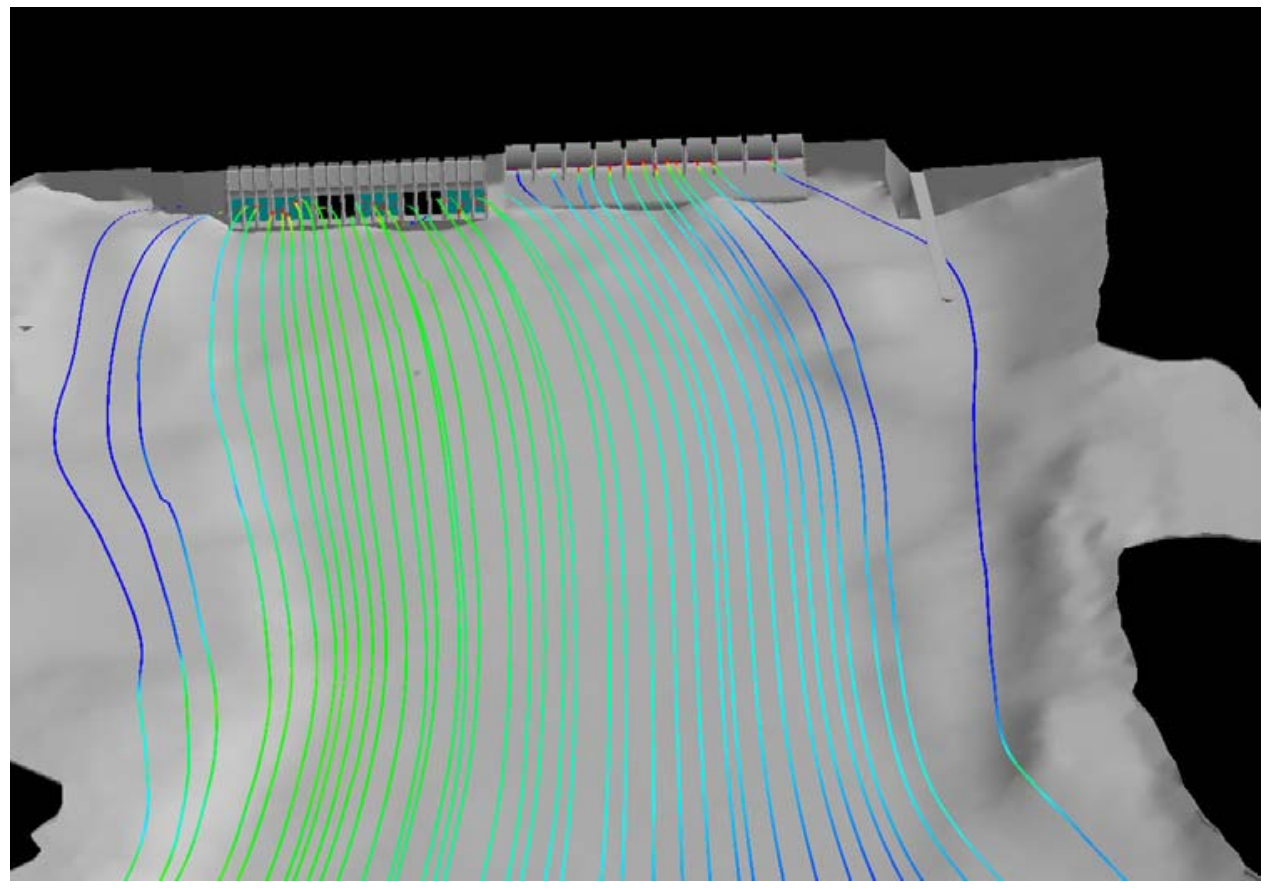

Figure 40. Flow paths colored according to velocity magnitude 


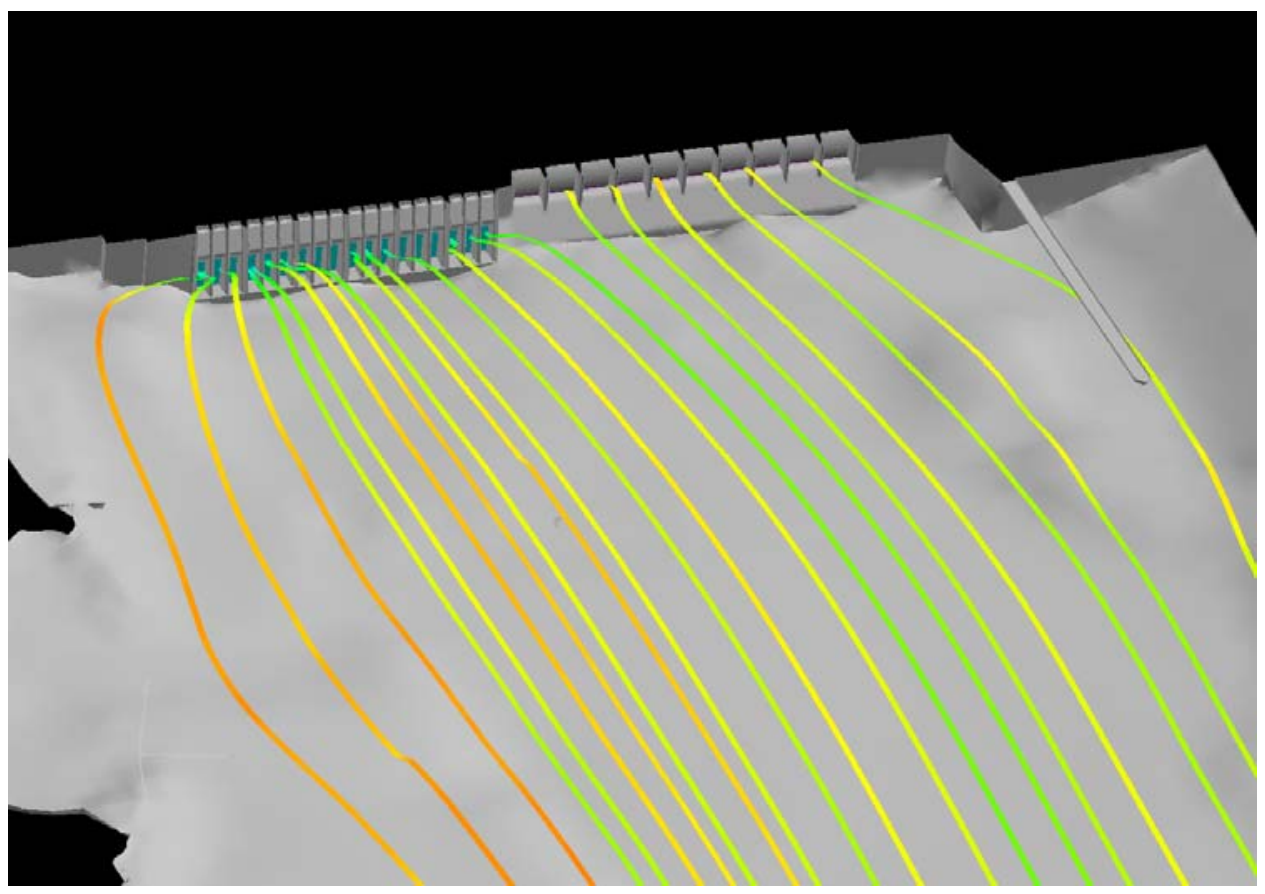

Figure 41. Close view of flow distribution across the dam 


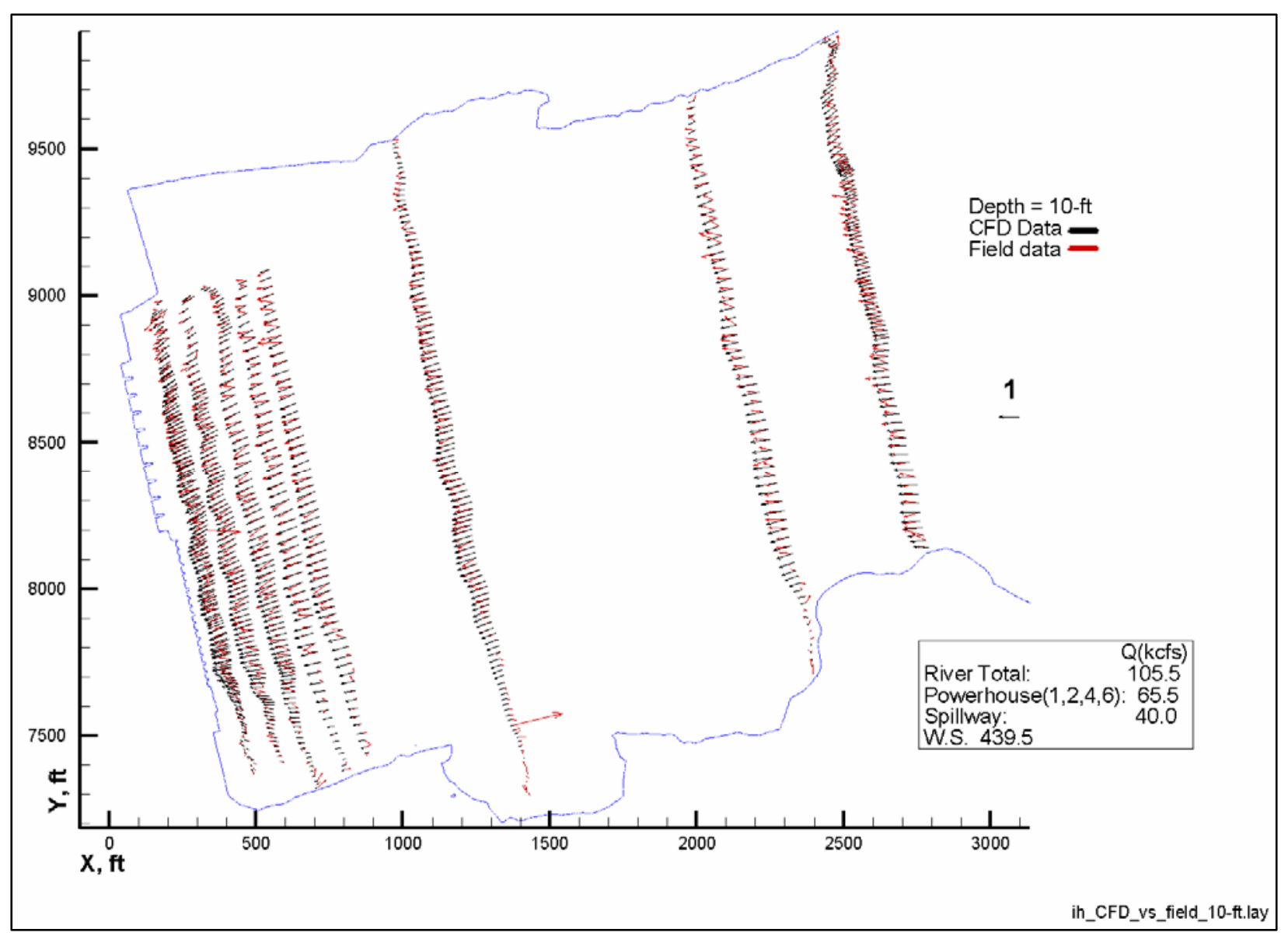

Figure 42. Comparison of prototype data (red) and CFD results (black) at 10-ft depth 


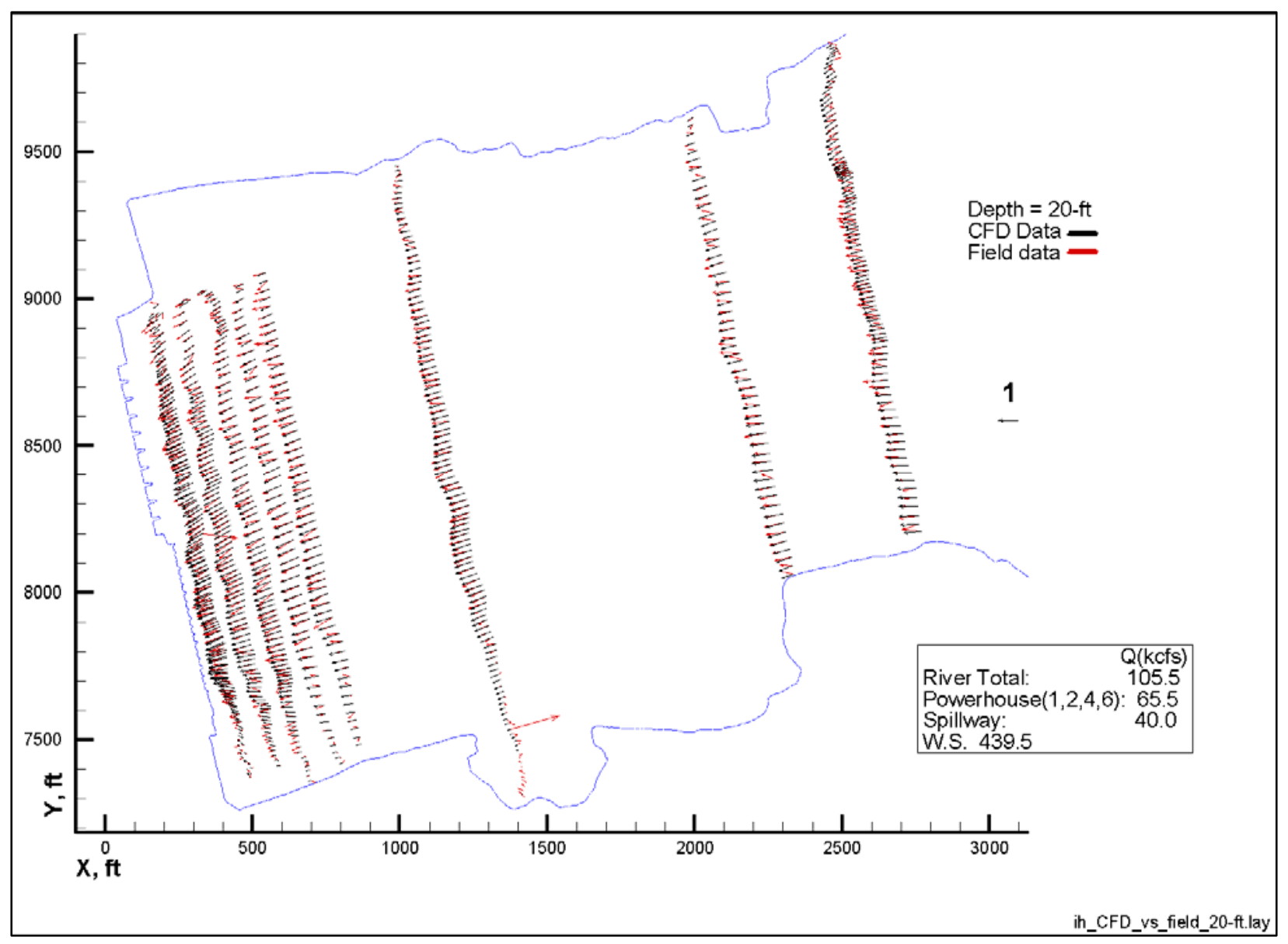

Figure 43. Comparison of prototype data (red) and CFD results (black) at 20-ft depth 


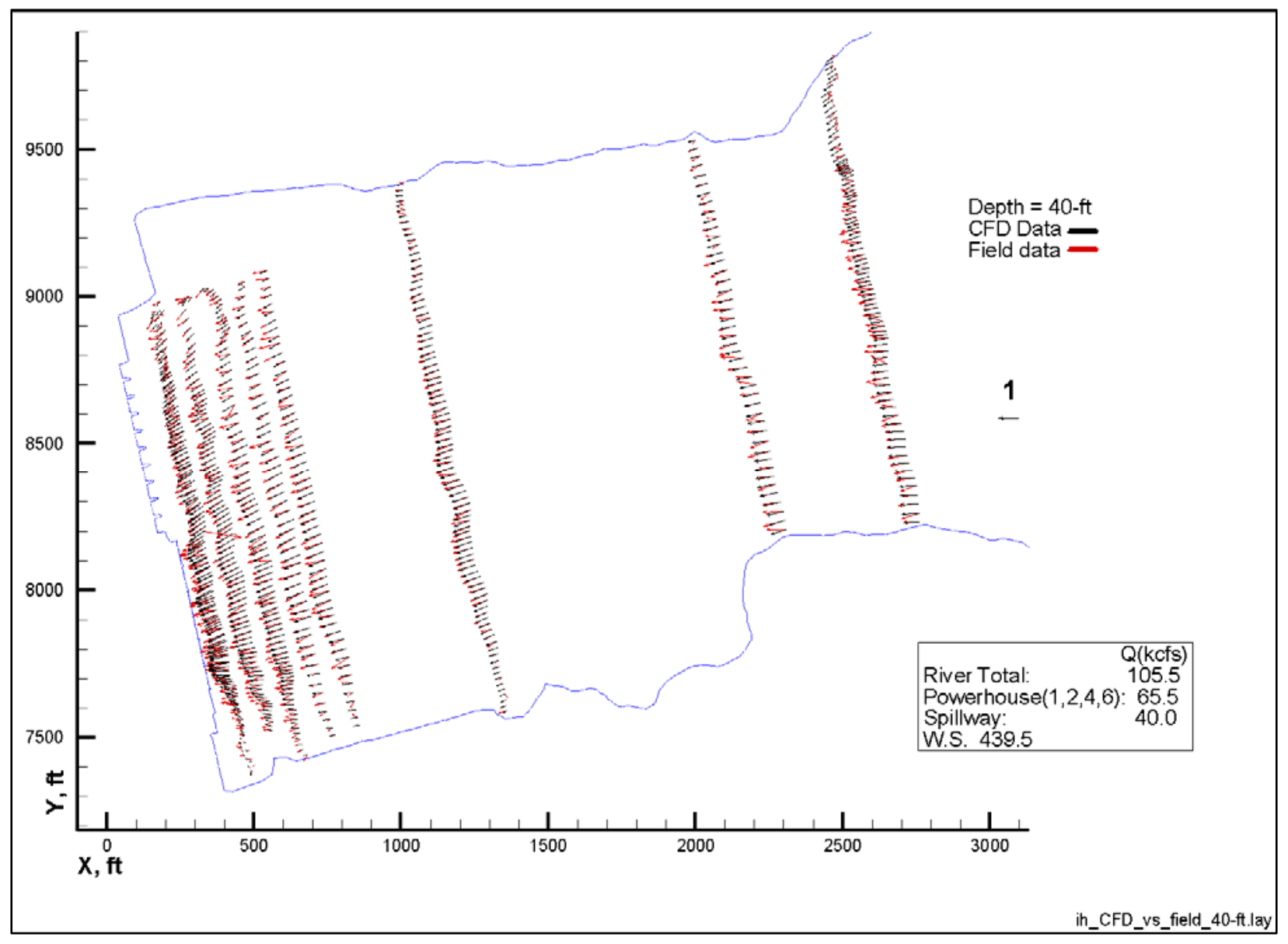

Figure 44. Comparison of prototype data (red) and CFD results (black) at 40-ft depth 


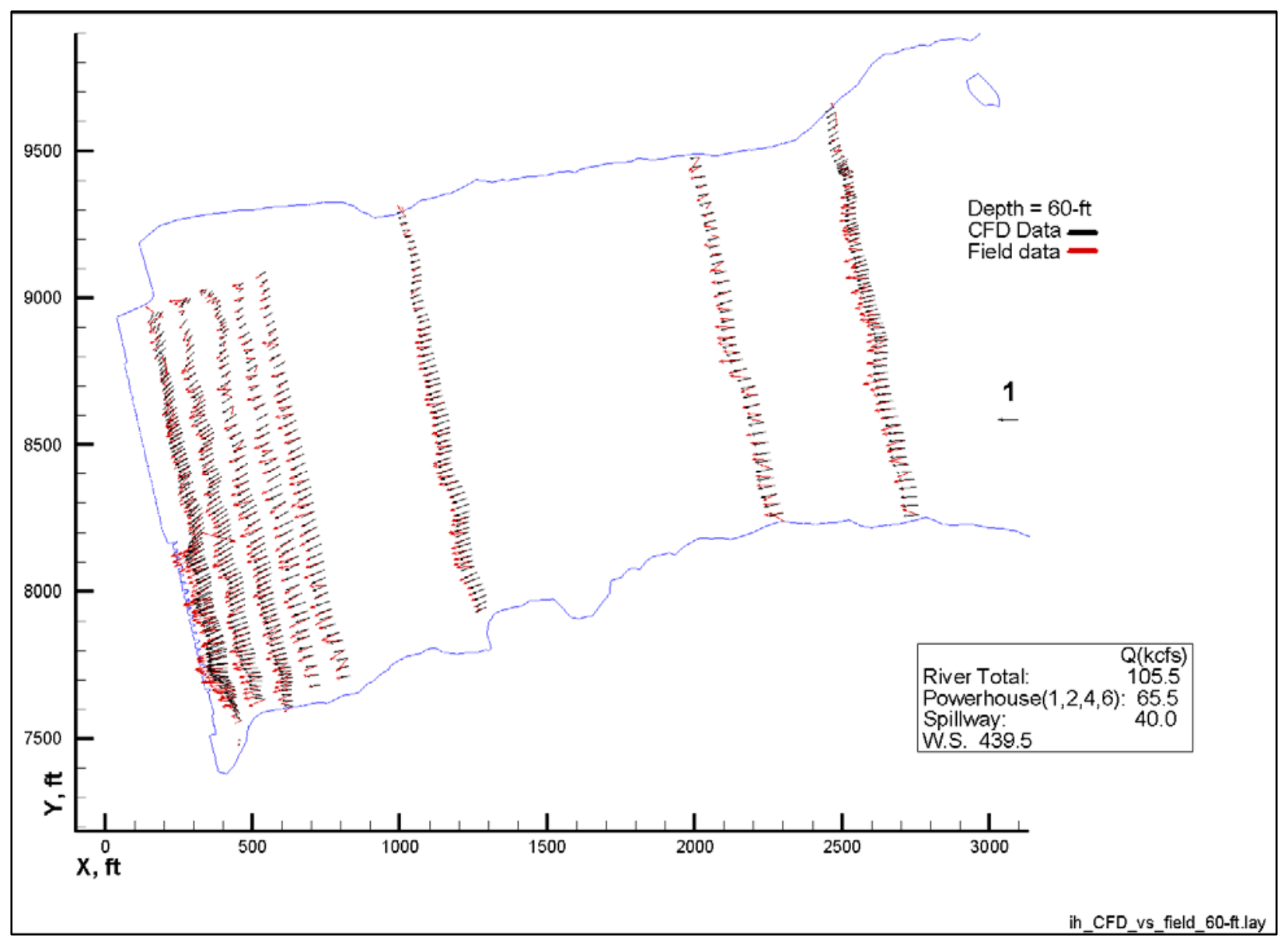

Figure 45. Comparison of prototype data (red) and CFD results (black) at 60-ft depth 


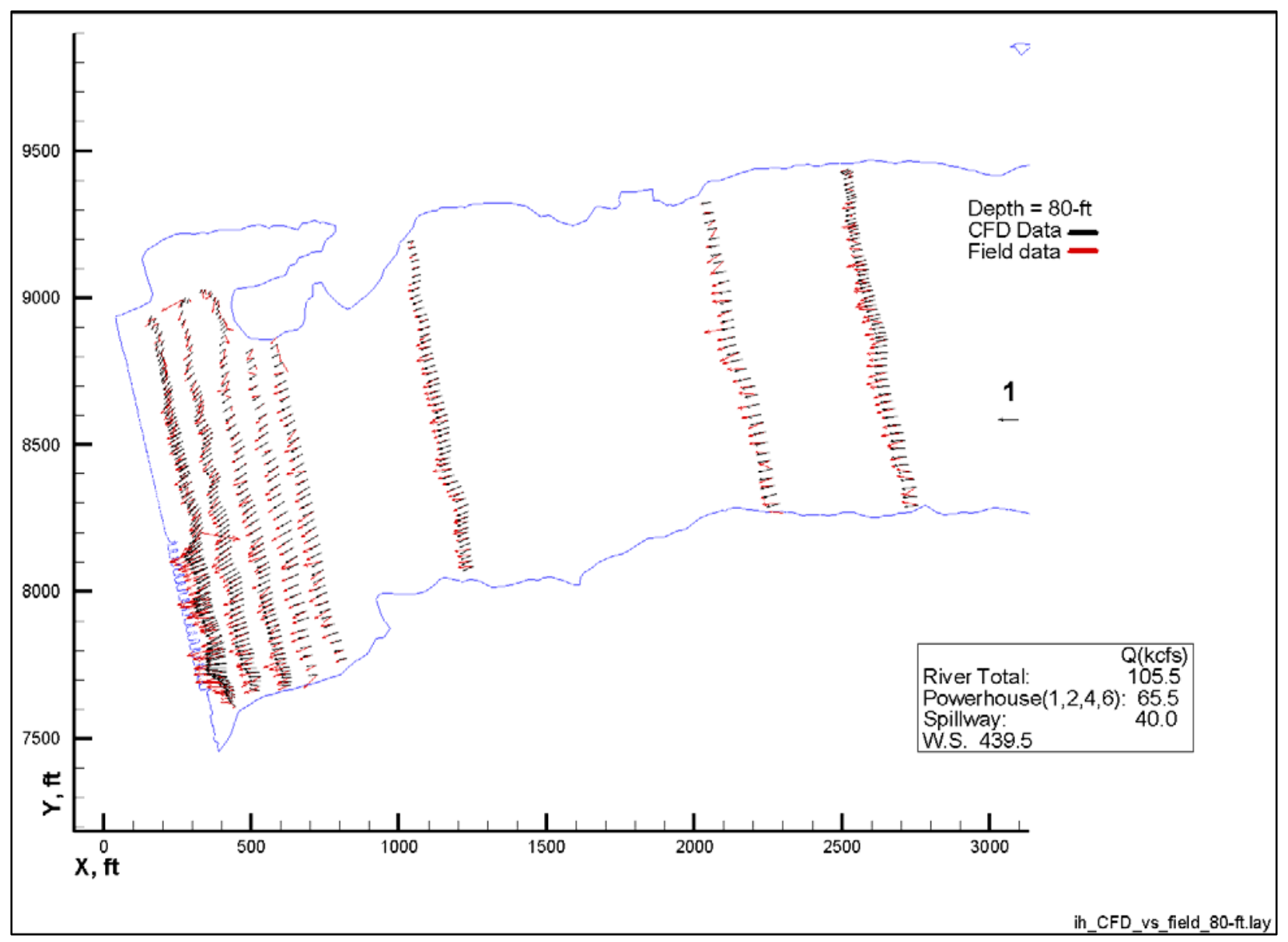

Figure 46. Comparison of prototype data (red) and CFD results (black) at 80-ft depth 


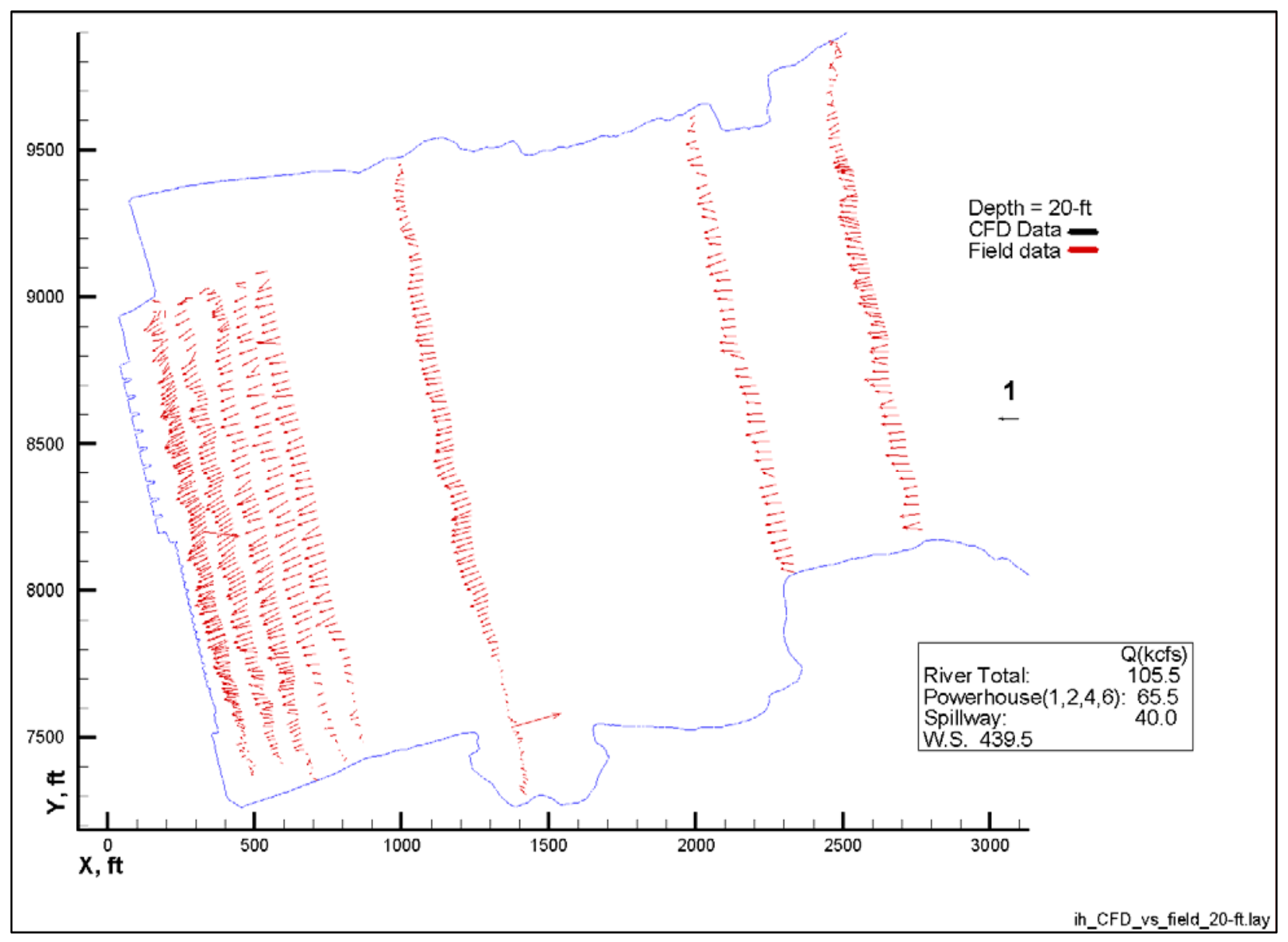

Figure 47. Prototype data at $20-\mathrm{ft}$ 


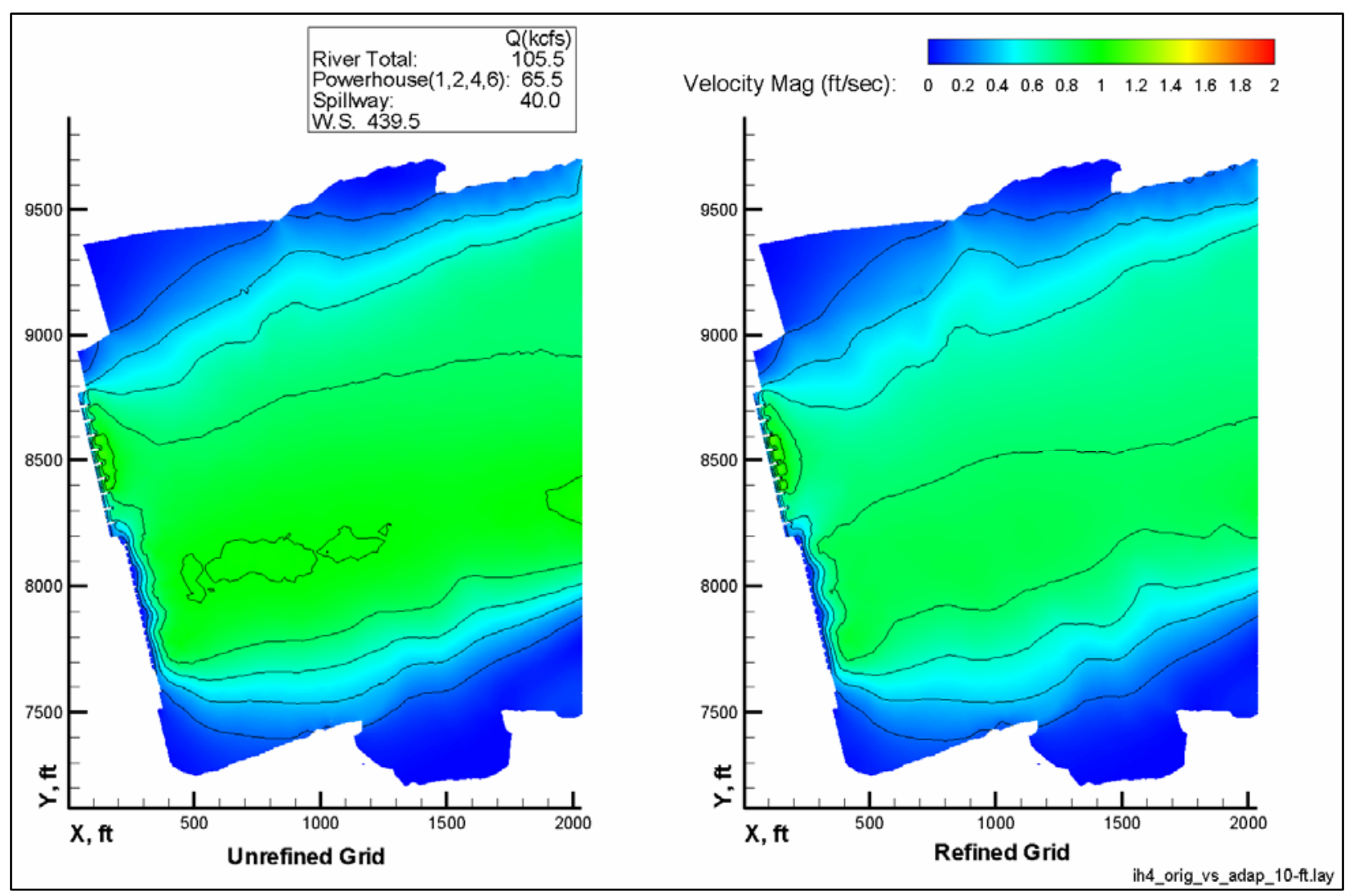

Figure 48. Comparison of unrefined mesh (153,602 nodes) and refined mesh (548,464 nodes) CFD results at $10-\mathrm{ft}$ depth 


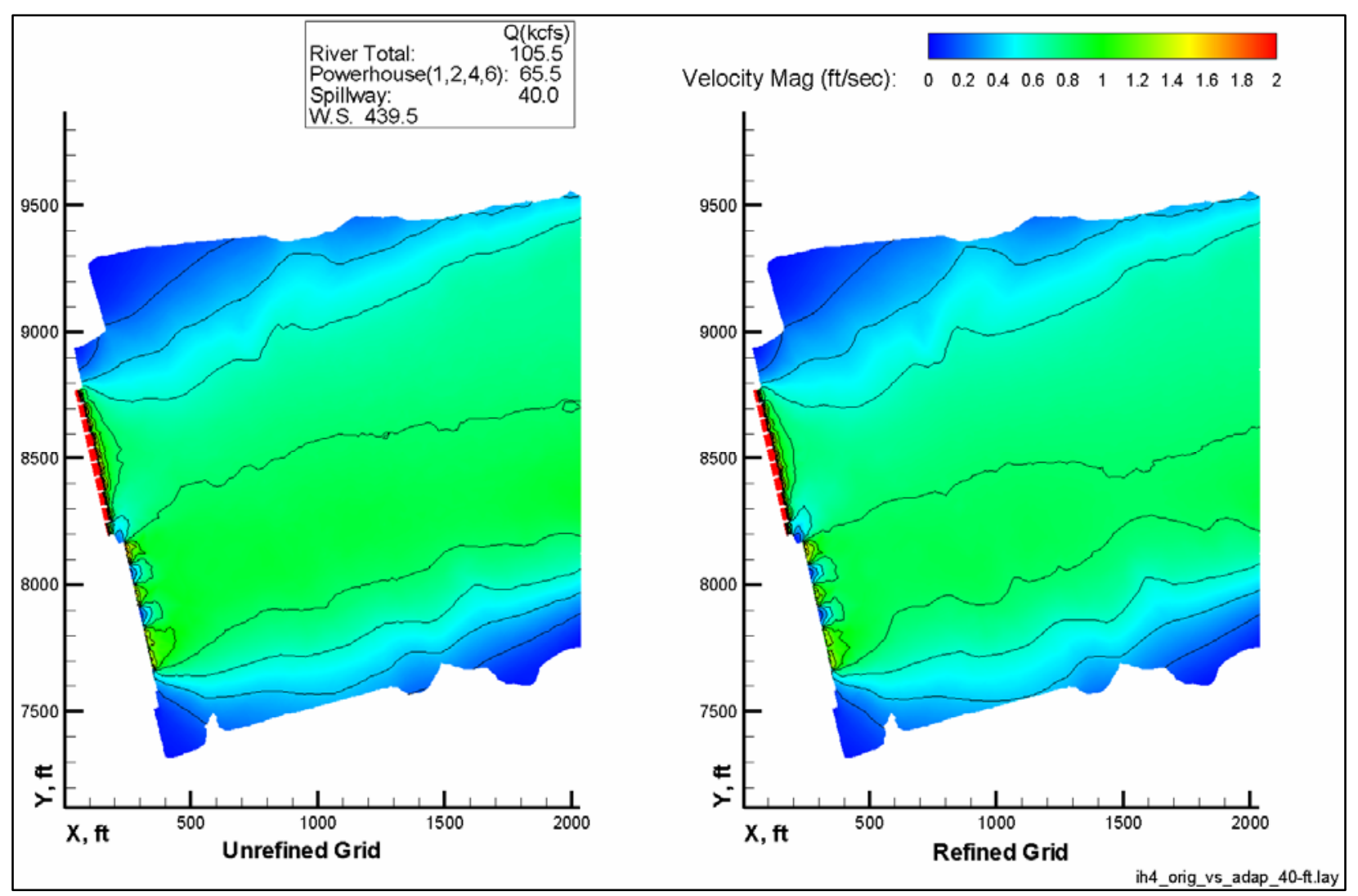

Figure 49. Comparison of unrefined mesh (153,602 nodes) and refined mesh (548,464 nodes) CFD results at $40-\mathrm{ft}$ depth 


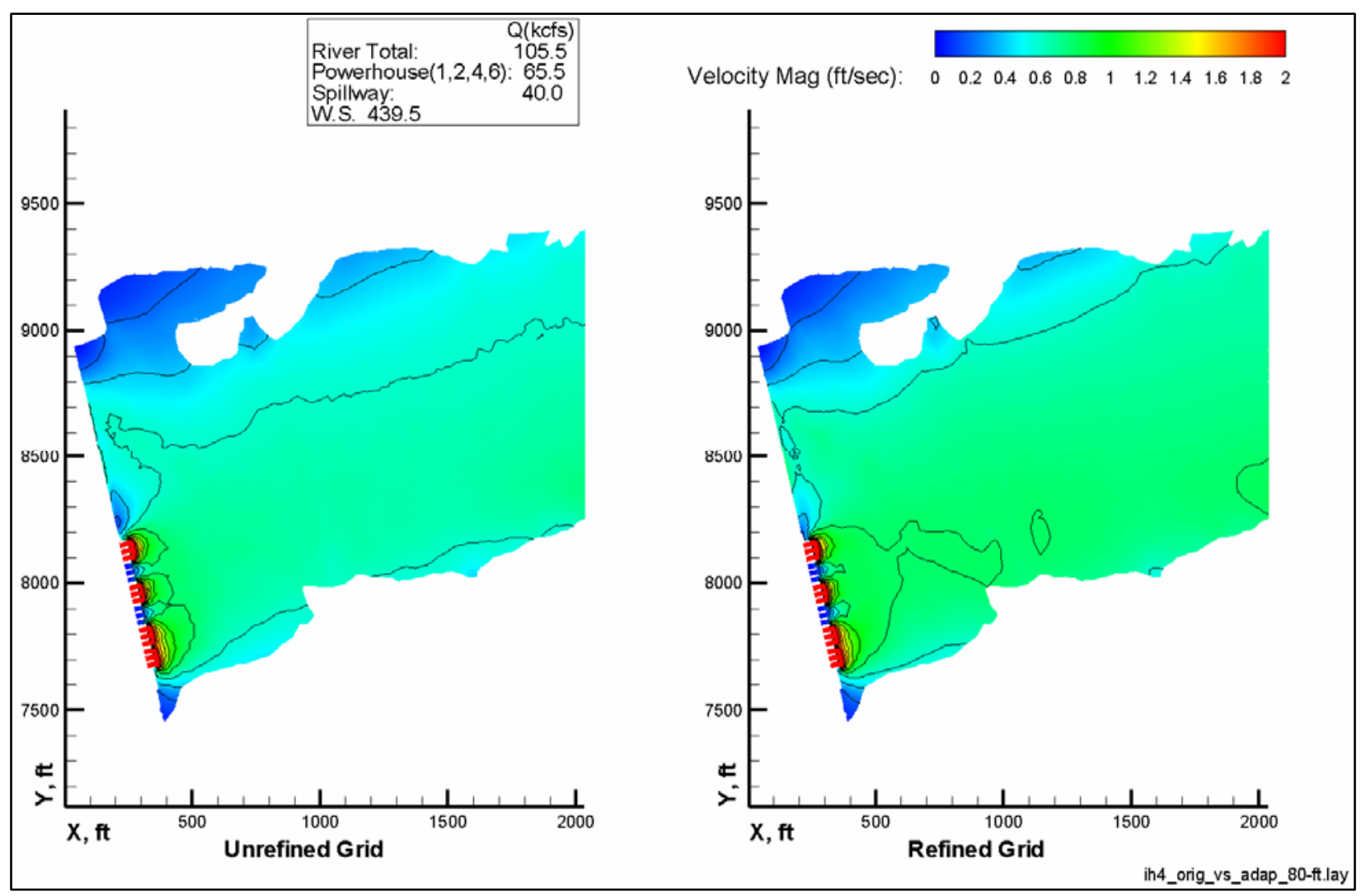

Figure 50. Comparison of unrefined mesh (153,602 nodes) and refined mesh (548,464 nodes) CFD results at $80-\mathrm{ft}$ depth 


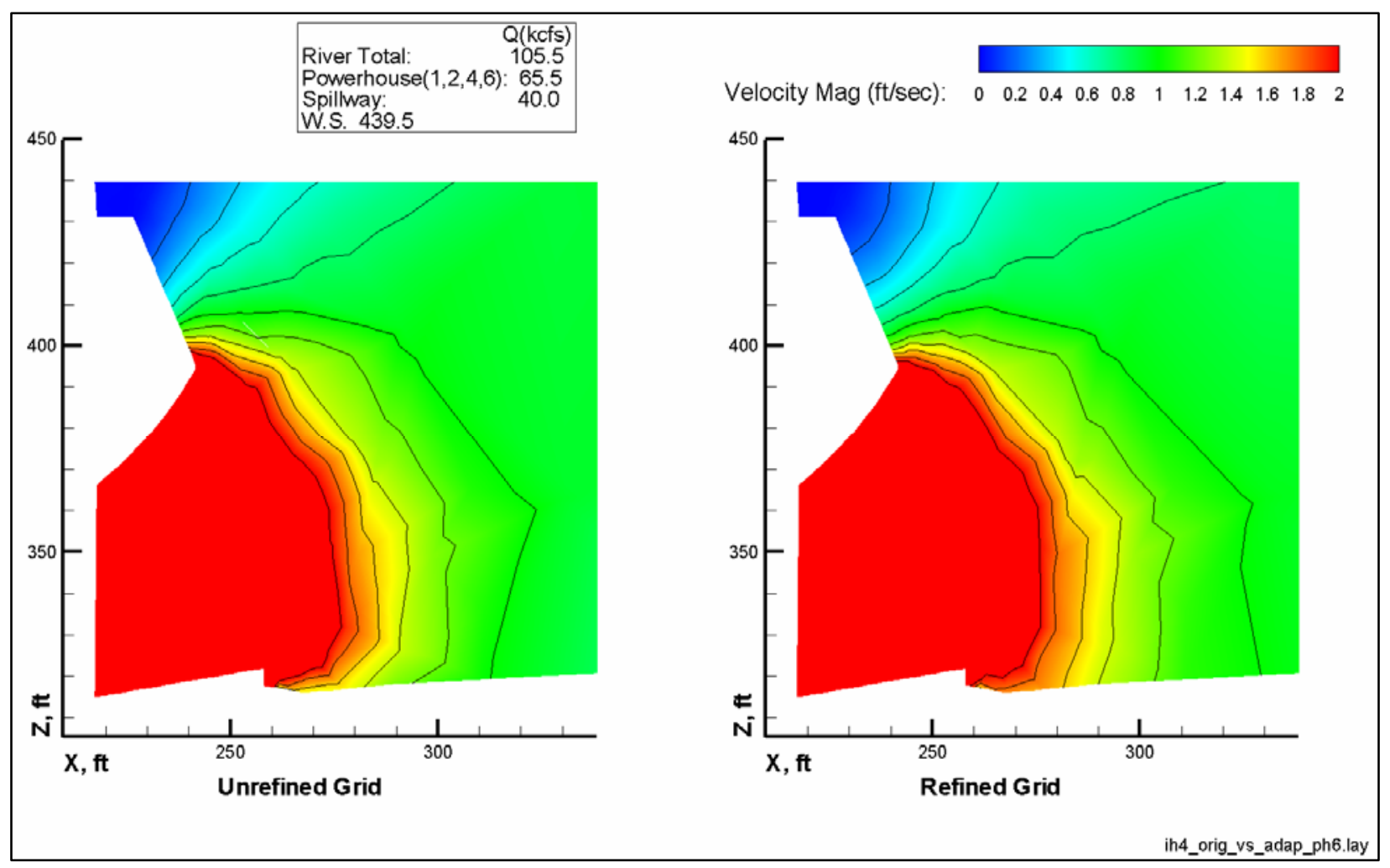

Figure 51. Comparison of unrefined mesh (153,602 nodes) and refined mesh (548,464 nodes) CFD results at powerhouse unit 6 


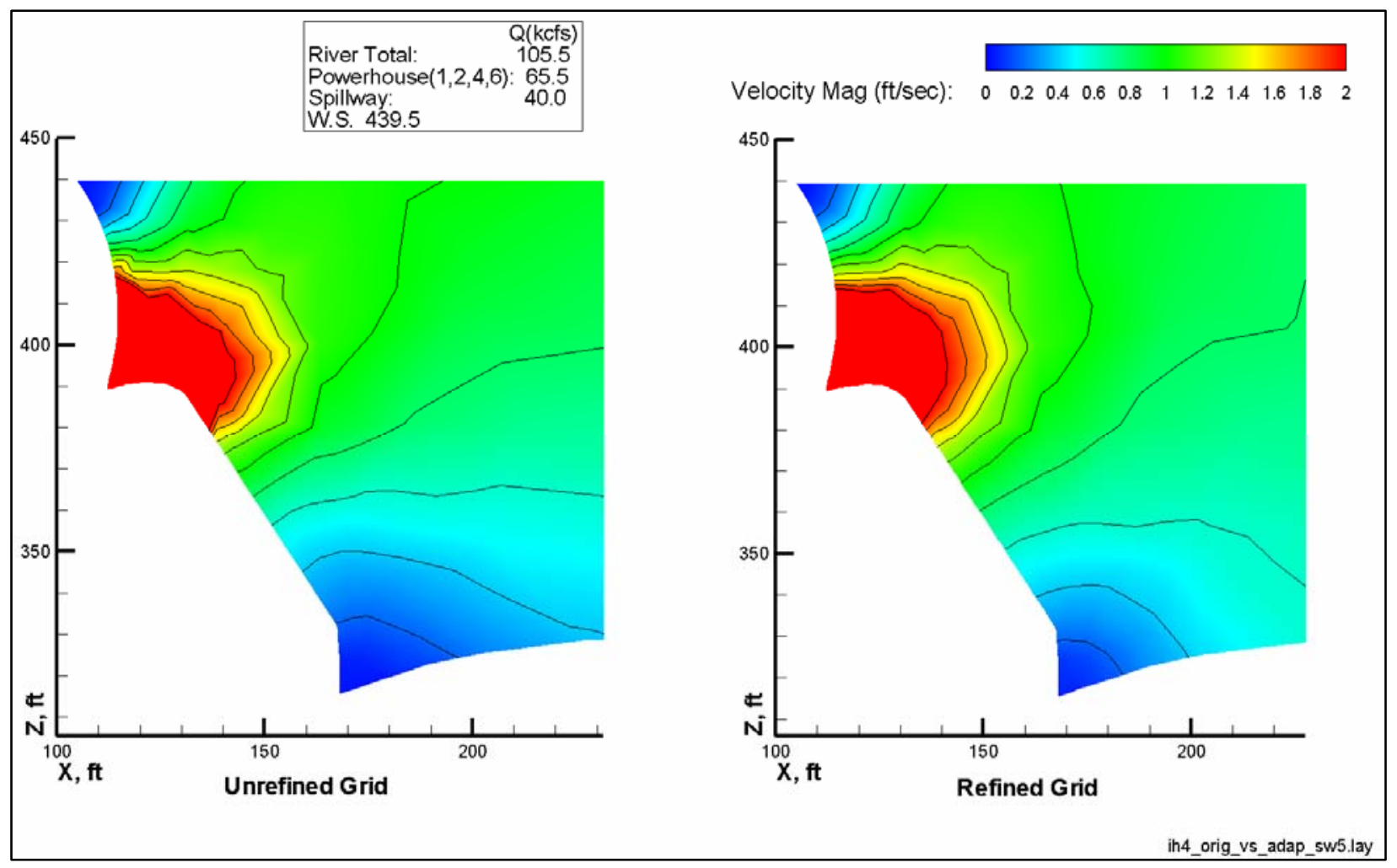

Figure 52. Comparison of unrefined mesh (153,602 nodes) and refined mesh (548,464 nodes) CFD results at spillway bay 5 


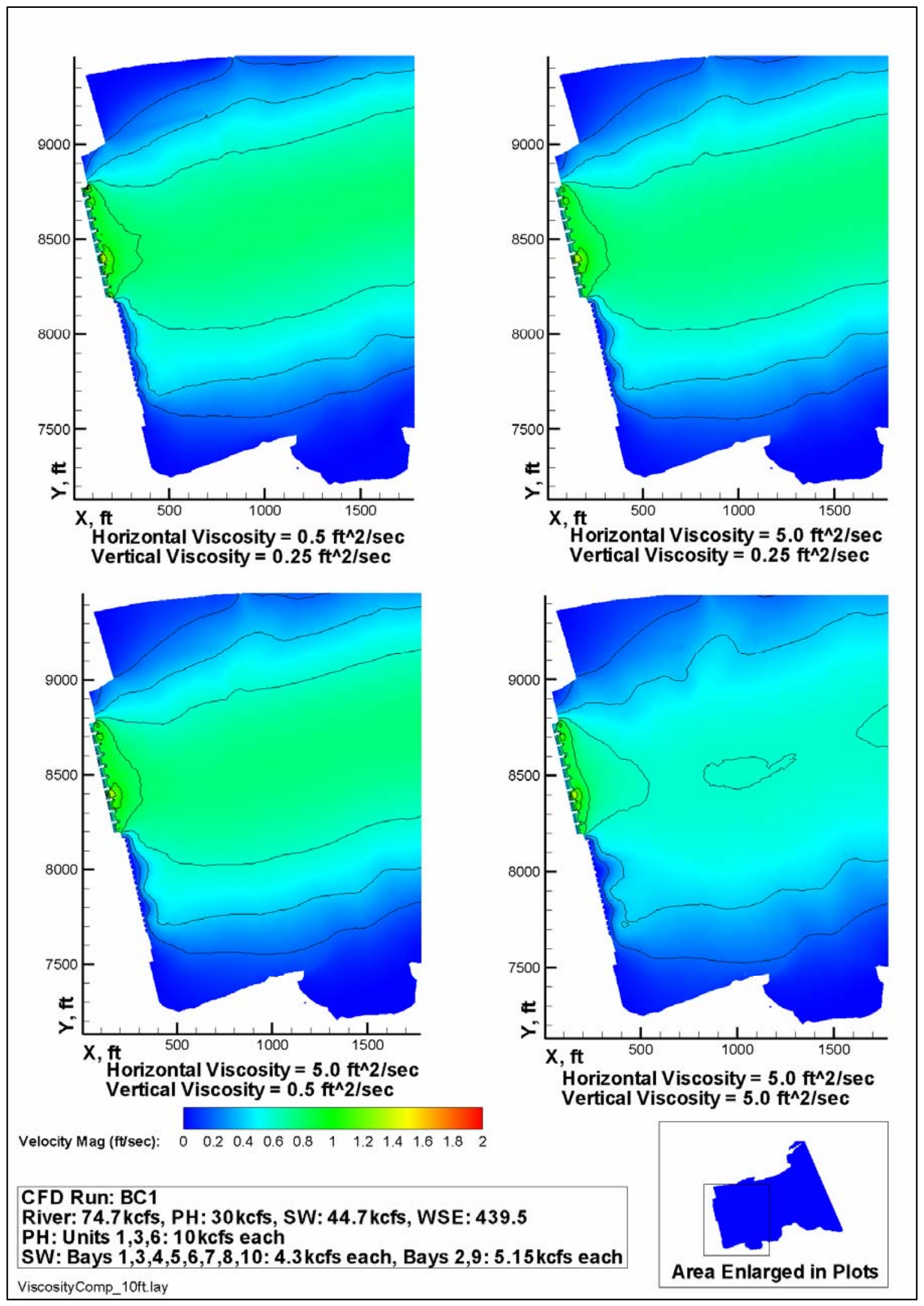

Figure 53. Velocity magnitude contours of flow at 10-ft depth 


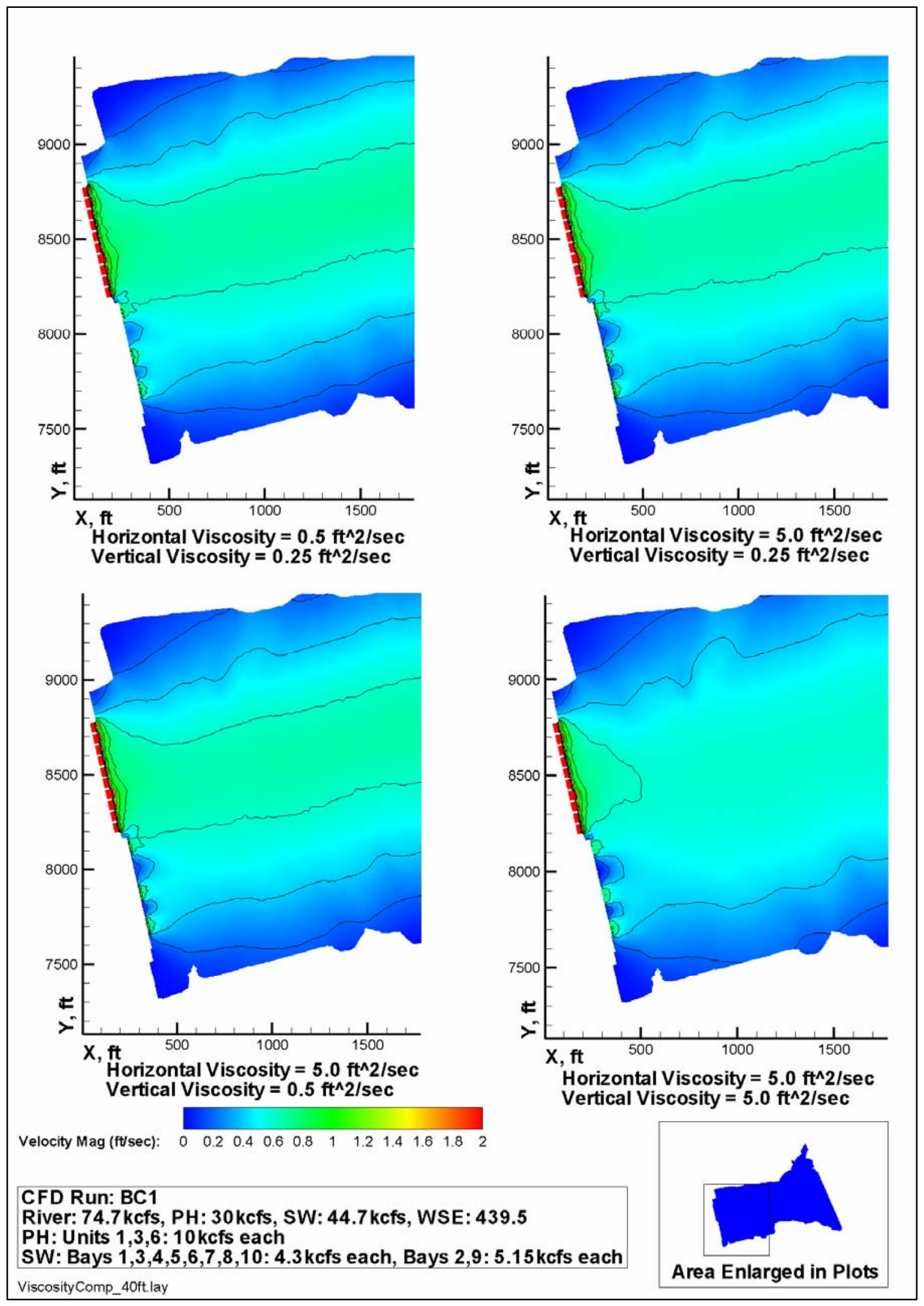

Figure 54. Velocity magnitude contours of flow at 40-ft depth 


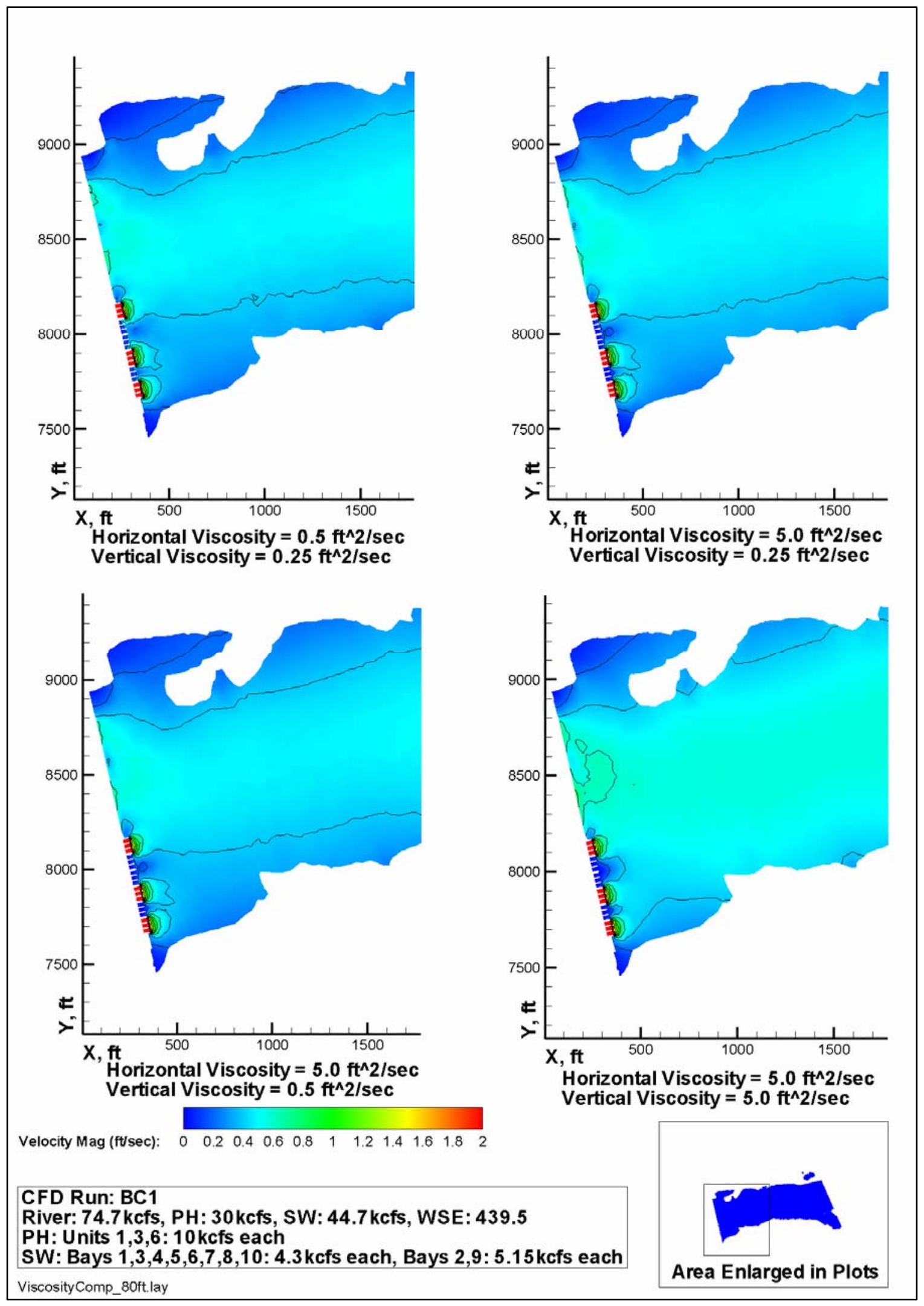

Figure 55. Velocity magnitude contours of flow at 80-ft depth 


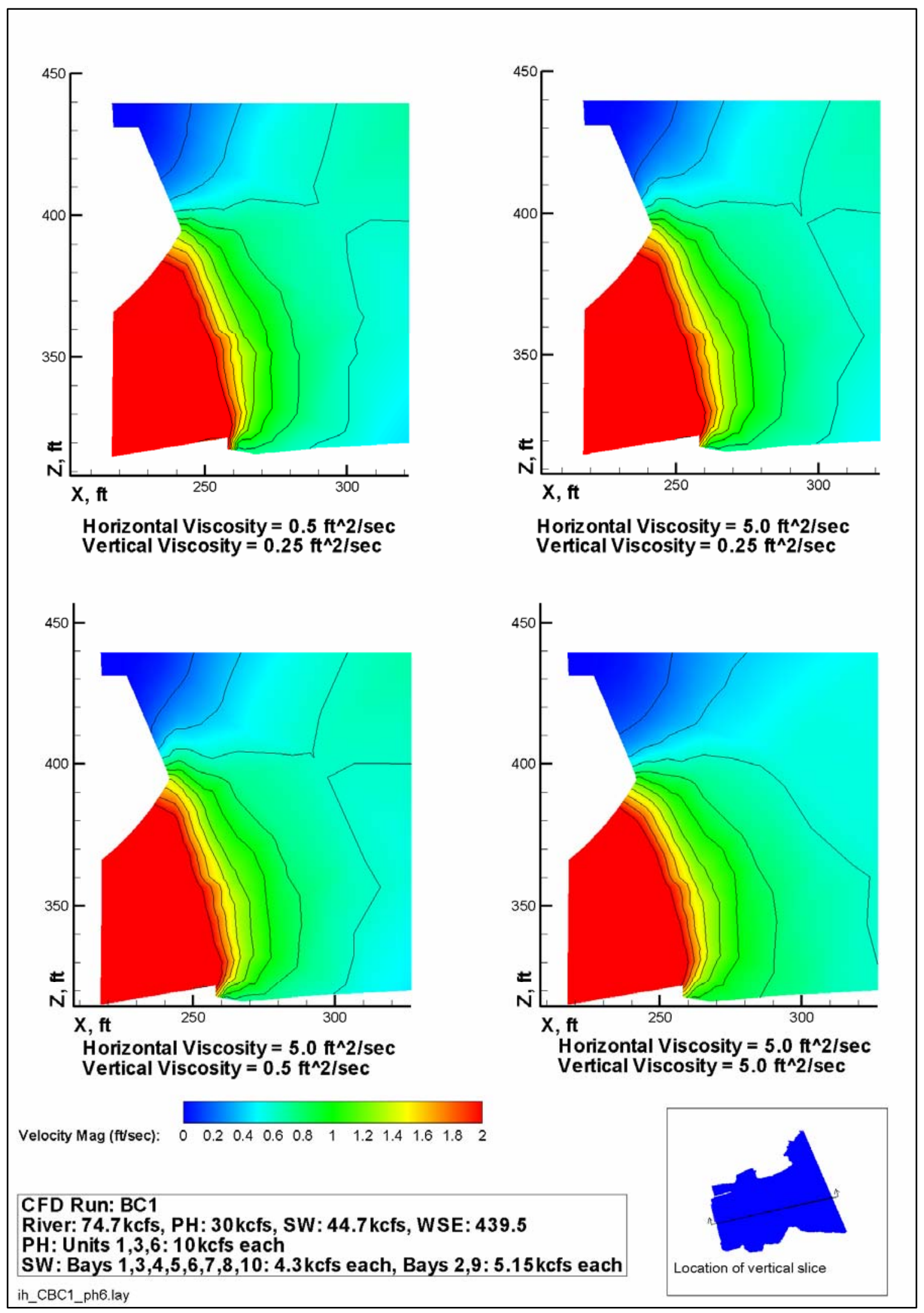

Figure 56. Velocity magnitude contours of flow entering powerhouse unit 6 


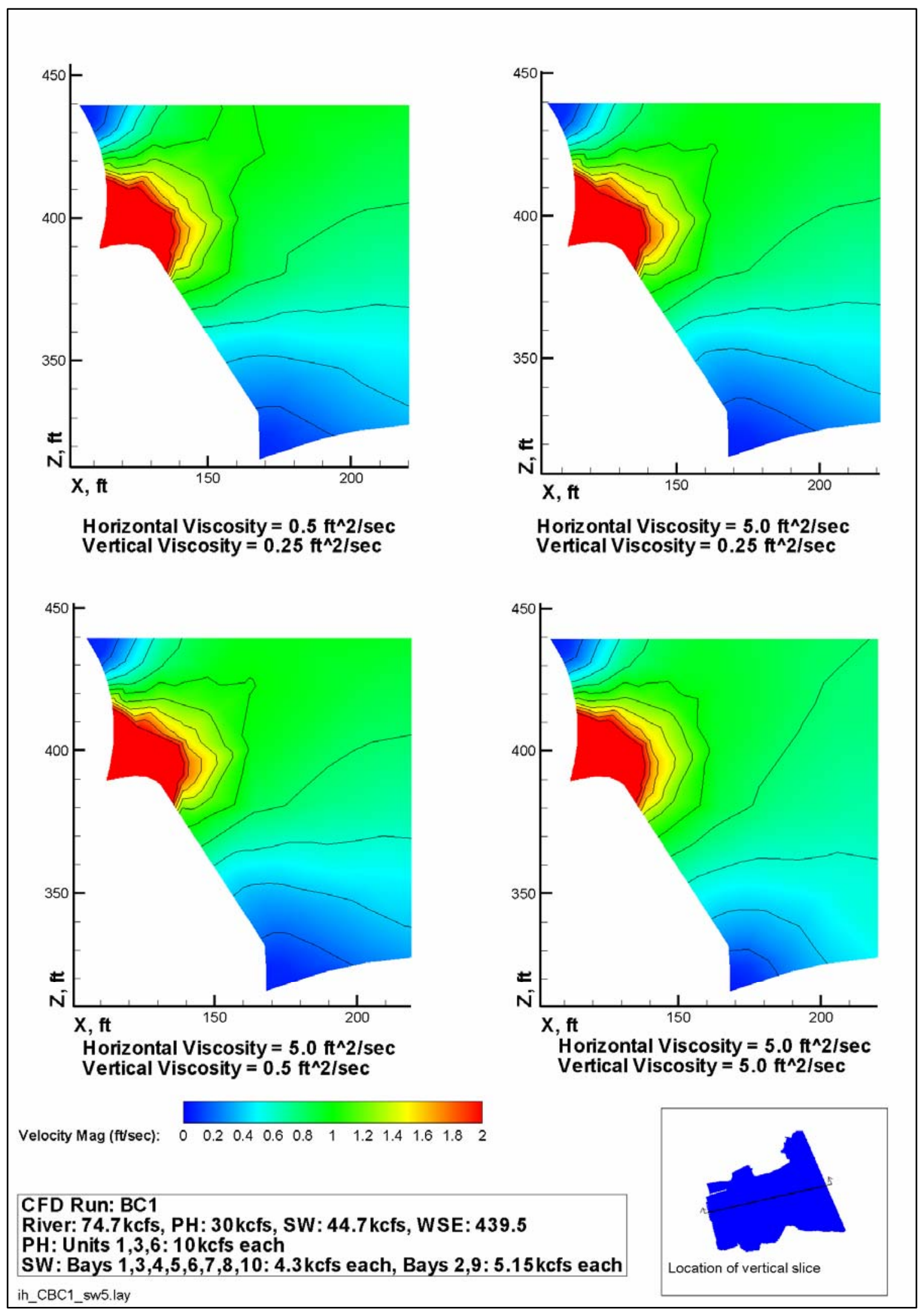

Figure 57 . Velocity magnitude contours of flow through spillway bay 5 


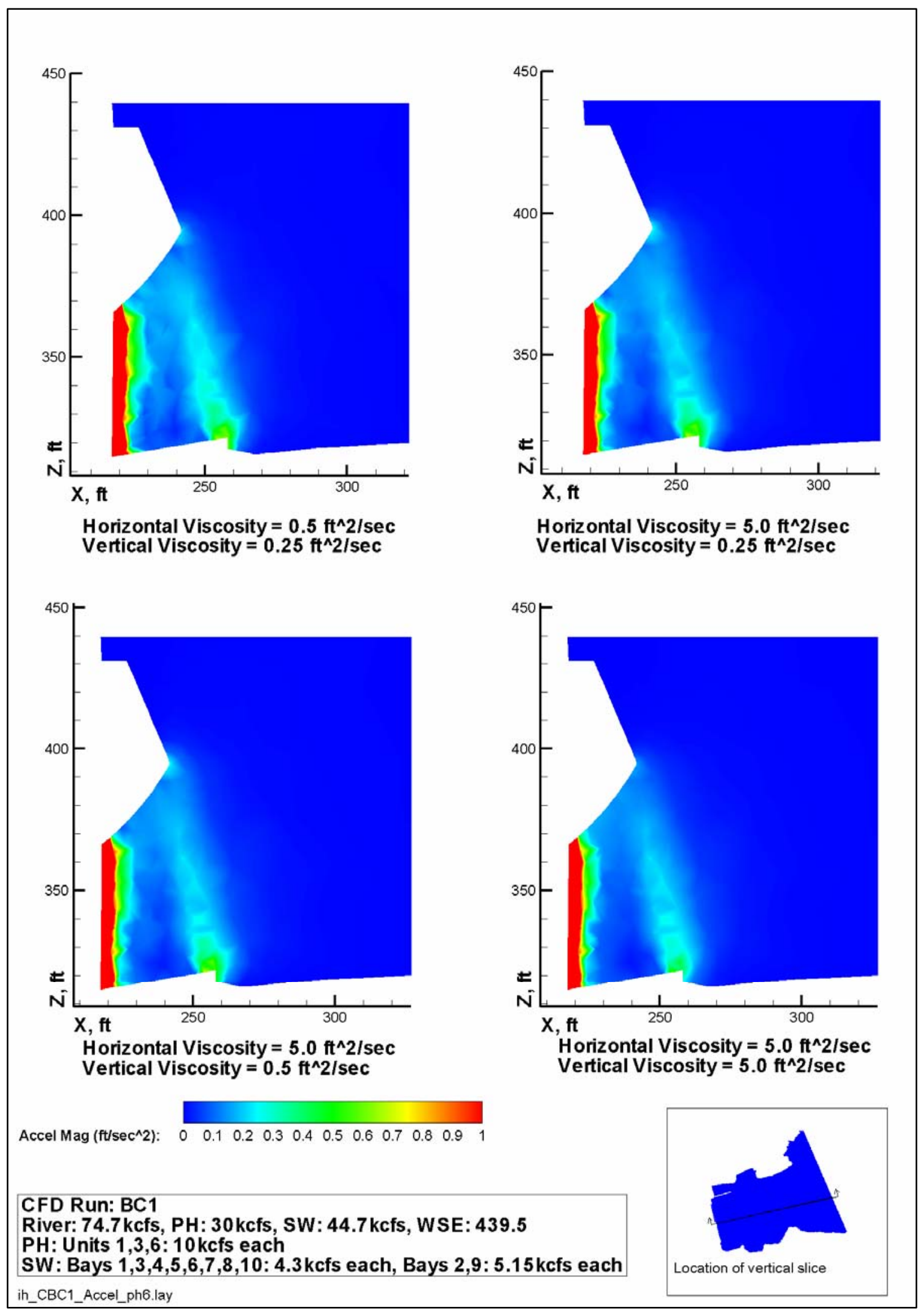

Figure 58. Acceleration magnitude contours of flow entering powerhouse unit 6 


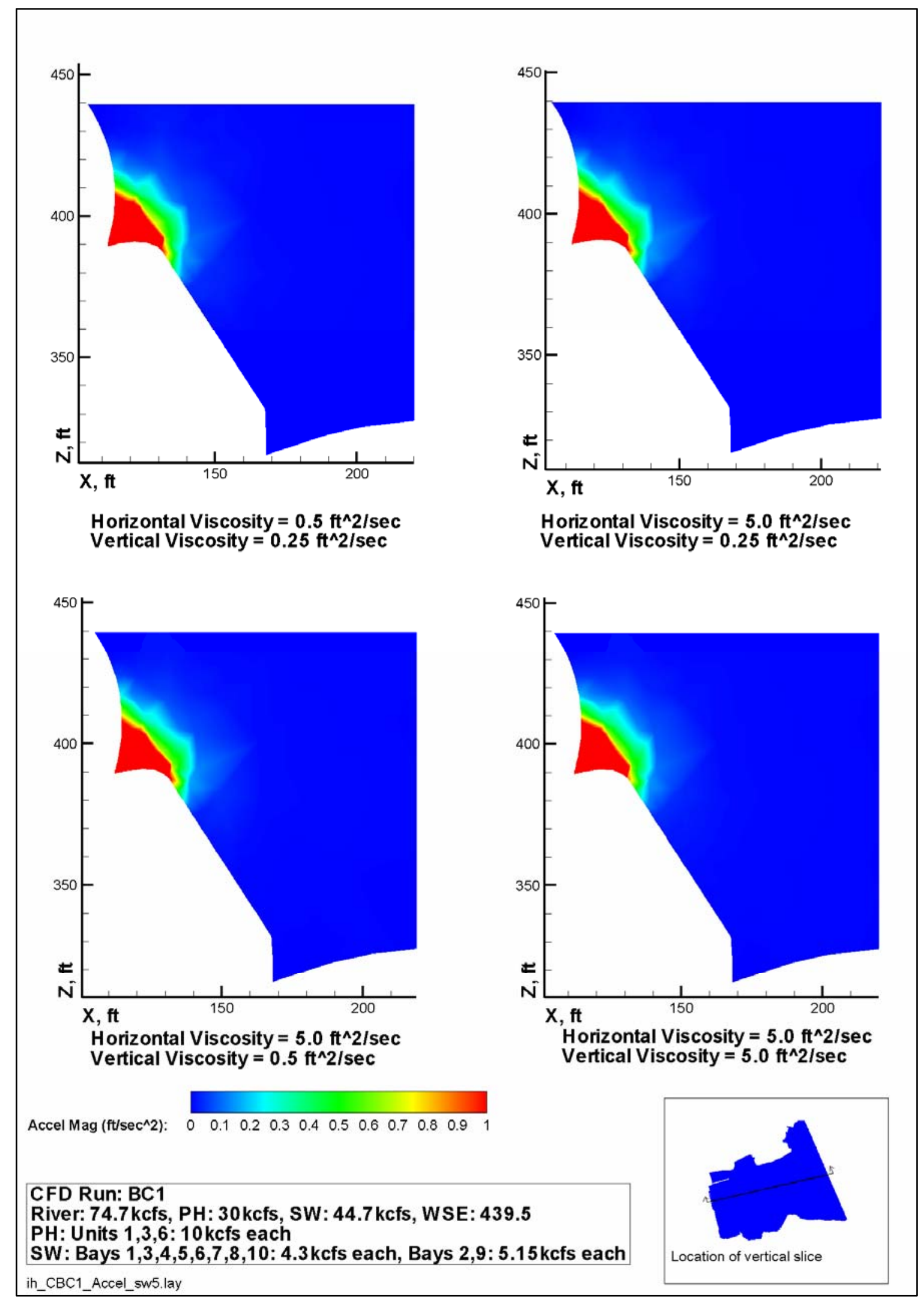

Figure 59. Acceleration magnitude contours of flow through spillway bay 5 


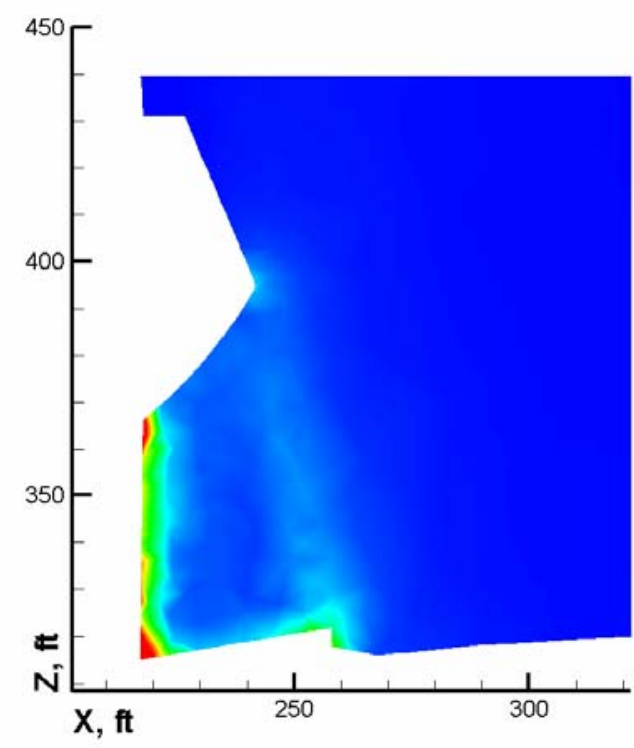

Horizontal Viscosity $=0.5 \mathrm{ft}^{\wedge} 2 / \mathrm{sec}$ Vertical Viscosity $=0.25 \mathrm{ft}^{\wedge} 2 / \mathrm{sec}$

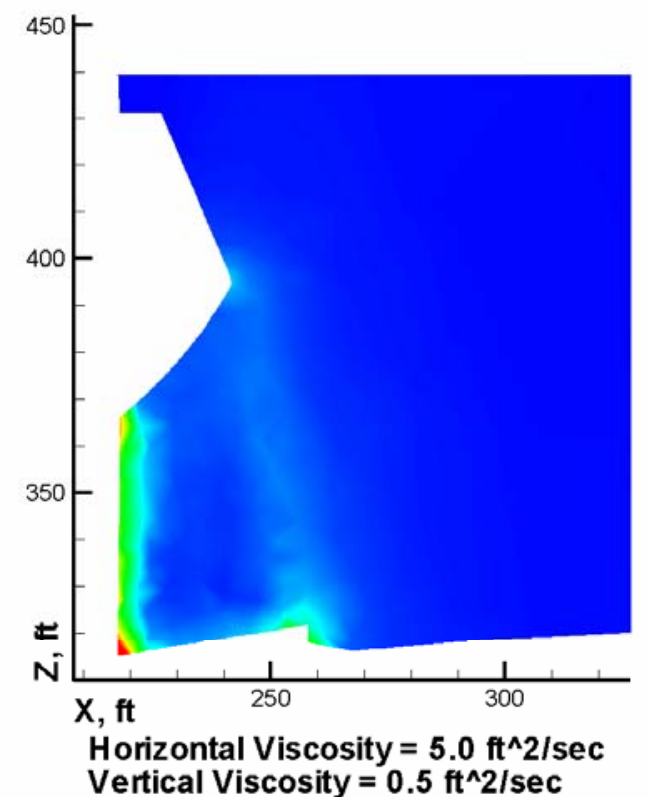

Strain Rate (1/sec): $\begin{array}{lllllllllll}0 & 0.1 & 0.2 & 0.3 & 0.4 & 0.5 & 0.6 & 0.7 & 0.8 & 0.9 & 1\end{array}$

\section{CFD Run: BC1}

River: $74.7 \mathrm{kcfs}$, PH: $30 \mathrm{kcfs}$, SW: $44.7 \mathrm{kcfs}$, WSE: 439.5

PH: Units 1,3,6:10 kcfs each

SW: Bays 1,3,4,5,6,7,8,10:4.3kcfs each, Bays 2,9: $5.15 \mathrm{kcfs}$ each

in_CBC1_Strain_ph6.lay

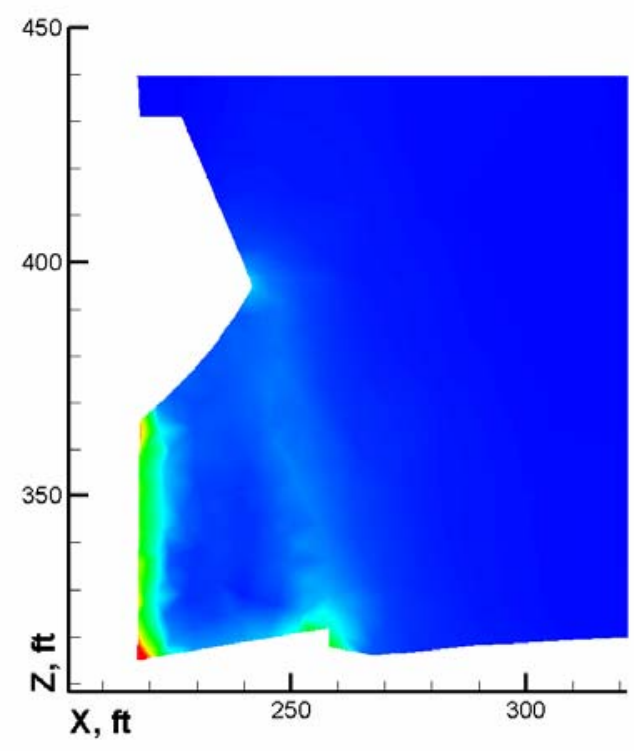

Horizontal Viscosity $=5.0 \mathrm{ft}^{\wedge} 2 / \mathrm{sec}$ Vertical Viscosity $=0.25 \mathrm{ft}^{\wedge} 2 / \mathrm{sec}$

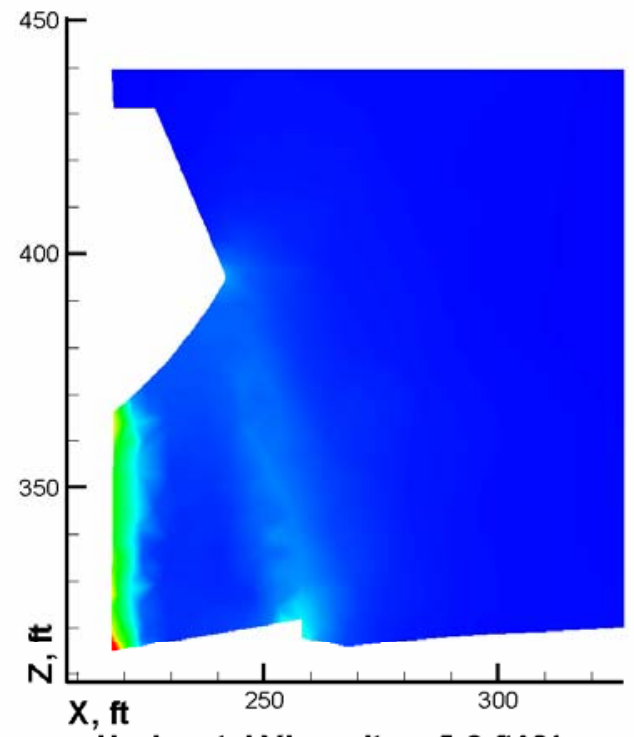

Horizontal Viscosity $=5.0 \mathrm{ft}^{\wedge} 2 / \mathrm{sec}$ Vertical Viscosity $=5.0 \mathrm{ft}^{\wedge} 2 / \mathrm{sec}$

Figure 60 . Strain rate contours of flow entering powerhouse unit 6 


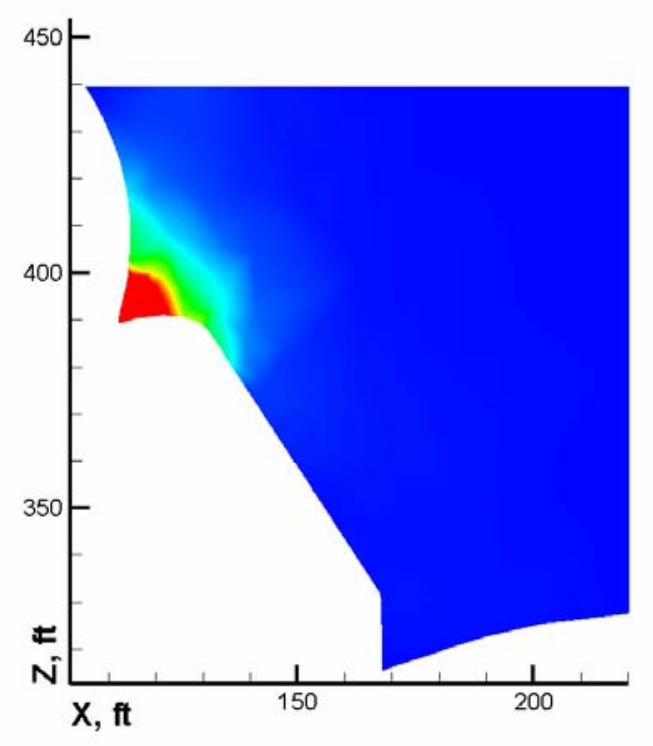

Horizontal Viscosity $=0.5 \mathrm{ft}^{\wedge} 2 / \mathrm{sec}$ Vertical Viscosity $=0.25 \mathrm{ft}^{\wedge} 2 / \mathrm{sec}$

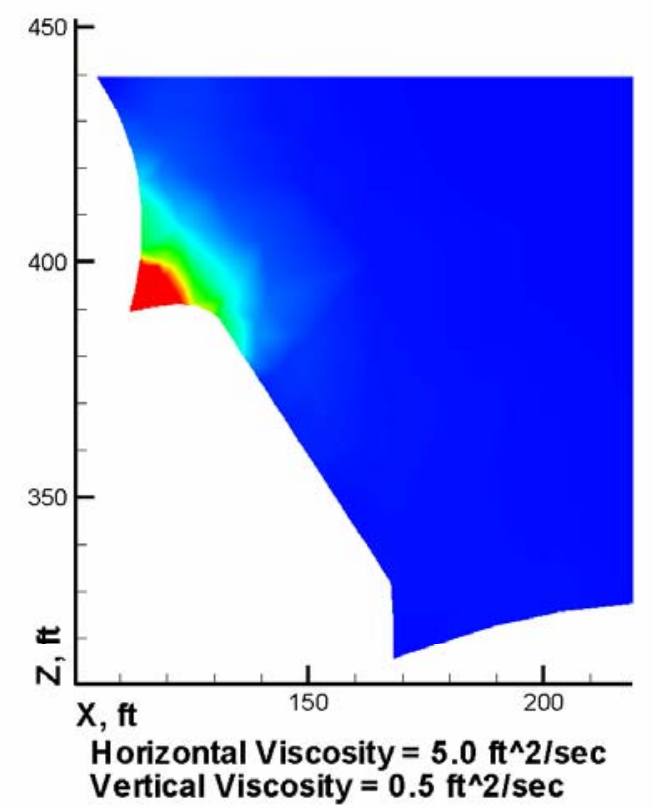

Strain Rate (1/sec): $\begin{array}{llllllllllll}0 & 0.1 & 0.2 & 0.3 & 0.4 & 0.5 & 0.6 & 0.7 & 0.8 & 0.9 & 1\end{array}$

\section{CFD Run: BC1}

River: $74.7 \mathrm{kcfs}, \mathrm{PH}: \mathbf{3 0 \mathrm { kcfs }}$, SW: $44.7 \mathrm{kcfs}$, WSE: 439.5

PH: Units 1,3,6:10 kcfs each

SW: Bays 1,3,4,5,6,7,8,10:4.3kcfs each, Bays 2,9: $5.15 \mathrm{kcfs}$ each

ih_CBC1_Strain_sw5.lay

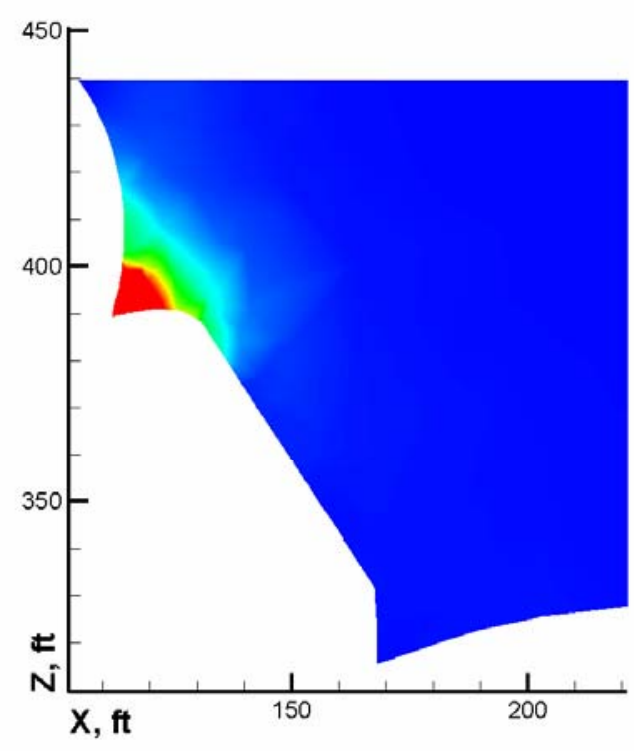

Horizontal Viscosity $=5.0 \mathrm{ft}^{\wedge} 2 / \mathrm{sec}$ Vertical Viscosity $=0.25 \mathrm{ft}^{\wedge} 2 / \mathrm{sec}$

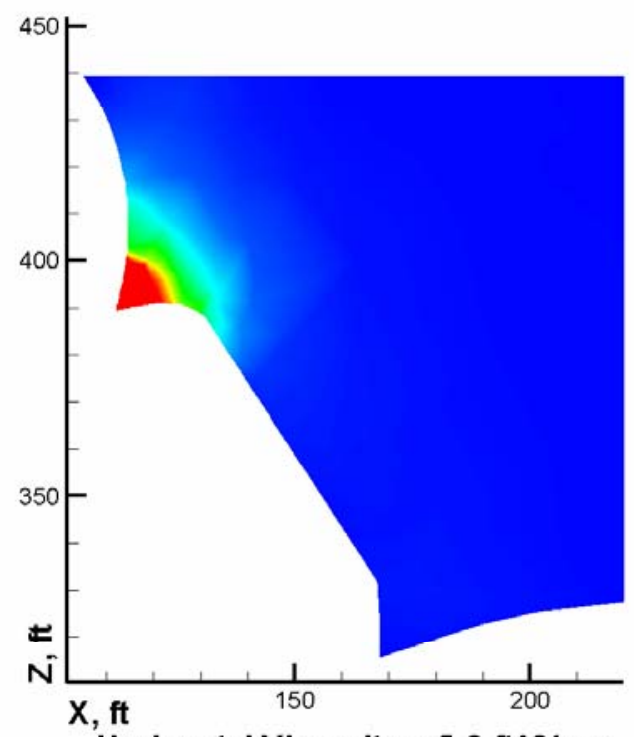

Horizontal Viscosity $=5.0 \mathrm{ft}^{\wedge} 2 / \mathrm{sec}$ Vertical Viscosity $=5.0 \mathrm{ft}^{\wedge} 2 / \mathrm{sec}$

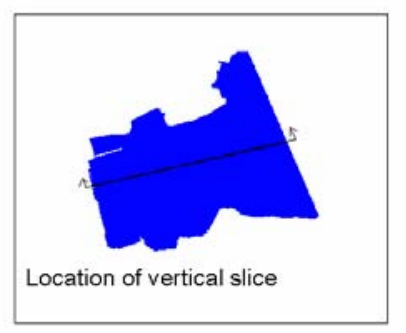

Figure 61 . Strain rate contours of flow through spillway bay 5 


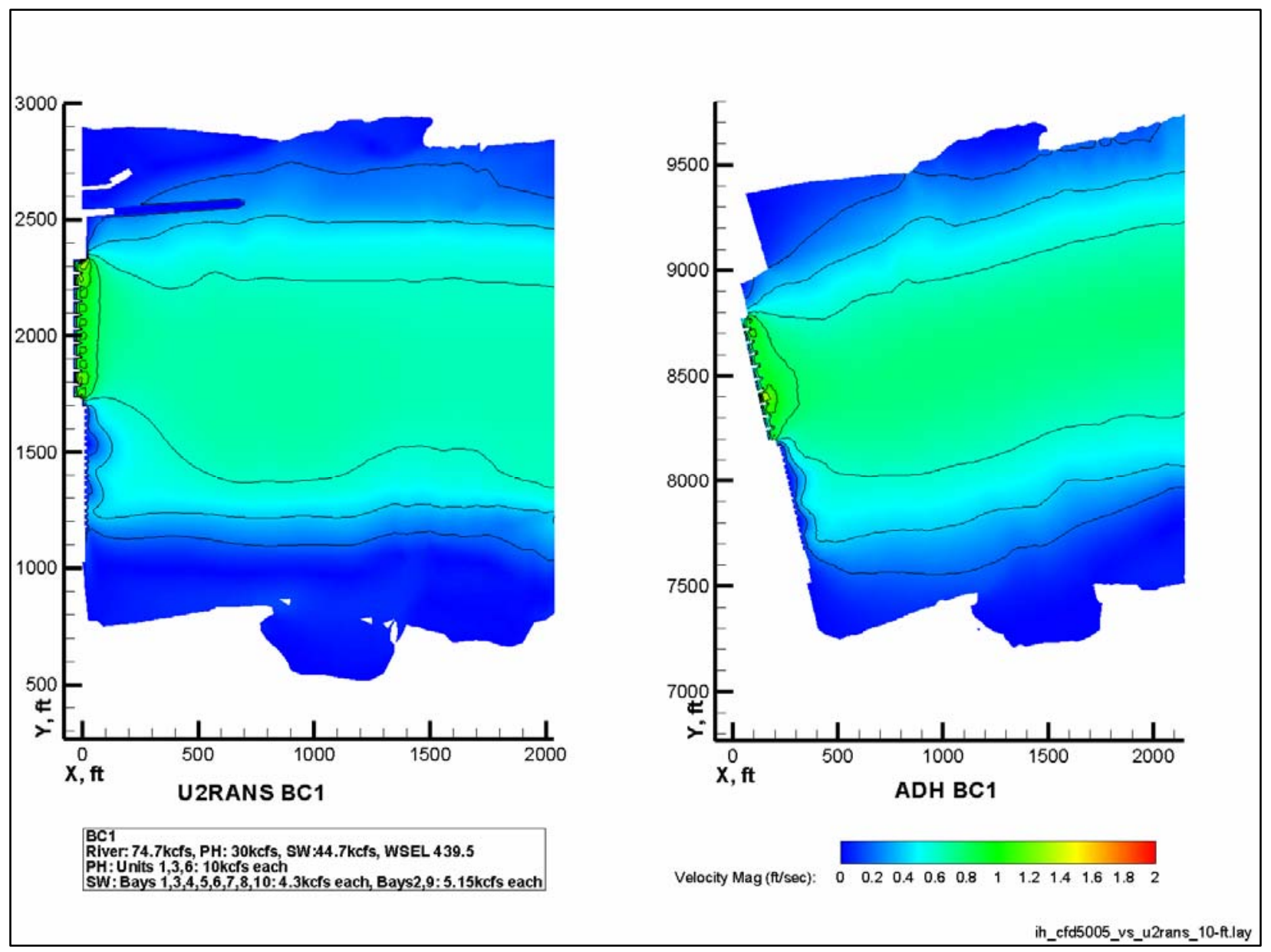

Figure 62. U2RANS (left) and ADH (right) model results showing velocity magnitude contours at 10-ft depth 


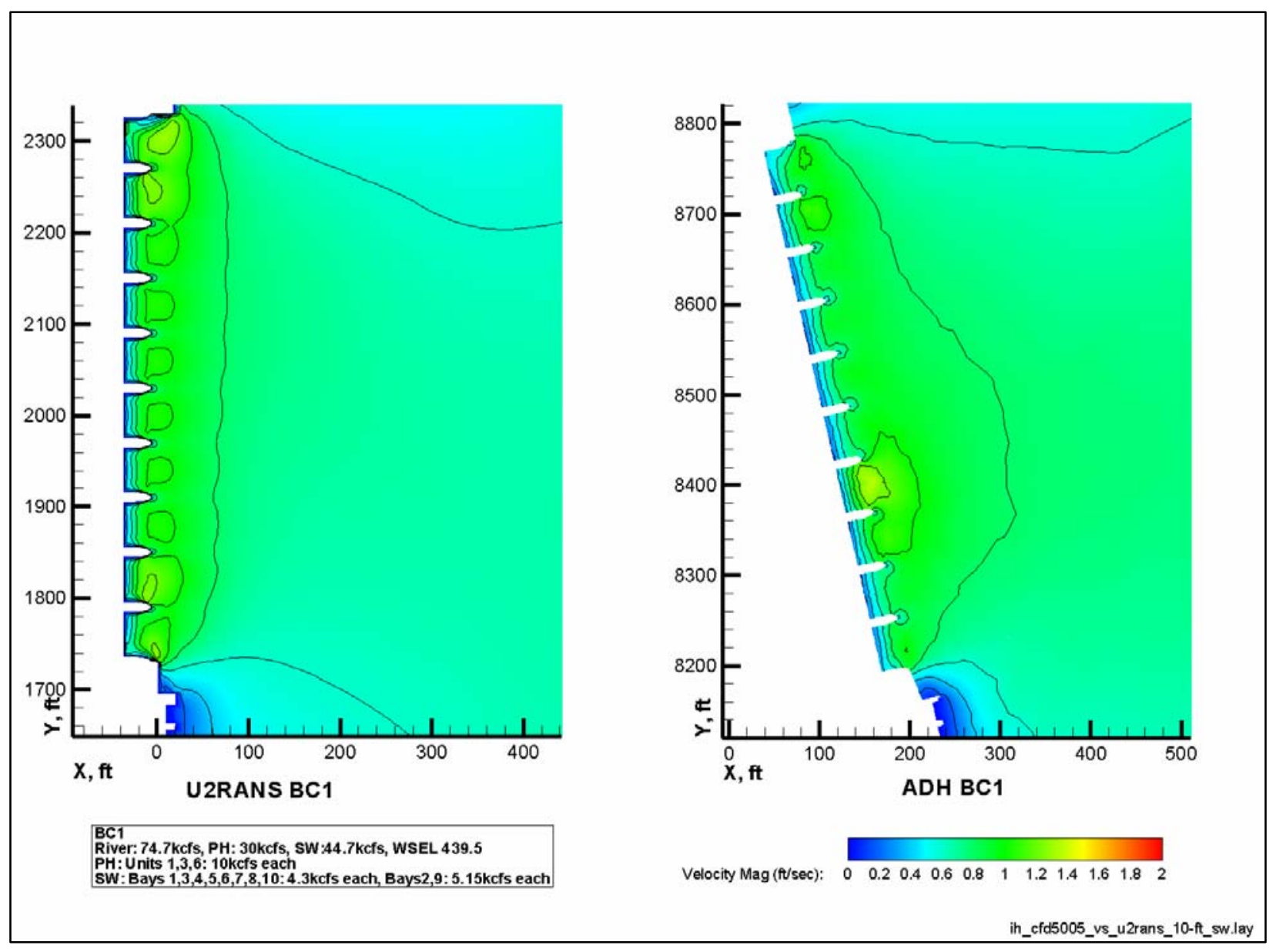

Figure 63. U2RANS (left) and ADH (right) model results showing velocity magnitude contours near the spillway at $10-\mathrm{ft}$ depth 


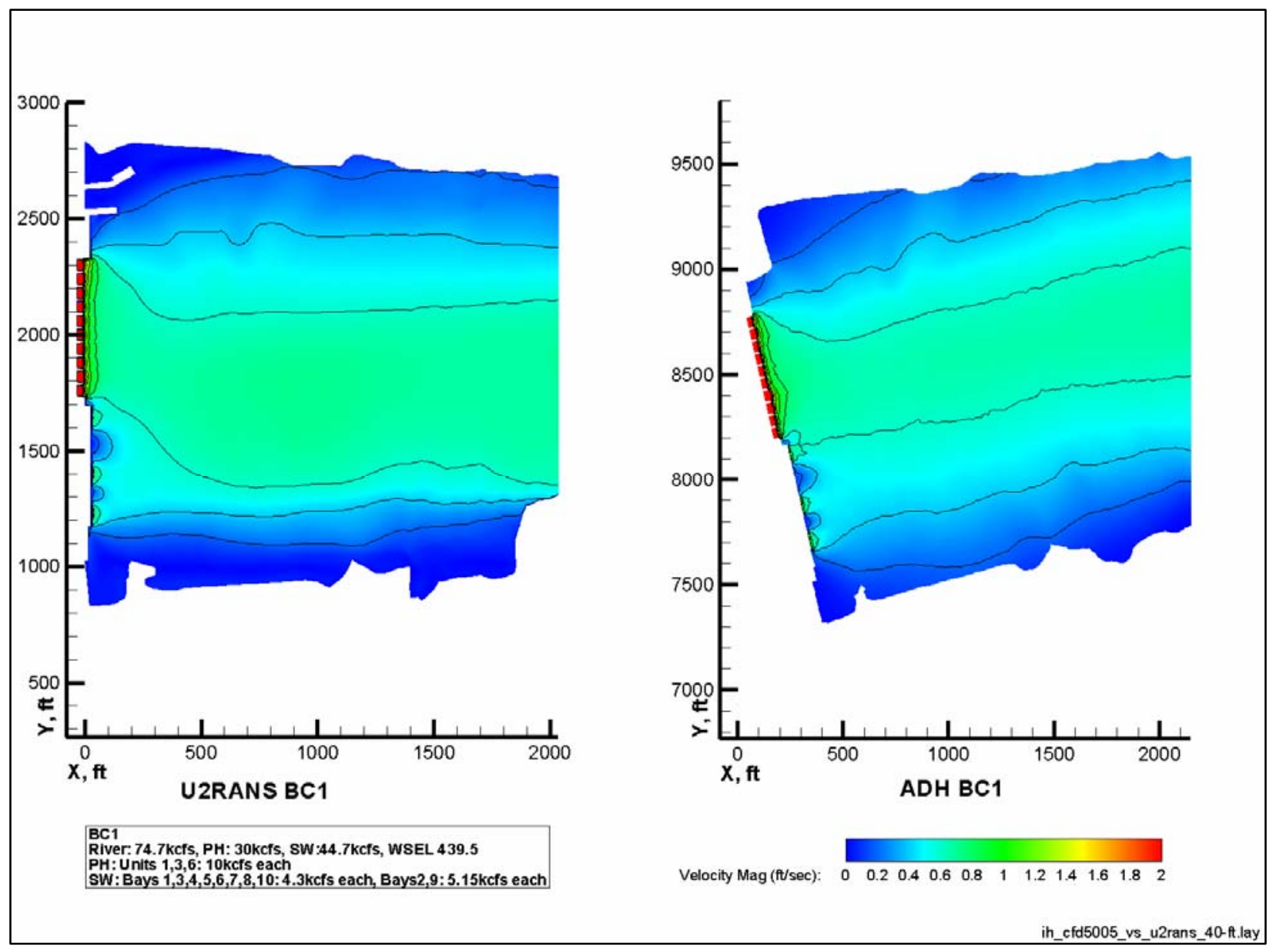

Figure 64. U2RANS (left) and ADH (right) model results showing velocity magnitude contours at 40 -ft depth 


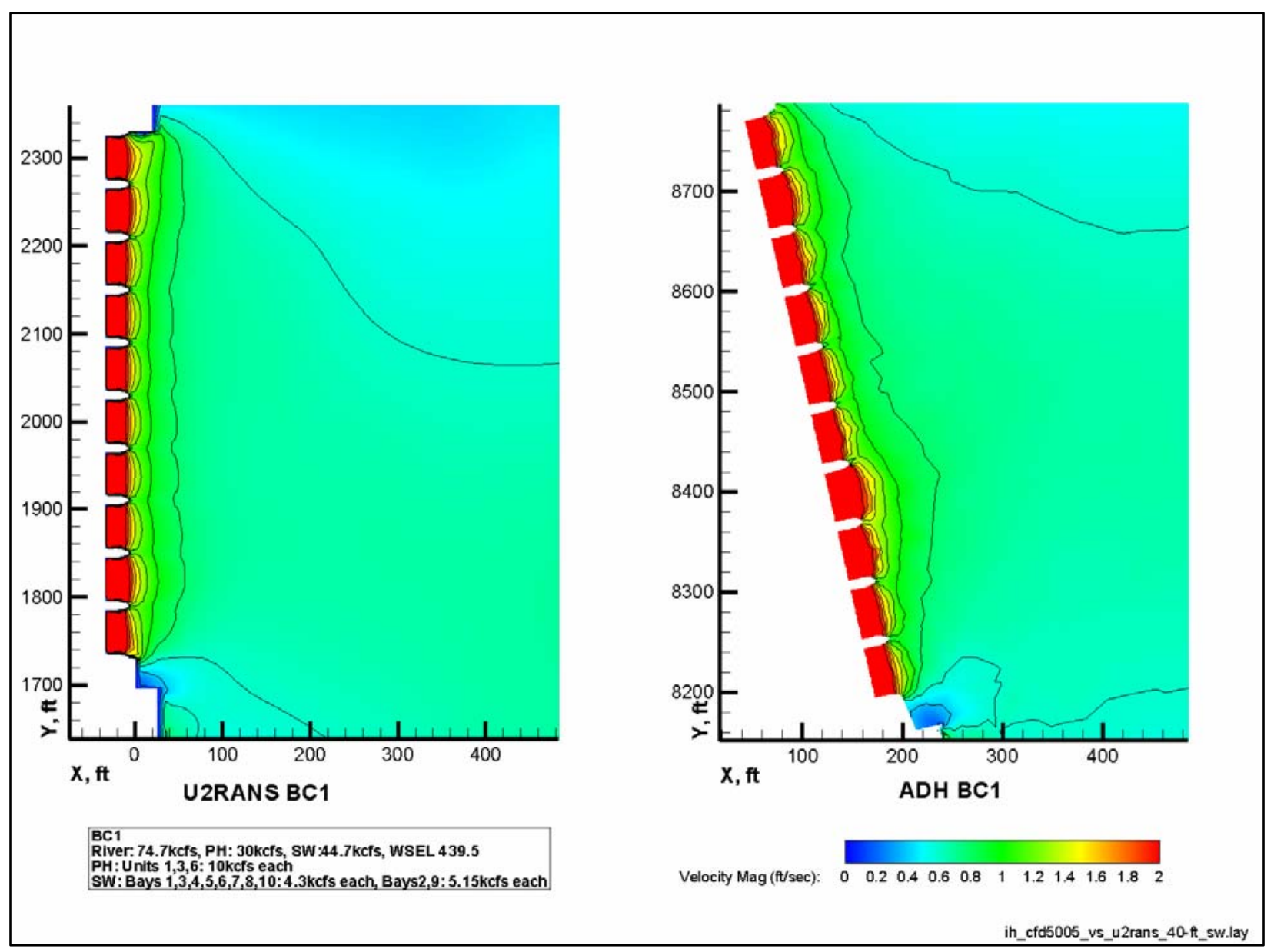

Figure 65. U2RANS (left) and ADH (right) model results showing velocity magnitude contours near the spillway at $40-\mathrm{ft}$ depth 


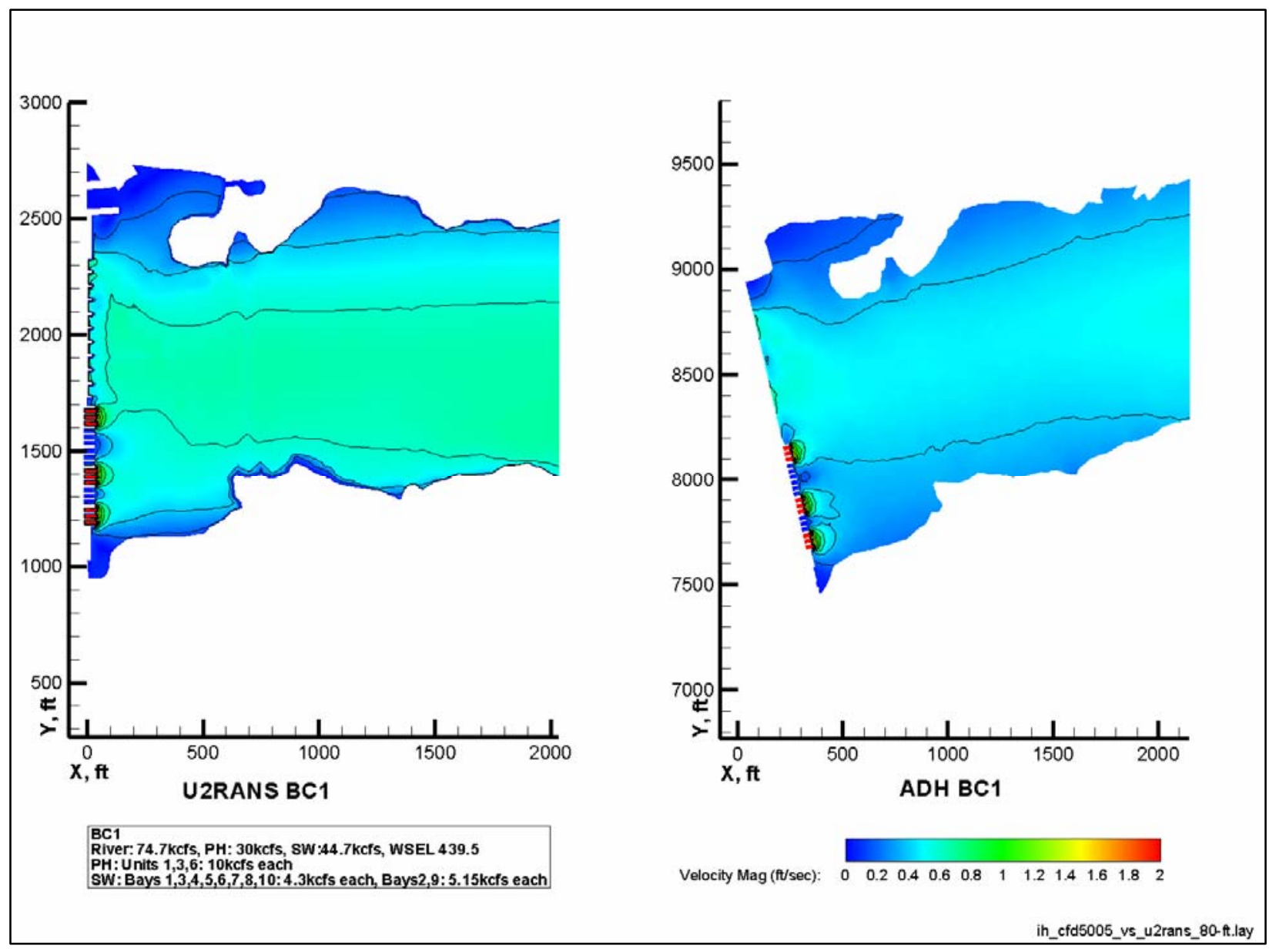

Figure 66. U2RANS (left) and ADH (right) model results showing velocity magnitude contours at 80 -ft depth 


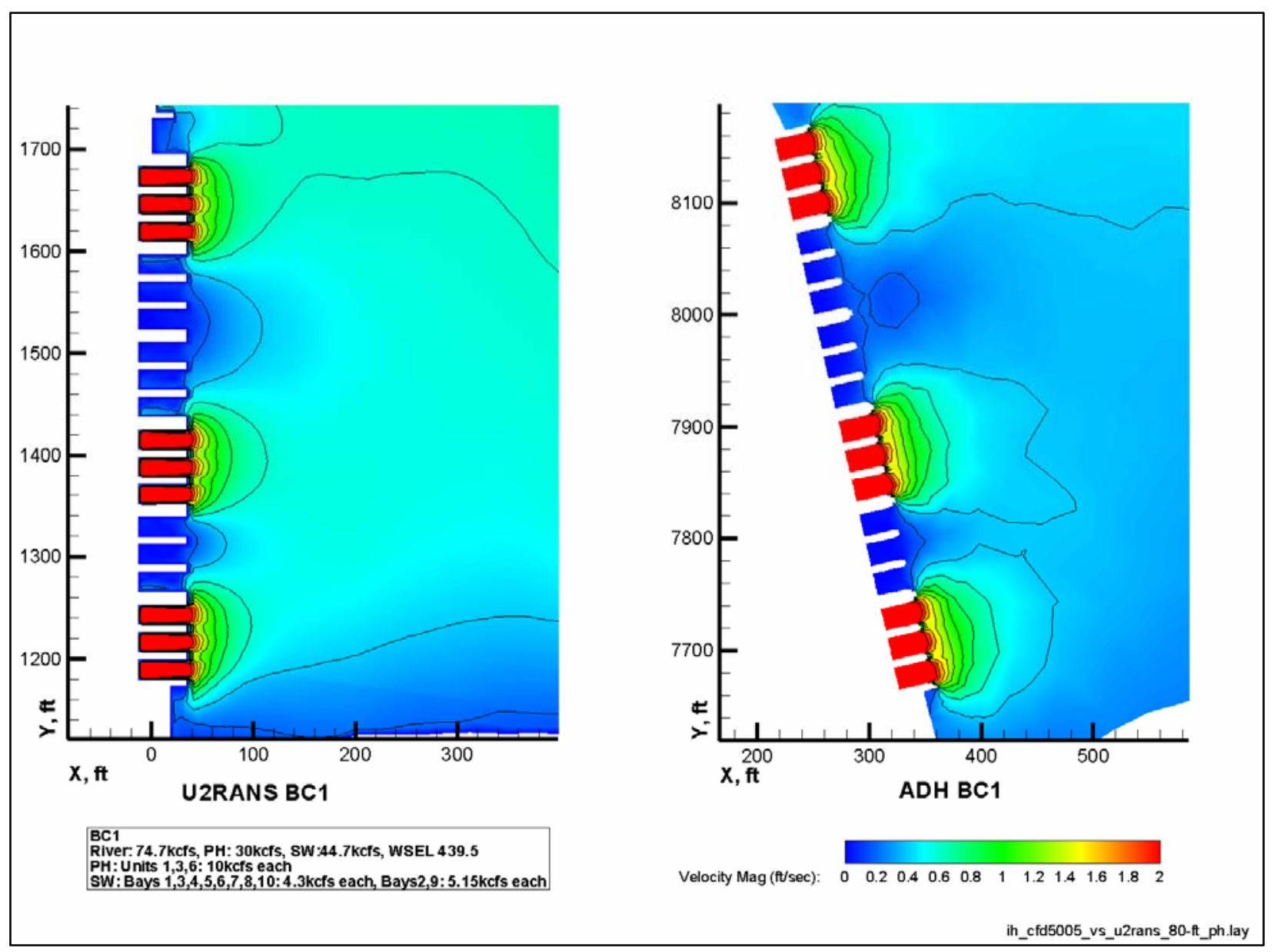

Figure 67. U2RANS (left) and ADH (right) model results showing velocity magnitude contours near the powerhouse at $80-\mathrm{ft}$ depth 


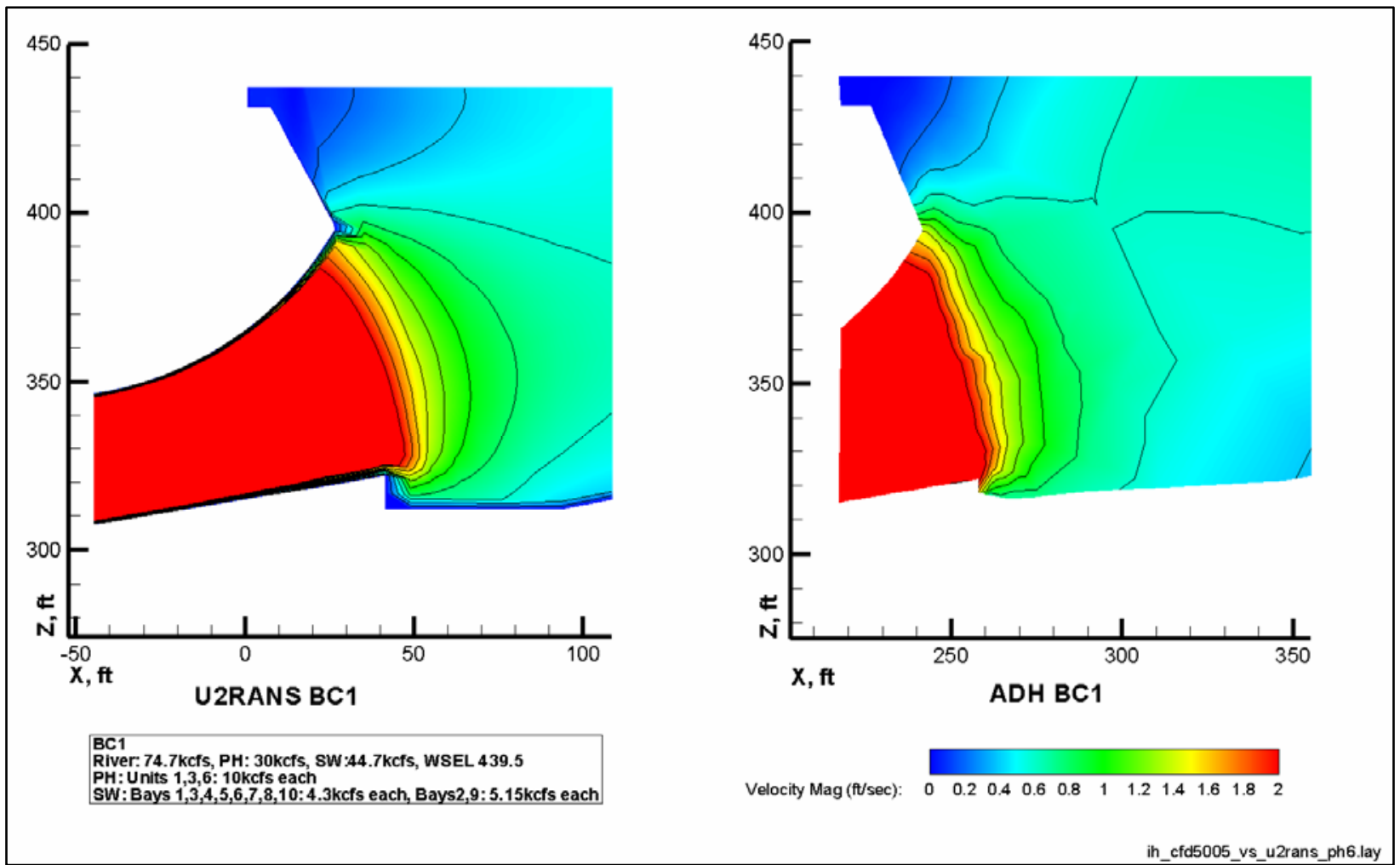

Figure 68. U2RANS (left) and ADH (right) model results showing velocity magnitude contours (on a vertical plane normal to dam axis) of flow entering powerhouse unit 6 


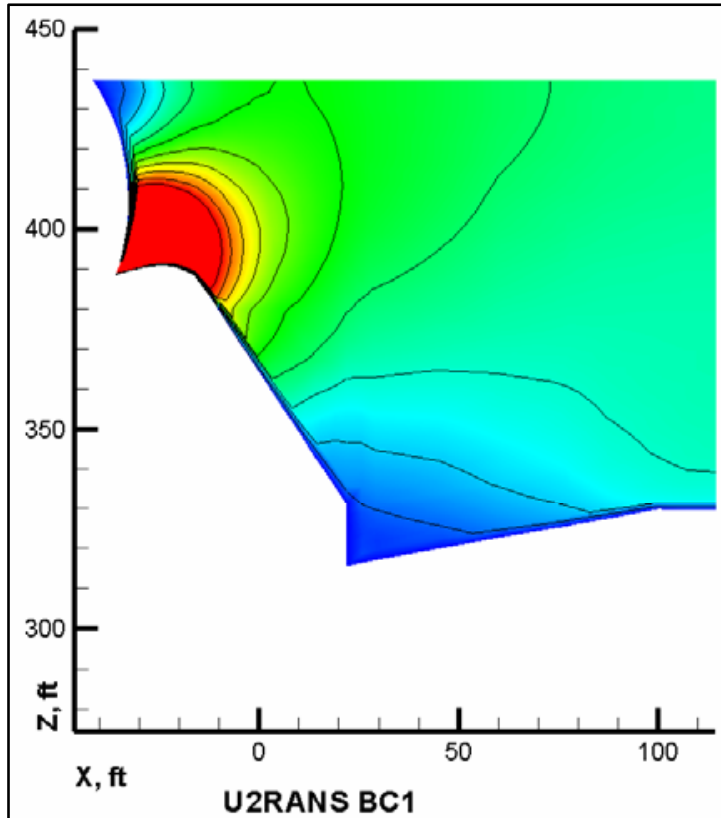

RC1 $74.7 \mathrm{kcfs}, \mathrm{PH}: 30 \mathrm{kcfs}$, SW $: 44.7 \mathrm{kcfs}$, WSEL 439.5

sW: Bays 1,3,4,5,6,7,8,10:4.3kcfs each, Bays2,9:5.15kcfs each

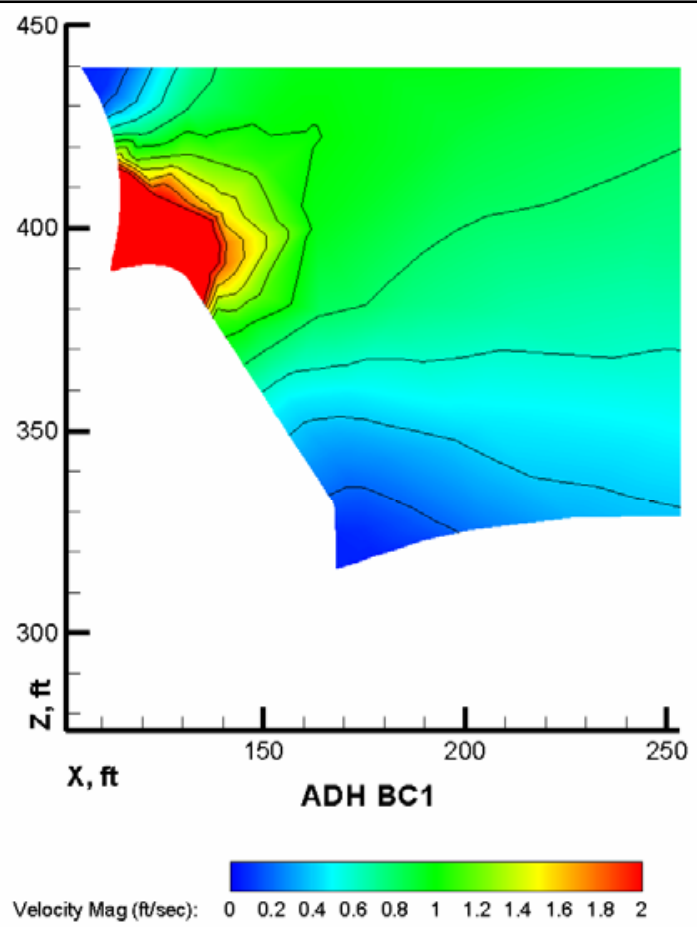

ih_cfd5005_vs_u2rans_sw5.lay

Figure 69. U2RANS (left) and ADH (right) model results showing velocity magnitude contours (on a vertical plane normal to dam axis) of flow entering spillway bay 5 


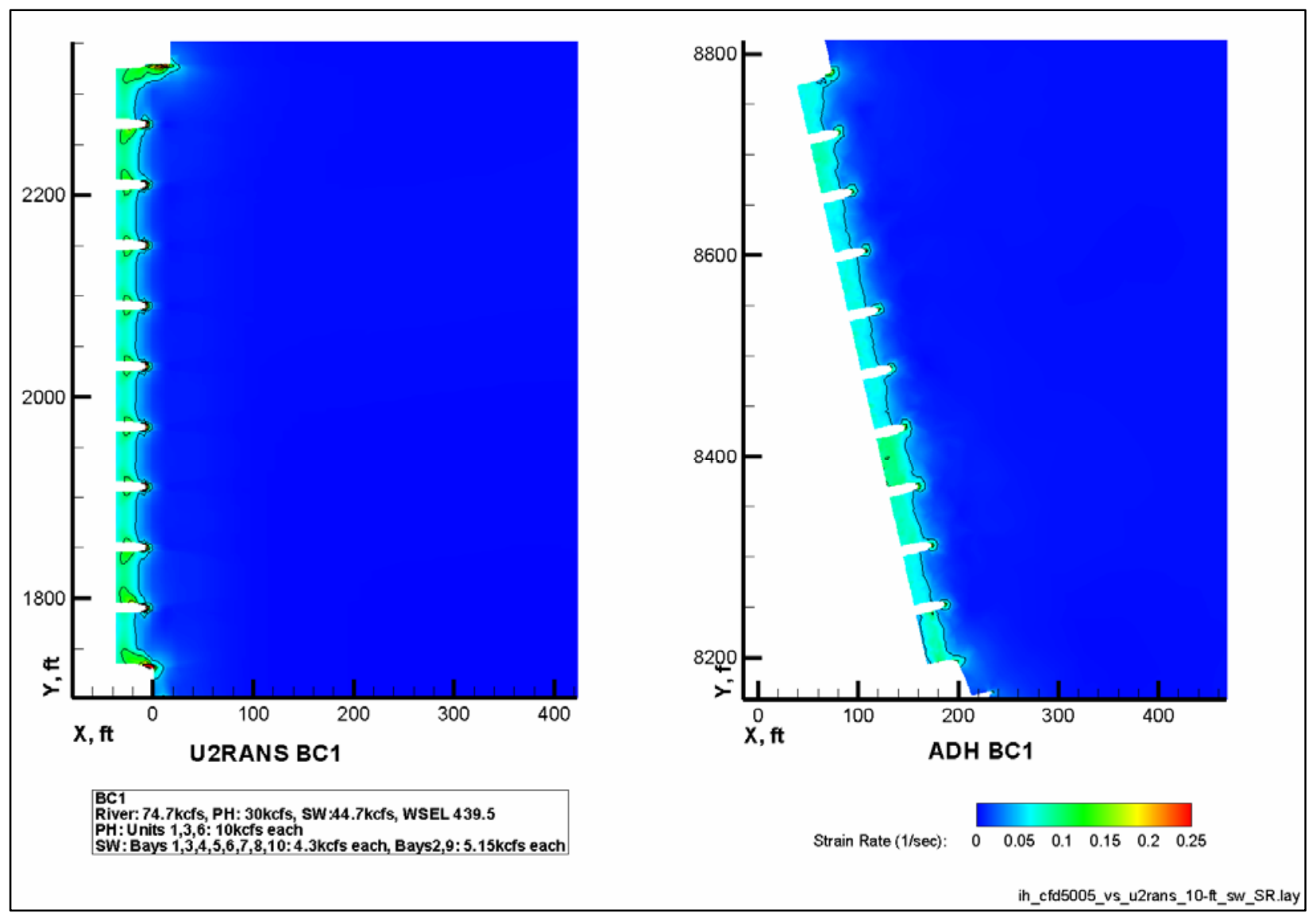

Figure 70. U2RANS (left) and ADH (right) model results showing strain rate contours near the spillway at 10-ft depth 


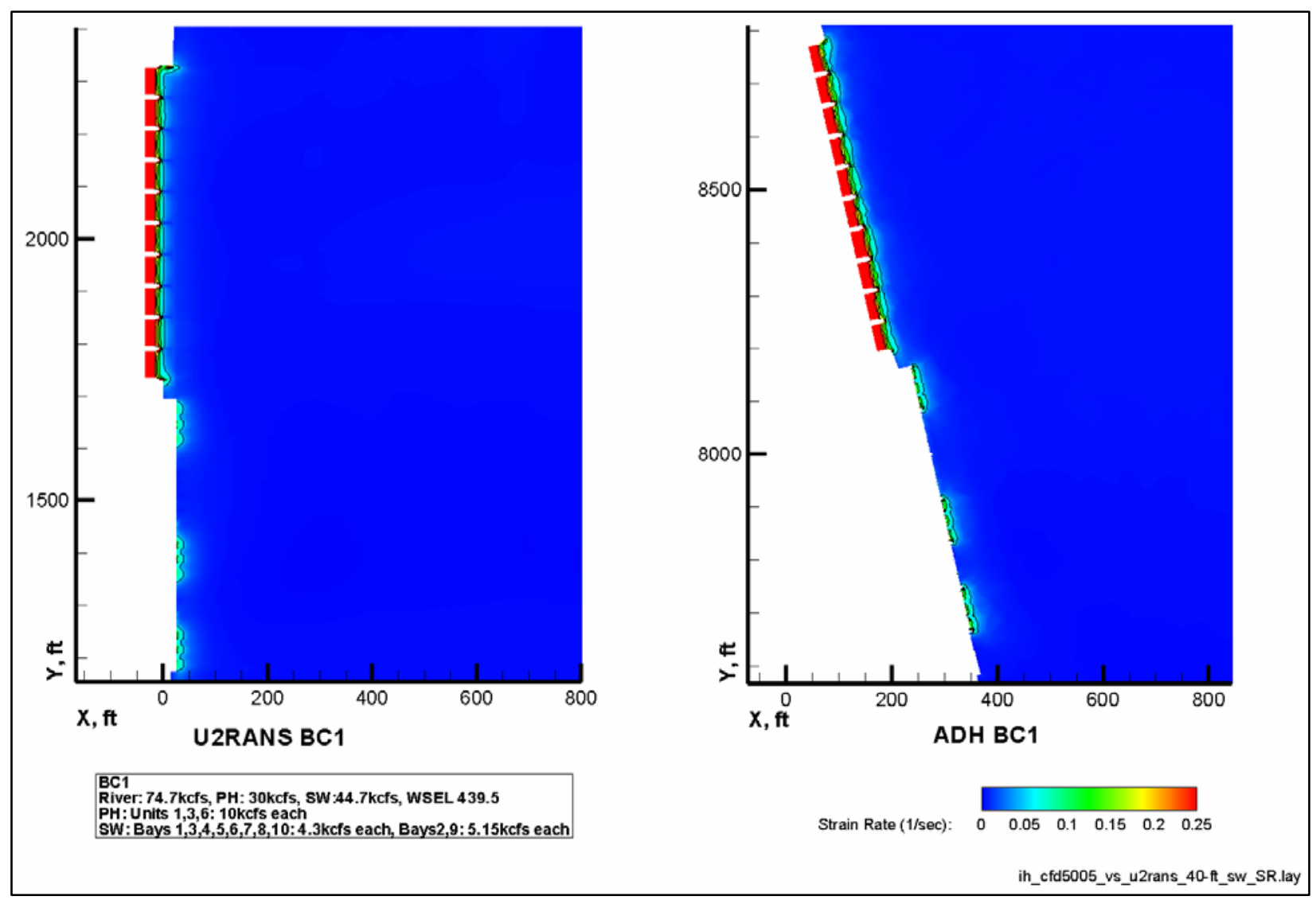

Figure 71. U2RANS (left) and ADH (right) model results showing strain rate contours in the forebay at 40-ft depth 


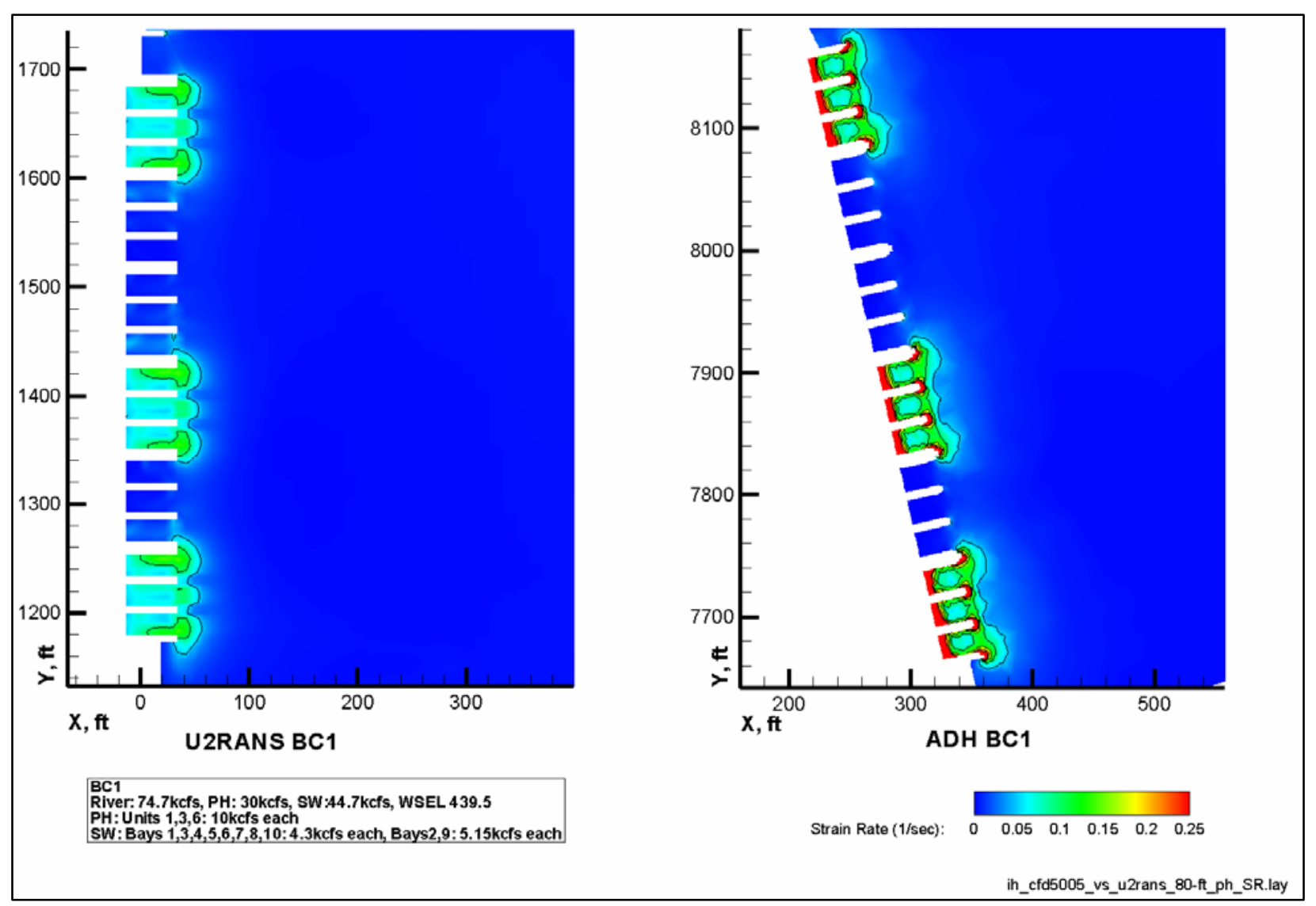

Figure 72. U2RANS (left) and ADH (right) model results showing strain rate contours near the powerhouse at $80-\mathrm{ft}$ depth 


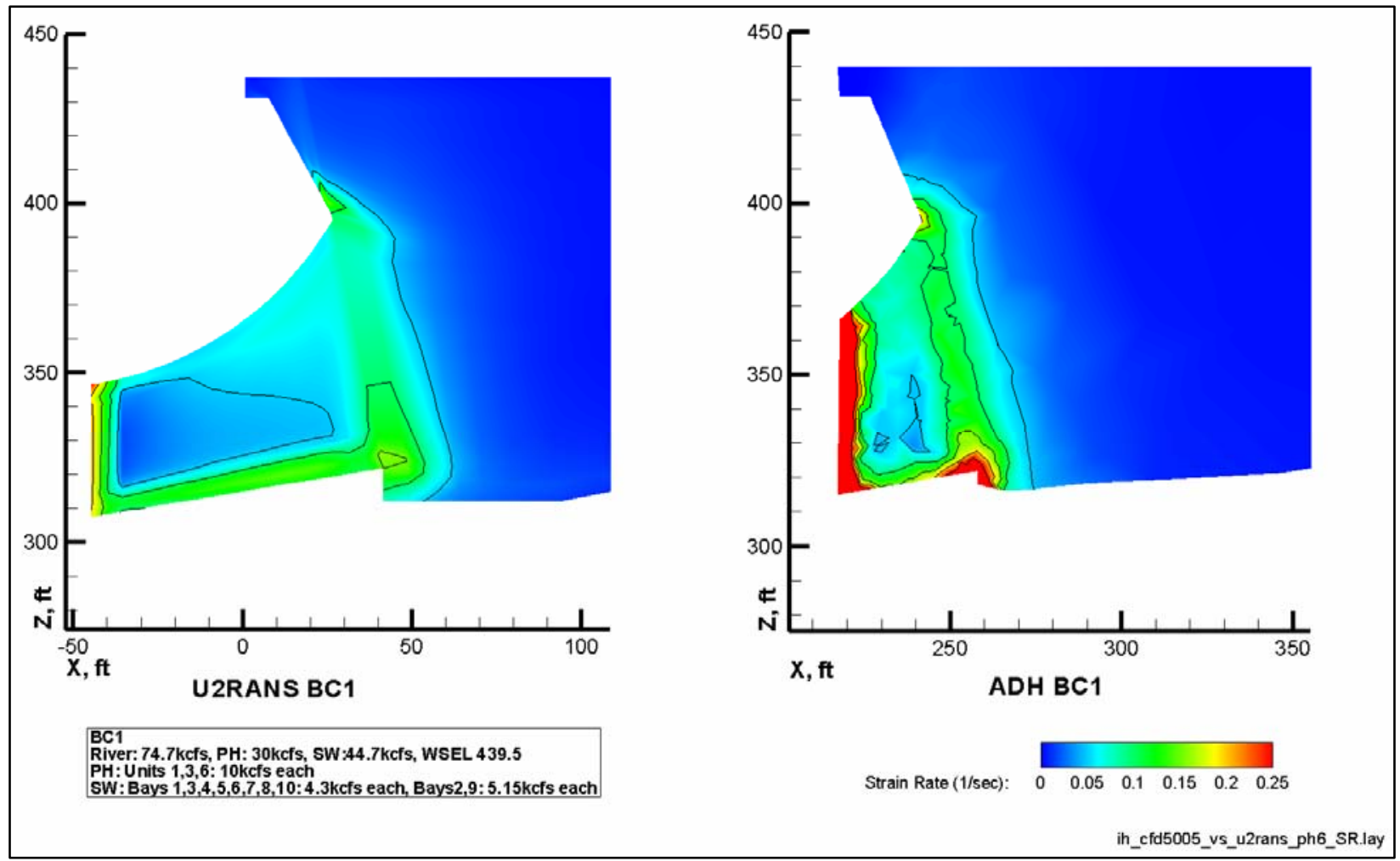

Figure 73. U2RANS (left) and ADH (right) model results showing strain rate contours (on a vertical plane normal to dam axis) of flow entering powerhouse unit 6 


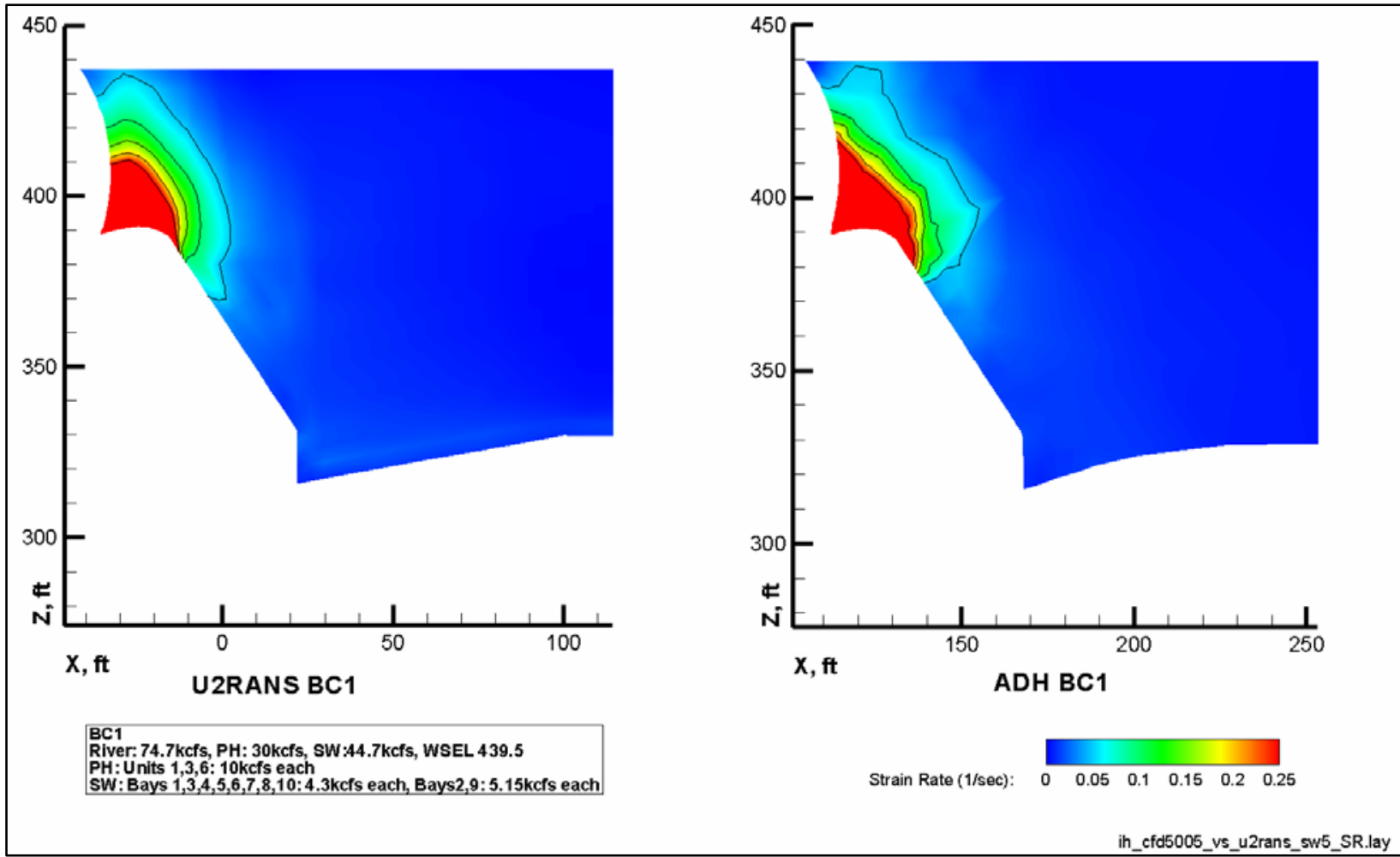

Figure 74. U2RANS (left) and ADH (right) model results showing strain rate contours (on a vertical plane normal to dam axis) of flow entering spillway bay 5 


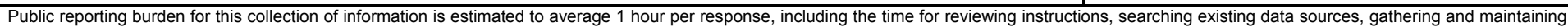

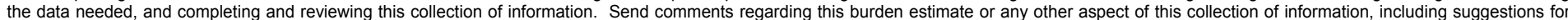

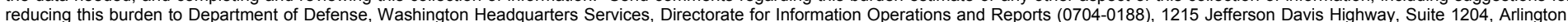

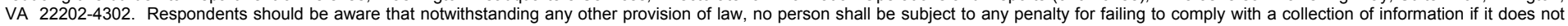
display a currently valid OMB control number. PLEASE DO NOT RETURN YOUR FORM TO THE ABOVE ADDRESS.
1. REPORT DATE (DD-MM-YYYY)
August 2005

$$
\text { Final report }
$$

\section{TITLE AND SUBTITLE}

Computational Model of Ice Harbor Forebay, Washington
3. DATES COVERED (From - To)

5a. CONTRACT NUMBER

5b. GRANT NUMBER

5c. PROGRAM ELEMENT NUMBER

5d. PROJECT NUMBER

5e. TASK NUMBER

5f. WORK UNIT NUMBER

8. PERFORMING ORGANIZATION REPORT NUMBER

ERDC/CHL TR-05-5

10. SPONSOR/MONITOR'S ACRONYM(S)

U.S. Army Engineer District, Walla Walla

201 North 3rd Avenue, Walla Walla, WA 99362

11. SPONSOR/MONITOR'S REPORT NUMBER(S)

\section{DISTRIBUTION / AVAILABILITY STATEMENT}

Approved for public release; distribution is unlimited.

\section{SUPPLEMENTARY NOTES}

\section{ABSTRACT}

This project serves as a demonstration of the three-dimensional (3D) numerical modeling capability of large reservoirs up to and including the complex geometries of the powerhouse, spillway, and lock guard wall structures. The 3D Navier-Stokes module of the Adaptive Hydraulic (ADH) computer code is used to compute the forebay flow at the Ice Harbor Dam. A numerical flow model of the Ice Harbor Dam forebay, which is located on the Snake River, was constructed. The model results are compared to field data and solutions obtained by an independent laboratory's in-house code.

\section{SUBJECT TERMS}

Computational fluid dynamics

Hydraulic structures

16. SECURITY CLASSIFICATION OF:

\begin{tabular}{|l|l|}
\hline a. REPORT & b. ABSTRACT \\
UNCLASSIFIED & UNCLASSIFIED \\
\hline
\end{tabular}

Ice Harbor Dam

Numerical model

Snake River

\begin{tabular}{|c|c|c|}
\hline $\begin{array}{l}\text { c. THIS PAGE } \\
\text { UNCLASSIFIED }\end{array}$ & $\begin{array}{l}\text { 17. LIMITATION } \\
\text { OF ABSTRACT }\end{array}$ & $\begin{array}{c}\text { 18. NUMBER } \\
\text { OF PAGES }\end{array}$ \\
& & 80 \\
\hline
\end{tabular}

19a. NAME OF RESPONSIBLE PERSON

19b. TELEPHONE NUMBER (include area code) 